\title{
Internal R\&D, external R\&D, and firm innovation : evidence from the pharmaceutical industry
}

Citation for published version (APA):

Wang, N. (2015). Internal $R \& D$, external $R \& D$, and firm innovation : evidence from the pharmaceutical industry. [Doctoral Thesis, Maastricht University]. Datawyse / Universitaire Pers Maastricht. https://doi.org/10.26481/dis.20150211nw

Document status and date:

Published: 01/01/2015

DOI:

10.26481/dis.20150211nw

Document Version:

Publisher's PDF, also known as Version of record

\section{Please check the document version of this publication:}

- A submitted manuscript is the version of the article upon submission and before peer-review. There can be important differences between the submitted version and the official published version of record.

People interested in the research are advised to contact the author for the final version of the publication, or visit the DOI to the publisher's website.

- The final author version and the galley proof are versions of the publication after peer review.

- The final published version features the final layout of the paper including the volume, issue and page numbers.

Link to publication

\footnotetext{
General rights rights.

- You may freely distribute the URL identifying the publication in the public portal. please follow below link for the End User Agreement:

www.umlib.nl/taverne-license

Take down policy

If you believe that this document breaches copyright please contact us at:

repository@maastrichtuniversity.nl

providing details and we will investigate your claim.
}

Copyright and moral rights for the publications made accessible in the public portal are retained by the authors and/or other copyright owners and it is a condition of accessing publications that users recognise and abide by the legal requirements associated with these

- Users may download and print one copy of any publication from the public portal for the purpose of private study or research.

- You may not further distribute the material or use it for any profit-making activity or commercial gain

If the publication is distributed under the terms of Article $25 \mathrm{fa}$ of the Dutch Copyright Act, indicated by the "Taverne" license above, 


\section{Internal R\&D, External R\&D, and Firm Innovation}

Evidence from the

Pharmaceutical Industry

Ning Wang

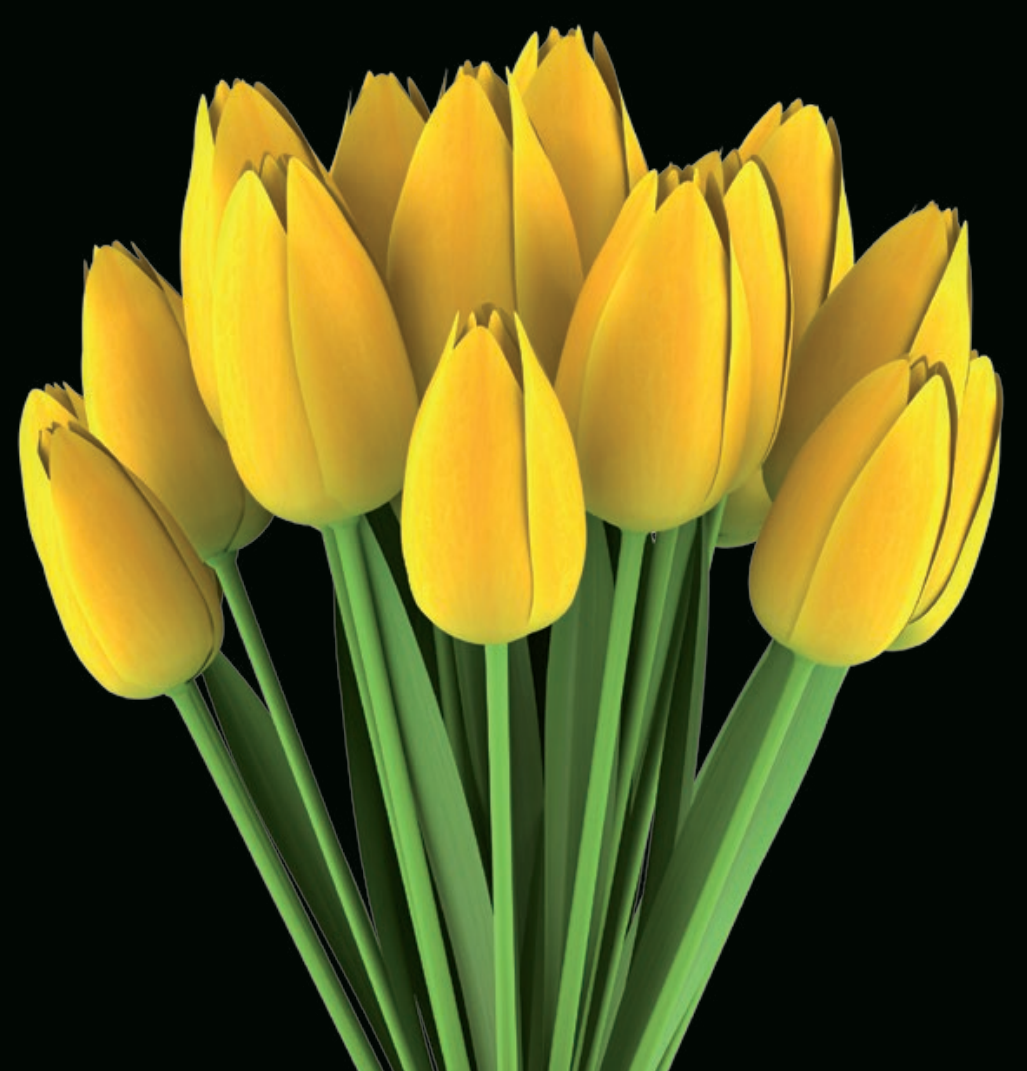


Internal R\&D, External R\&D, and Firm Innovation

Evidence from the Pharmaceutical Industry

CNing Wang, Maastricht 2014

Maastricht University

ISBN 978-94-6159-373-3

All rights reserved. No part of this publication may be reproduced, stored in a retrieval system, or utilized in any form or by any means without the prior consent in writing by the author.

Printed by: Datawyse/Universitaire Pers Maastricht 


\title{
INTERNAL R\&D, EXTERNAL R\&D, AND FIRM INNOVATION EVIDENCE FROM THE PHARMACEUTICAL INDUSTRY
}

\author{
DISSERTATION \\ to obtain the degree of Doctor at Maastricht University, \\ on the authority of the Rector Magnificus, Prof. Dr. L. L. G. Soete, \\ in accordance with the decision of the Board of Deans, \\ to be defended in public \\ on Wednesday 11 February, 2015, at 12:00 hours
}

by

Ning Wang

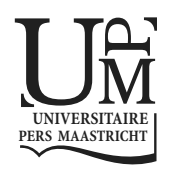




\section{Supervisor:}

Prof. Dr. John Hagedoorn

Assessment committee:

Prof. Dr. Frank Moers (chair)

Prof. Dr. Martin A. Carree

Dr. Boris B. Lokshin

Prof. Dr. Pierre A. Mohnen 
7 a my Que ge. For being wonderfully open -minded 



\section{Acknowledgements}

My thanks first of all go to my dissertation supervisor, John Hagedoorn, for his guidance and encouragement along my way of doing Ph.D. at Maastricht University. In retrospect, I benefited enormously from all those interesting and fruitful discussions with John, which helped me learn to think as a researcher. Until now two studies presented in this dissertation have been published, co-authored with John, in Research Policy. Many thanks to John for being supportive and patient especially during my last phase of working on this dissertation in Shanghai, for his generously sharing data, and above all, for him being a wonderful coach. My thanks also go to the members of the reading committee, Frank Moers, Martin Carree, Boris Lokshin, and Pierre Mohnen, for their time and helpful suggestions and comments.

As a foreign student, I would like to take the opportunity to express my gratitude for a quite friendly work environment in the Department of Organization and Strategy. I was fortunate to work with some really nice colleagues. Katrin Hussinger, Sjir Uitdewilligen, and Maarten Cuijpers, thanks for listening to all kinds of my questions and for sharing opinions, and Marc van Ekert for sharing knowledge of the CATI database. Kitty van Straaten helped me with administrative procedures after my arrival in Maastricht. Anita Weijzen always patiently answered my questions and provided help during my graduation phase. I also wish to thank all kind persons I have met in Maastricht who may not remember that ever offered me any help but I am truly grateful to.

Finally, my most special thanks to the most important person in my life, my husband Yue, for keeping me smile throughout.

Ning Wang

Shanghai, Oct 2014 



\section{Contents}

1 Introduction 1

1.1 Research questions 2

1.2 Industrial context of the dissertation 4

1.3 Outline and publications 5

2 The Lag Structure of the Relationship between Patenting and Internal R\&D Revisited

2.1 Introduction

2.2 Theoretical background and hypothesis $\quad 10$

$\begin{array}{ll}2.3 \text { Data and variable construction } & 13\end{array}$

$\begin{array}{ll}\text { 2.3.1 Data and sample } & 13\end{array}$

2.3.2 Dependent variable 14

$\begin{array}{ll}2.3 .3 \text { Independent variables } & 15\end{array}$

2.3.4 Control variables 16

$\begin{array}{lll}2.4 & \text { Estimation } & 17\end{array}$

2.4.1 Multiplicative distributed lag model $\quad 17$

2.4.2 Dynamic linear feedback model 19

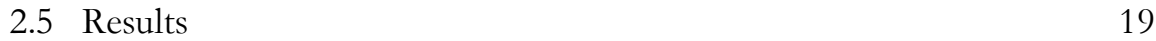

2.5.1 Results for hypothesis 19

$\begin{array}{lll}2.5 .2 & \text { Robustness of results } & 24\end{array}$

$\begin{array}{lll}2.6 & \text { Discussion and conclusions } & 25\end{array}$

Appendix 2A Autoregressive estimates for internal R\&D 28

Appendix 2B Estimation models and the moment conditions 29

3 Is There Complementarity and Substitutability between Internal and External R\&D Strategies?

3.1 Introduction 33

3.2 Theory and hypotheses $\quad 35$

3.3 Methodology 42

3.3.1 Data and sample $\quad 42$

3.3.2 Dependent variable $\quad 45$

3.3.3 Independent variables $\quad 46$

3.3.4 Control variables $\quad 47$

3.3.5 Estimation technique 49

3.4 Results $\quad 52$

3.4.1 Results for hypotheses $\quad 52$

$\begin{array}{ll}3.4 .2 \text { Robustness of results } & 57\end{array}$

3.5 Discussion and conclusions $\quad 59$

3.5.1 Managerial implications: A simulation analysis $\quad 59$

$\begin{array}{ll}\text { 3.5.2 Limitations and future research } & 62\end{array}$ 
Appendix 3A Estimation technique 64

Appendix 3B Simulation analysis $\quad 65$

4 Benefiting from Interfirm R\&D Alliances: Network Stucture and Innovative Output

4.1 Introduction 67

4.2 Theoretical backgrounds and hypotheses 70

4.2.1 Structural holes and innovative output $\quad 73$

$\begin{array}{ll}\text { 4.2.2 Indirect ties and innovative output } & 77\end{array}$

4.3 Methodology 80

4.3.1 Data and sample $\quad 80$

4.3.2 Dependent variables $\quad 83$

4.3.3 Independent variables $\quad 84$

4.3.4 Control variables $\quad 85$

4.3.5 Estimation technique $\quad 88$

4.4 Results 88

4.5 Discussion and conclusions 94

5 Conclusions

5.1 Overview of main findings and implications 99

5.1.1 The role of internal R\&D in firm innovation 99

5.1.2 The role of internal \& external R\&D in firm innovation 101

5.1.3 The role of $\mathrm{R} \& \mathrm{D}$ alliance network in firm innovation $\quad 102$

5.2 Limitations and suggestions for future research 104

$\begin{array}{ll}\text { Bibliography } & 107\end{array}$

$\begin{array}{ll}\text { Valorization } & 123\end{array}$

$\begin{array}{ll}\text { Curriculum Vitae } & 129\end{array}$ 


\section{Tables and Figures}

\section{Tables}

Table 2.1 Descriptive statistics 15

Table 2.2 Correlation matrix between patenting and internal R\&D 16

Table 2.3-a Estimates of the knowledge production function from 20

Table 2.3-b Estimates of the knowledge production function from 23 patents

Table 2A-1 Autoregressive estimates for Log R\&Dt 28

Table 3.1 Descriptive statistics and bivariate correlation matrix 53

Table $3.2 \quad$ Fixed-effects negative binomial regression predicting 54 biotechnology patents

Table 3.3 Robustness of results 58

Table $3.4 \quad$ Simulation results for interactive effects between internal 61 and external R\&D

Table 3B-1 Simulation results for interactive effects between internal 65 and $R \& D$ alliances

Table 3B-2 Simulation results for interactive effects between internal $\quad 65$ and R\&D acquisitions

Table 4.1-a Descriptive statistics and bivariate correlation matrix 89

Table 4.1-b Descriptive statistics and bivariate correlation matrix 90

Table 4.2 Fixed-effects negative binomial regression predicting 92 innovative output

\section{Figures}

Figure 3.1 Interactive effects between internal and external R\&D 56 under relative change

Figure 4.1 Illustration of interfirm R\&D alliance network in the industry 



\section{CHAPTER 1}

\section{INTRODUCTION}

The principal purpose of this dissertation is to develop a better understanding of the impact of internal and external research and development (R\&D) strategies of firms on their innovative output. On the one hand, to the extent that internal R\&D is an important, and perhaps even the most important, contributor to firm innovativeness (Griliches, 1979; Scherer, 1982), the impact of in-house R\&D on firm innovation has attracted enormous attention in the literature (Blundell et al., 2002; Gurmu and Pérez-Sebastián, 2008; Hall et al., 1986; Hausman et al., 1984; Montalvo, 1997; Pakes and Griliches, 1984a). On the other hand, the openness of firms to external R\&D sources is another key element for firm innovation. In view of the increasing complexity and multidisciplinarity of research, even the largest and most self-contained organizations cannot keep abreast of all the relevant technological advances solely through their internal R\&D (Teece, 1988; Veugelers, 1997). Recent years have actually witnessed more and more firms pursuing an 'open innovation' (Chesbrough, 2003) approach by leveraging internal and external knowledge development in parallel so as to build and hone their innovative capabilities. Concurrent with the open innovation approach, a rather voluminous literature has emerged that examines the relationship between internal and external R\&D strategies in shaping firms' innovative performance (Cassiman and Veugelers, 2006; Hess and Rothaermel, 2011; Laursen and Salter, 2006; Lokshin et al., 2008; Rothaermel and Hess, 2007; Schmiedeberg, 2008; Vega-Jurado et al., 2009).

In particular, R\&D alliances are an important manifestation of external $R \& D$ strategies pursued by firms. Studies in the innovation and interorganizational learning literatures suggest that $R \& D$ alliances and the resultant network are key vehicles through which firms can gain access to external knowledge or technology sources (Hagedoorn, 1993, 2002; Hagedoorn and Duysters, 2002b; Hill and Rothaermel, 2003; Park et al., 2002; Powell et al., 1996; Rothaermel, 2001; Rothaermel and Hess, 2007; Teece, 1992; Walker et al., 1997). With the dramatic increase of firms' engagement in R\&D alliances in the 1980s and 1990s in hightech industries (Hagedoorn et al., 2002), there has been a growing literature on interfirm alliance networks, particularly with regard to network structures or configurations, as critical determinants of firms' innovative performance (Ahuja, 2000a; Baum et al., 2000; McEvily and Zaheer, 1999; Koka and Prescott, 2008; Schilling 
and Phelps, 2007; Vanhaverbeke et al., 2012). Overall, the studies in this dissertation align with the above research literature and focus specifically on the impact of internal and external R\&D strategies of firms on their innovative output.

The rest of this introductory chapter proceeds as follows. In Section 1.1, we provide an overview of the research questions underlying the core studies of this dissertation. Section 1.2 presents the main reasons for selecting the pharmaceutical industry as the context of this dissertation. Finally, Section 1.3 gives an outline of the remaining chapters, together with a summary of the publications upon which chapters 2 and 3 are based.

\subsection{RESEARCH QUESTIONS}

This dissertation mainly addresses the role of internal R\&D, external R\&D (and its interactions with internal $\mathrm{R} \& \mathrm{D}$ ), and $\mathrm{R} \& \mathrm{D}$ alliance network in firm innovation. More specifically, three research questions as follows are to be empirically examined in the dissertation:

1. What is the lag structure of the relationship between firm patenting and internal R\&D?

2. Under what conditions is there complementarity or substitutability between internal and external R\&D strategies in shaping a firm's innovative output?

3. Benefiting from interfirm R\&D alliances: What are the effects of alliance network structure on a focal firm's innovative output?

Firstly, in the attempt to learn about gestation lags in knowledge production of internal R\&D by firms, researchers have repeatedly examined the relationship between R\&D expenditures and patents, which are taken as an output indicator of R\&D (Bound et al., 1984; Griliches, 1990). The question of interest is the lag structure of the patents-R\&D relationship, studied by considering the number of patents applied for and received by firms as a function of their current and lagged $\mathrm{R} \& \mathrm{D}$ expenditures. In line with a cumulative knowledge production or innovation process of firms, the current patenting output is expected to be dependent not only on recent R\&D (i.e., a short-run effect of $R \& D$ ) but also on R\&D investments in the distant past (i.e., a long-run effect of R\&D). So far the earlier work in this area has investigated the relationship between patenting and internal R\&D activity of firms for the U.S. manufacturing sector during the 1970s (Blundell et al., 2002; Hall et al., 1986; Hausman et al., 1984; Montalvo, 1997; Pakes and Griliches, 1984a) and over the 1980s (Gurmu and Pérez-Sebastián, 2008). However, these previous studies suggest that there was very little direct evidence of anything but simultaneity in the year-to-year movement of patents and R\&D expenditures, or 
that the lag effects on patents were identified only for more recent R\&D. To explore the potential long-run impact of internal R\&D on firm patenting, the first empirical study in this dissertation revisits the classic research question regarding the lag structure of the patents-R\&D relationship in the context of the global pharmaceutical industry. Specifically, we focus on the patenting and internal R\&D activities of incumbent pharmaceutical firms.

Secondly, a substantial body of research literature has examined the interrelationship between internal and external R\&D strategies in relation with firms' innovative output, which has been accompanied by mixed empirical evidence. One set of studies demonstrate that internal and external $\mathrm{R} \& \mathrm{D}$ are complementary innovation activities, suggesting their interrelatedness in improving a firm's innovative performance (Cassiman and Veugelers, 2006; Lokshin et al., 2008; Rothaermel and Hess, 2007; Schmiedeberg, 2008). By contrast, a second set of studies indicates that there is substitutability (or, no complementarity) between internal and external R\&D strategies (Hess and Rothaermel, 2011; Laursen and Salter, 2006; VegaJurado et al., 2009). The above studies are thus inconclusive about the relationship between different innovation mechanisms and focus merely on either complementarity or substitutability. However, as suggested by Cassiman and Veugelers (2006), understanding under what conditions different $R \& D$ strategies may in fact be complementary is more important than merely determining what activities are complementary per se. Given the scarcity of prior work on this line of research (exceptions are Cassiman and Veugelers, 2006; Hess and Rothaermel, 2011), the second empirical study seeks to provide empirical evidence on the conditions under which there is complementarity or substitutability between internal and external R\&D strategies within the context of the global pharmaceutical industry. In particular, the focus in this study is on incumbent pharmaceutical firms, examining the contingency role of their in-house $\mathrm{R} \& \mathrm{D}$ efforts in determining the condition which there may actually be complementarity or substitutability between internal and external R\&D strategies.

Finally, the third empirical study moves from a dyad level to a network level to investigate the impact of alliance network structure on a firm's innovative output. In spite of the growing consensus on the facilitative role of alliance networks, there has been an ongoing debate over the relative efficacy of different forms of network structure-network closure (Coleman, 1988) vs. structural holes (Burt, 1992) — as critical determinants of firm innovation. The empirical evidence has produced a rather mixed picture of how firms should be structurally embedded in interfirm alliance networks (e.g., Ahuja, 2000a; Baum et al., 2000; McEvily and Zaheer, 1999; Schilling and Phelps, 2007). To reconcile these conflicting arguments and results, researchers have proposed a contingency approach (Ahuja, 2000a; Burt, 2000). However, until recently there are relatively few studies (exceptions are Koka 
and Prescott, 2008; Vanhaverbeke et al., 2012) that have employed such an approach to examine the effects of the different forms of interfirm network structure on a focal firm's innovative output. Relatedly, apart from network closure vs. structural holes as aforementioned, the role of indirect ties is another important aspect of alliance network structure relating to a focal firm's innovative output. As argued by Ahuja (2000a), indirect ties are essentially characterized by a dual role vis-a-vis the focal actor-both as sources of information and as competitors in terms of using similar information. Although scholars have long studied the relationship between indirect ties and innovation, most research in this tradition has largely focused on the benefits from indirect ties as information sources but paid little attention to the role of indirect ties as potential competitors. To fill such research gaps, the goal of the third empirical study is to examine the impact of two aspects of interfirm network structure, i.e., structural holes and indirect ties, on a focal firm's innovative output. A contingency approach is utilized in the study by considering the various dimensions of a focal firm's innovative output-new technology and new products - and identifying their divergent requirements on the focal firm's network structure of interfirm R\&D alliances. Specifically, the analytic focus is on incumbent pharmaceutical firms as the focal actors in the pharmaceutical industry network of interfirm R\&D alliances.

\subsection{INDUSTRIAL CONTEXT OF THE DISSERTATION}

The industrial context of the three empirical studies in this dissertation is the global pharmaceutical industry. In particular, we focus on incumbent pharmaceutical firms' internal and external R\&D strategies in relation with their innovative output. Incumbent pharmaceutical firms are defined as pharmaceutical companies that were in existence prior to the emergence of biotechnology. These incumbents, such as Bayer, Hoffmann-La Roche, Merck, and Pfizer, are generally mature and very large enterprises which have dominated the pharmaceutical industry since the 1940s. The main reasons for selecting the pharmaceutical industry as the context of this dissertation are as follows.

On the one hand, continued innovation is particularly salient for the pharmaceutical industry which is characterized by high levels of R\&D intensity and propensity to patent. The pharmaceutical industry represents one of the highest R\&D intensities because firm performance depends on continuous innovation through discovery and development of proprietary drugs, which creates patent races, temporary monopolies, and winner-take-all scenarios (Rothaermel and Hess, 2007). Recent figures show that pharmaceutical firms invest as much as five times more in $R \& D$, relative to their sales, than the average U.S. manufacturing firm (CBO Study, 2006). In addition, patenting activity is an important source of technological 
advantage in the pharmaceutical industry (Henderson and Cockburn, 1994). Research evidence indicates that in contrast to many other high-technology industries, such as computers and semiconductors, the pharmaceutical industry places the highest importance on patents (Cohen et al., 2000; Levin et al., 1987). Since it is usually a lengthy and costly process for pharmaceutical firms to discover, develop, and gain regulatory approval for a new drug, absent patent protection, imitators could free ride on innovator's drug approval and duplicate the compound for a small fraction of the originator's costs (Grabowski, 2006).

On the other hand, in addition to investing heavily in internal R\&D, incumbent pharmaceutical firms have engaged significantly in external R\&D strategies to improve their innovative performance. During the last one and a half decades of the twentieth century, the pharmaceutical industry can be characterized as a hightech sector with a strong dual market structure, which is largely determined by a small group of incumbent pharmaceutical firms and a large group of entrepreneurial biotechnology companies (Hagedoorn et al., 2008). In the mid-1970s, the advent of biotechnology led to significant scientific and technological breakthroughs in genetic engineering (recombinant DNA, 1973) and hybridization (monoclonal antibodies, 1975). These advances have been altering the drug discovery process profoundly in the following decades, accompanied by the upsurge of numerous new dedicated biotechnology firms which possess strong competences in drug discovery and development in the field of biotechnological research. The new biotechnology is considered competence destroying for incumbent pharmaceutical firms, which were traditionally organic chemistry based (Powell et al., 1996; Stuart et al., 1999). In adapting to the new technological regime and an attempt to build up biotechnology competencies, incumbent pharmaceutical firms have engaged significantly in external $R \& D$ strategies, such as $R \& D$ alliances with and $R \& D$ acquisitions of, small biotechnology companies, to supplement their in-house R\&D efforts (Eisenhardt and Martin, 2000; Higgins and Rodriguez, 2006; Rothaermel, 2001; Rothaermel and Hess, 2007). Such a simultaneous pursuit of internal and external R\&D strategies by incumbent pharmaceutical firms exemplifies an open innovation approach and thus makes the pharmaceutical industry an interesting arena in which to study the impact of internal and external R\&D on firm innovation.

\subsection{OUTLINE AND PUBLICATIONS}

The main body of this dissertation consists of three empirical studies as to be shown in Chapters 2, 3, and 4, examining the three research questions as aforementioned, respectively. In each chapter, we provide an overview of the extant literature and formulate the hypotheses to be tested, followed by methodology, the 
empirical results, and a discussion of the main findings. The three chapters can be read independently of each other. Lastly, Chapter 5 revisits the main findings and their implications and it then discusses the limitations that commonly exist in the three studies, together with some possible avenues for future research.

Specifically, Chapter 2 (Study 1) and Chapter 3 (Study 2) presented in the dissertation are based upon the corresponding articles as below:

- The lag structure of the relationship between patenting and internal R\&D revisited. 2014. Research Policy 43(8): 1275-1285 (With John Hagedoorn);

- Is there complementarity or substitutability between internal and external R\&D strategies? 2012. Research Policy 41(6): 1072-1083 (With John Hagedoorn). 


\section{CHAPTER 2}

\section{THE LAG STRUCTURE OF THE RELATIONSHIP BETWEEN PATENTING AND INTERNAL R\&D REVISITED ${ }^{1 *}$}

\subsection{INTRODUCTION}

In the attempt to learn about gestation lags in knowledge production of in-house R\&D by firms, researchers have repeatedly examined the relationship between $R \& D$ expenditures and patents, which are taken as an output indicator of $R \& D$ (Bound et al., 1984; Griliches, 1990)..$^{2}$ The question of interest is the lag structure of the patents-R\&D relationship, studied by considering the number of patents applied for and received by firms as a function of their current and lagged R\&D expenditures. Pakes and Griliches (1984a) is probably the first attempt to look at the time shape of the distributed lag between patenting and internal R\&D activity of firms. In their panel-data model (with a log-log functional form), Pakes and Griliches (1984a) found evidence of a lag truncation effect in the distributed lag of $\mathrm{R} \& \mathrm{D}$ on patents. The estimated coefficient on the last lag of $\mathrm{R} \& \mathrm{D}$, with five lagged R\&D terms in their model, was significantly higher than the coefficients of more recent $\mathrm{R} \& \mathrm{D} .^{3}$

Hausman et al. (1984) and Hall et al. (1986) analyzed the same research question whether there is a lag in the relationship between patenting and R\&D expenditures. Using a more appropriate functional form that explicitly reflected the non-negativity and discreteness of patent counts in the context of panel data,

\footnotetext{
${ }^{1 *}$ This chapter is based on Wang, N. and Hagedoorn, J. 2014. The lag structure of the relationship between patenting and internal R\&D revisited. Research Policy 43(8): 1275-1285.

${ }^{2}$ Internal $\mathrm{R} \& \mathrm{D}$ is usually measured as annual $\mathrm{R} \& \mathrm{D}$ expenditures by firms. A related question is to what extent patents serve as a good indicator of the output of R\&D. Patents are directly related to inventiveness and represent an externally validated measure of technological novelty (Griliches, 1990). However, the use of patents as an economic indicator of knowledge increments has some limitations. For instance, not all inventions are patentable or patented, and the inventions that are patented differ greatly in their economic significance (Bound et al., 1984; Griliches, 1990; Pakes and Griliches, 1984a).

${ }^{3}$ The coefficient of the fifth year could be proxying for a series of small effects of the more basic research done six years ago or earlier, thus suggesting a lag "truncation" effect (Pakes and Griliches, 1984a). See Pakes and Griliches (1984b) for further discussion of this issue.
} 
Hausman et al. (1984) found a U-shaped lag structure in the random-effects estimation but not in their conditional fixed-effects version. When they conditioned their estimates on the total number of patents received by a firm over the observed years, no coefficients except for the contemporaneous R\&D were statistically significant in either the Poisson or negative binomial model. Hall et al. (1986) found similar results and concluded that there was very little direct evidence of anything but simultaneity in the year-to-year movement of patents and R\&D expenditures, though an indirect analysis performed in their study suggested a possible distributed lag structure.

The consistency of the previously described panel-data models ${ }^{4}$ rests on the assumption that patents are an indicator of the output or 'success' of R\&D rather than the input of R\&D (Hall et al., 1986). However, as the patent application tends to occur relatively early in the life of a research project and the bulk of R\&D expenditures often occur after the application is made, new patents virtually generate the need for future R\&D expenditures (Griliches, 1990; Hall et al., 1986). Therefore, $R \& D$ expenditures should be seen as a predetermined variable instead of a strictly exogenous one. Such concern in the relationship of patents to internal R\&D activity was first addressed by Hall et al. (1986) using a simple version of a Granger causality test, with a view to testing if past success in patenting leads to an increase in a firm's future R\&D investments. ${ }^{5}$ Montalvo (1997) applied a quasidifferenced generalized method of moments (GMM) estimator to the analysis of the patents-R\&D relationship so as to obtain consistent estimates in the presence of predetermined regressors, i.e., R\&D expenditures. ${ }^{6}$ The results turned out to be somewhat inconclusive as well: the estimated coefficient on contemporaneous R\&D was not statistically significant while the first lag of $R \& D$ had a significant effect on patents.

Blundell et al. (2002) extended the quasi-differenced GMM estimation with an application to a dynamic linear feedback model and proposed an alternative esti-

\footnotetext{
${ }^{4}$ See Guo and Trivedi (2002) for a cross section analysis of the patents-R\&D relationship. Their estimation results were in line with Hall et al. (1986).

${ }^{5}$ Following Hall et al. (1986), a Granger causality test was performed in this study as well (see the results shown in Appendix 2A: Table 2A-1). The current level of $\log R \& D$ was predicted with two lags of $\operatorname{LogR} \& \mathrm{D}$ (based on an approximate AR (2) specification) as well as contemporaneous and lagged LogPatent. As shown from column (6) through (10), the estimated coefficient on contemporaneous LogPatent was significant, but lagged LogPatent terms were of no help in predicting future R\&D. The same behavioral pattern of lagged LogPatent was identified even when contemporaneous LogPatent was left out of the equation in columns (11)-(14). Thus, there was no evidence suggesting that past success in patenting led to an increase in a firm's future R\&D investments above and beyond that implied by its R\&D history.

${ }^{6}$ Chamberlain (1992) and Wooldridge (1997) developed a quasi-differenced GMM estimator that is consistent for count panel data models with predetermined regressors. The quasi-differenced GMM estimation has been applied to the analysis of the patents-R\&D relationship by Montalvo (1997), Crépon and Duguet (1997), Cincera (1997), and Gurmu and Pérez-Sebastián (2008).
} 
mator, the pre-sample mean (PSM) estimator, based upon pre-sample information on the dependent variable. In their application to the analysis of the patents-R\&D relationship, the results for the dynamic linear feedback model from the PSM estimator indicated a much lower depreciation rate of internal R\&D investments-a potential long-run effect of in-house R\&D on firm patenting - than that implied by the results from the multiplicative distributed lag model in prior literature. A recent study on the patents-R\&D relationship by Gurmu and Pérez-Sebastián (2008) reported lagged R\&D effects that were moderately higher than those previously found, but the lag effects on patents were identified only for more recent R\&D.

So far the earlier work in this area, as aforementioned, has investigated the relationship between patenting and internal R\&D activity of firms for the U.S. manufacturing sector during the 1970s (Blundell et al., 2002; Hall et al., 1986; Hausman et al., 1984; Montalvo, 1997; Pakes and Griliches, 1984a) and over the 1980s (Gurmu and Pérez-Sebastián, 2008). Our study aims to revisit this classic research question regarding the lag structure of the patents-R\&D relationship by applying recently developed estimation techniques on firm-level panel data for the global pharmaceutical industry from 1986 to 2000. Prior research suggests that the relationship between patenting and internal R\&D activity of firms differs across industries (Griliches, 1990; Hall et al., 1986). We attempt to address this concern by taking a closer look at the lag structure of the patents-R\&D relationship within one industry. We focus on the global pharmaceutical industry for two main reasons. First, the pharmaceutical industry as a high-technology sector is characterized by highlevels of patenting propensity and R\&D intensity. Previous studies demonstrate that patenting activity is an important source of technological advantage in the pharmaceutical industry (Henderson and Cockburn, 1994; Levin et al., 1987). In addition, recent figures show that pharmaceutical firms invest as much as five times more in $\mathrm{R} \& \mathrm{D}$, relative to their sales, than the average U.S. manufacturing firm (CBO Study, 2006). Second, empirical evidence clearly indicates that the proportion of research (' $R$ ') in $R \& D$ expenditures is the main contributor to patents, whereas the bulk of development ('D') costs lead more to products and processes (Czarnitzki et al., 2009).7 Given that the 'D' part of R\&D expenditures, relative to ' $R$ ', is mostly the larger one, the estimated patents-R\&D elasticity would be biased downwards when development costs are of minor relevance for patent production (Czarnitzki et al., 2009; Griliches, 1990). As the pharmaceutical industry is actually among the most research-intensive sectors with a very large share of ' $\mathrm{R}$ ' (CBO Study, 2006), studying the pharmaceutical industry may alleviate the abovementioned problem.

\footnotetext{
${ }^{7}$ Using Flemish R\&D Survey data, Czarnitzki et al. (2009) provided empirical evidence on the differential contribution of research ('R') and development ('D') to patents and identified a high premium of research ('R'), relative to overall $R \& D$, towards firm patenting.
} 
Our empirical analysis, using both a multiplicative distributed lag model and a dynamic linear feedback model, differs from previous work that examines the patents-R\&D relationship in three aspects. First, our estimation results exhibit direct evidence on lagged R\&D effects, with the first lag ( $t-1)$ of $R \& D$ being significant in all distributed lag specifications. Evidence for the contribution of the first lag of $R \& D$ to the current year's patent counts is of more than $25 \%$ of the total R\&D elasticity. Second, a U-shaped lag structure of the patents-R\&D relationship is found in most estimations of the multiplicative distributed lag model. This finding suggests a potential long-run effect of internal R\&D investments on firm patenting. Finally, the estimation results from the dynamic linear feedback model coincide with those from the multiplicative distributed lag model, indicating not only lag effects from more recent R\&D but also an overall long-run effect of internal $R \& D$ investments in the distant past on the knowledge production or innovation process of incumbent pharmaceutical firms.

The remainder of this paper is structured as follows. In Section 2.2, we provide the theoretical background to the expected lag effects of internal R\&D investments by firms, lags effects that may last during the long run of the knowledge production or innovation process. In that section, we also formulate our main hypothesis. Section 2.3 describes the derivation of the data set and looks at the properties of the various variables. Section 2.4 proceeds by presenting the two count panel data models underlying our empirical analysis-the multiplicative distributed lag model and the dynamic linear feedback model —and their associated estimation techniques. The empirical results are reported in Section 2.5. Section 2.6 summarizes our main results and their implications and it then discusses some possible future lines of work.

\subsection{THEORETICAL BACKGROUND AND HYPOTHESIS}

Knowledge production or innovation is often described as a recombinant process that involves combining existing bits of knowledge in the creation of new knowledge (Fleming, 2001; Kogut and Zander, 1992). A firm's existing bits of knowledge or knowledge stock are built up over time through its previous investments in R\&D (Hall et al., 1986). In the context of the relationship between patents and $R \& D$ expenditures, the annual $R \& D$ expenditures are considered to be investments which add to a firm's knowledge stock, and patents are taken as an output indicator of new knowledge creation or innovation (Hall et al., 1986; Hausman et al., 1984). As argued by Scotchmer (1991), the innovation process is of a cumulative nature such that early innovations (i.e., knowledge stock) provide a 
boost or a technological foundation for later innovations (i.e., new knowledge). ${ }^{8}$ This forms a theoretical rationale underlying the lag effects of R\&D investments in the sense of contributions to firm innovativeness.

A firm's knowledge stock usually depreciates as time passes (Hall et al., 1986) since knowledge tends to become obsolete and it no longer matches the demands of its current environment (Eisenhardt, 1989; Helfat and Raubitschek, 2000). In this respect, more recently created knowledge is often considered more valuable for knowledge production or innovation because of organization-environment fit (Sørensen and Stuart, 2000), capability building in emerging areas (McGrath, 1999), temporal local search (Helfat, 1994; Martin and Mitchell, 1998), and cognitive and institutional pressures (Martins and Kambil, 1999; Nerkar, 2003). In other words, in the case of the patents-R\&D relationship, recent $R \& D$ investments are expected to have a greater impact on firm patenting, while the contribution of older $\mathrm{R} \& \mathrm{D}$ has become less valuable with the passage of time.

However, research also suggests that recent knowledge may not necessarily be representative of the technologically superior or optimal solution that has emerged (Abrahamson, 1996). In contrast, a firm's older knowledge spread across long time spans, accruing from its R\&D investments in the past, may also be influential with respect to new knowledge creation or innovation (Garud and Nayyar, 1994; Nerkar, 2003). For example, incumbent pharmaceutical firms often review their previously discarded experimental compounds, some of which failed in clinical trials as long as twenty years ago, hoping that an old compound intended for one treatment may be useful in treating something different nowadays (Simons, 2006). The rationale for the important role of older knowledge is that it is characterized by increased reliability and legitimacy, as older knowledge is usually better tested and understood by firms than recently created knowledge, thereby decreasing the chances of costly errors and increasing the likelihood of successful innovation (Katila, 2002; March, 1991). The far-reaching influence of older knowledge implies that even long past R\&D investments by firms can still play a crucial part in their knowledge production or innovation, or put differently, the lag effects produced by internal $\mathrm{R} \& \mathrm{D}$ investments may last over a long time horizon.

Such potential long-run effect of in-house R\&D is consistent with a real options logic for managing $\mathrm{R} \& \mathrm{D}$ investment strategies of firms. As stated by Myers (1984: 135) “... the value of R\&D is almost all option value ...”. R\&D investments can be considered to be real options that convey the right for firms to preserve their decision rights for the future of their investment choices (Garud and Nayyar, 1994; McGrath, 1997). For firms operating in a rapidly changing environment, it is important to constantly direct their R\&D efforts towards new techno-

\footnotetext{
${ }^{8}$ We are thankful for an anonymous referee's valuable advice on this point.
} 
logical areas that are often characterized by high levels of technical uncertainty. ${ }^{9}$ In the face of technical uncertainty, it is in the best interests of firms to invest immediately, otherwise they might be subject to a discounting penalty or even the risk of lock-out (McGrath, 1997). After taking out the initial investment, i.e., the opened option, firms may have strong incentives to persist in making investments in the same area (McGrath and Nerkar, 2004). This is due to increases in absorptive capacity that, with the cumulative experience through a track record of investments, makes the assimilation of subsequent knowledge in the same area easier, faster, and less expensive (Cohen and Levinthal, 1990; McGrath and Nerkar, 2004). Such sequential investing in internal $\mathrm{R} \& \mathrm{D}$ leads to a cumulative, path-dependent knowledge production or innovation process, which makes the very early option investments in R\&D valuable or even vital for a firm's success in later innovations (Cook et al., 2011). Alternatively, a firm may choose to wait after the earlier investments or even exit the area it invested in before. In this way, the earlier investments in R\&D can still serve as part of the firm's stock of knowledge. In particular, the knowledge derived from such R\&D investments may demonstrate a great potential value at a future date when conditions favor its (re)use, for instance, through coevolution of complementary knowledge, markets, institutions, or standards that are necessary for employing the useful but untapped knowledge (Garud and Nayyar, 1994; Nerkar, 2003). To the extent that it might take a very long time for these favorable conditions to emerge, there are time lags for a firm's past knowledge to become conducive for future knowledge creation or innovation. Hence, from the perspective of real options reasoning, early R\&D investments by firms are expected to generate a long-lasting impact on future knowledge creation or innovation.

The above indicates that internal $\mathrm{R} \& \mathrm{D}$ investments by firms give rise to, not only lag effects in the short run that arise from more recent $\mathrm{R} \& \mathrm{D}$, but also a potential long-run effect resulting from their distant R\&D history in the knowledge production or firm innovation process. We therefore propose the following main hypothesis:

Hypothesis: Taking patents as an output indicator of firms' innovativeness, lag effects of firms' internal R\&D investments are expected to impact their long run knowledge production process.

\footnotetext{
${ }^{9}$ Technical uncertainty refers to the likely costs and probabilities of accomplishing technical success. This form of uncertainty can only be reduced through investment by firms. Such technical uncertainty creates pressure on firms to invest immediately (Dixit and Pindyck, 1994; McGrath, 1997).
} 


\subsection{DATA AND VARIABLE CONSTRUCTION}

\subsubsection{Data and Sample}

The research setting for this study is the global pharmaceutical industry, which is on the verge of profound mutations as a new biotechnology-based technological regime has emerged. In particular, we will focus on incumbent pharmaceutical firms which attempt to build up innovative capabilities within this new technological regime. Incumbent pharmaceutical firms are defined as pharmaceutical firms that were in existence prior to the emergence of biotechnology. These incumbents, such as Bayer, Hoffmann-La Roche, Merck, and Pfizer, are generally mature and very large firms that dominated the industry since the 1940s. In the mid-1970s, new biotechnology brought along significant scientific and technological breakthroughs in genetic engineering (recombinant DNA, 1973) and hybridization (monoclonal antibodies, 1975). These advances virtually serve as a radical process innovation for incumbent pharmaceutical firms in the way new drugs are discovered and developed (Pisano, 1997a).

To mitigate a potential survivor bias, we started with a comprehensive set of incumbent pharmaceutical firms alive as of 1986 based on various industry sources. ${ }^{10}$ Through this process, we identified 89 incumbent pharmaceutical firms, defined as pharmaceutical firms that were founded prior to the emergence of biotechnology in the mid-1970s. In case horizontal mergers and acquisitions (M\&As) took place among the incumbent pharmaceutical firms during the 1986-2000 study period, both the acquired and the acquiring firms were kept in the sample and treated as unbalanced data up to the merger or acquisition year. A further scrutiny criterion for the sample firms is based on the absence of large jumps over the study period. Following Hall et al. (1986), a jump is defined as an increase in total assets or employment of more than 100 per cent or a decrease of more than 50 per cent. ${ }^{11}$ This test was not applied unless the change in total assets was greater than two million dollars or the change in employment was greater than 500 employees. Most incumbent pharmaceutical firms survived the scrutiny criterion of the absence of large jumps and four firms were left out of our sample. ${ }^{12}$ Our study ultimately ended up with an unbalanced panel sample of 85 firms covering the 15-year period from 1986 to 2000, giving 1,186 firm-year observations.

\footnotetext{
${ }^{10}$ The sample for this study was drawn by referring to Compustat, Datastream, Amadeus, SIC reports, Ernst and Young's Annual Biotech Industry Reports, Scrip's Pharmaceutical Yearbook, amongst others.

${ }^{11}$ For the sample firms in our study, total assets are a better indicator of scale change than capital stock, which was used in Hall et al. (1986).

${ }^{12}$ In a very few cases, where failure to pass the scrutiny criterion occurred toward the end of the study period, we kept such firms in the sample and treated them as unbalanced data by considering their data of post-failure year(s) 'missing'.
} 
An important source of data for our study is the Technology Profile Report maintained by the U.S. Patent and Trademark Office (USPTO). All patent data used in this study are based on successful patent applications, i.e., granted patents. The application date of a patent is only reported when the patent is actually granted. On average it takes three years for the USPTO to grant a patent after it was originally applied for by an inventing firm. In contrast, there is essentially no lag time between the completed invention and the patent application date, which is on average no more than three months (Darby and Zucker, 2010). Thus, the patent application date is closely tied to the timing of the new knowledge creation and it should be used as the relevant time placer for patents (Hall et al., 2001; Trajtenberg, 1990). Accordingly, we assigned a granted patent to the particular year in which the patent was originally applied for. For instance, a patent applied for in 1986 but granted in 1989 is considered a 1986 patent. Since patents can be assigned to both the parent firm and its various levels of subsidiaries, we identified all subsidiaries of firms in the sample, using D\&Bs Who Owns Whom, and then aggregated the number of granted patents to the parent level or the entire corporate level (Ahuja, 2000a; Sampson, 2007). Further, we used USPTO patent data for both U.S. and non-U.S. firms. Although U.S. patent data could imply a bias against non-U.S. firms, it is mentioned in the literature that, given the importance of the U.S. market, the patent protection offered by U.S. authorities, and the level of technological sophistication of the U.S. market, it is inevitable that non-U.S. firms, in particular leading large firms, file their patents in the USA (Hagedoorn and Cloodt, 2003; Patel and Pavitt, 1991). Moreover, as suggested by Ahuja and Katila (2001), to maintain a certain level of consistency, reliability and comparability, choosing one patenting system is preferred to using several patenting systems across nations.

Financial figures and employment data were obtained from Compustat and Datastream (Thomson Financial). For all firms, financial data were converted to U.S. dollars and are inflation-adjusted in millions of year 2000 dollars.

\subsubsection{Dependent Variable}

The dependent variable for this study is the number of patents applied for by an incumbent pharmaceutical firm in a given year that are eventually granted, which is taken as an output indicator of advances in knowledge, or more in general, firm innovativeness. As displayed in Table 2.1, the frequency distribution of the number of patents is characterized by heavy upper tails with a range of 0 to 800 , a mean value of about 94 , and a relatively low median value of 45 . The first and third quartile values are 14 and 116 patents, respectively. Over the whole study period, the proportion of zero patents is only $1 \%$, while the fraction with at least 100 patents is $29 \%$. Compared to previous studies (see e.g., Cincera, 1997; Gurmu and Pérez- 
Sebastián, 2008; Hall et al., 1986; Hausman et al., 1984), the variance of the number of patents is slightly larger than the mean, indicating the presence of a moderate overdispersion in our patent data. ${ }^{13}$

Table 2.1 Descriptive Statistics

\begin{tabular}{lllll}
\hline Variable & Mean & S. D. & Min & Max \\
\hline R\&D expenditures & 504.75 & 587.83 & 1.51 & 2767.50 \\
Number of patents & 94.11 & 128.95 & 0 & 800 \\
First quartile number of patents & 14 & & & \\
Median number of patents & 45 & & & \\
Third quartile number of patents & 116 & & & \\
Fraction with zero patents & 0.01 & & & \\
Fraction with at least 100 patents & 0.29 & & & \\
Pre-sample mean & 69.30 & 91.76 & 0.10 & 362.80 \\
Equity & 4720.16 & 4825.73 & 7.08 & 17507.77 \\
European firm & 0.30 & 0.46 & 0 & 1 \\
U.S. firm & 0.33 & 0.47 & 0 & 1 \\
Pharma firm & 0.46 & 0.50 & 0 & 1 \\
\hline
\end{tabular}

\subsubsection{Independent Variables}

The main explanatory variables of interest are the natural logarithms of current and lagged values of internal R\&D investments. We measured an incumbent pharmaceutical firm's internal R\&D investments by its annual R $\approx D$ expenditures. The annual $R \& D$ expenditures are considered to be investments that add to a firm's stock of knowledge (Hall et al., 1986). Table 2.1 shows that incumbent pharmaceuticals are $R \& D$-intensive firms, their average $R \& D$ expenditures amounting to approximately 505 million dollars per year. From Table 2.2 we can see that R\&D expenditures by incumbent pharmaceutical firms are highly correlated over time, with the first order autocorrelation of about 0.99 and the correlation between R\&D regressors all above 0.95. We will discuss this issue of a highly persistent $R \& D$ series at greater length in the forthcoming sections. All R\&D expenditures are inflationadjusted in millions of year 2000 dollars.

\footnotetext{
${ }_{13}^{13}$ See Guo and Trivedi (2002), Gurmu and Pérez-Sebastián (2008) for the flexible techniques that are more desirable for highly overdispersed data.
} 


\subsubsection{Control Variables}

The logarithm of pre-sample mean of patents is included to proxy for the unobserved heterogeneity in firm knowledge production (Blundell et al., 1995, 2002). We used the average number of patents by a pharmaceutical firm in the period from 1981 to 1985 , i.e., a five-year period of pre-sample history, to construct the pre-sample mean variable.

Table 2.2 Correlation Matrix between Patenting and Internal R\&D

\begin{tabular}{|c|c|c|c|c|c|c|}
\hline & Patents $_{\mathrm{t}}$ & $\log R \& D_{t}$ & $\log R \& D_{t-1}$ & $\log R \& D_{t-2}$ & $\log R \& D_{t-3}$ & $\log R \& D_{t-4}$ \\
\hline $\log R \& D_{t}$ & 0.6101 & & & & & \\
\hline $\log R \& D_{t-1}$ & 0.6167 & 0.9933 & & & & \\
\hline $\log R \& D_{t-2}$ & 0.6217 & 0.9839 & 0.9930 & & & \\
\hline $\log R \& D_{t-3}$ & 0.6273 & 0.9749 & 0.9838 & 0.9933 & & \\
\hline $\log R \& D_{t-4}$ & 0.6299 & 0.9651 & 0.9749 & 0.9847 & 0.9934 & \\
\hline $\log R \& D_{t-5}$ & 0.6318 & 0.9504 & 0.9624 & 0.9740 & 0.9826 & 0.9922 \\
\hline
\end{tabular}

Following previous studies (Gurmu and Pérez-Sebastián, 2008; Hall et al., 1986; Hausman et al., 1984), we used a time-constant regressor, i.e., the logarithm of book value of equity in year 2000 in millions of dollars, as a measure for firm size. For those firms that fail to survive till year 2000, the end year value of equity is used and inflation-adjusted.

To control for country-specific institutional configurations that are significant in shaping firms' propensities to patent (Jaffe and Trajtenberg, 1999), we included two indicator variables based upon the location of company headquarters. One indicator variable is coded as 1 if a pharmaceutical firm is headquartered in the United States $(1=$ U.S. Firm $)$, and the other indicator is coded as 1 if a pharmaceutical firm is headquartered in Europe (1 = European Firm), with a Japanese location as the reference category. The global nature of our data set is reflected in the fact that $33 \%$ of the firms are U.S. based, $30 \%$ are European based, with the remaining $37 \%$ headquartered in Japan.

In contrast to previous studies (Gurmu and Pérez-Sebastián, 2008; Hall et al., 1986; Hausman et al., 1984) where a scientific sector dummy was used to distinguish R\&D-intensive industries from other manufacturing industries, our study focuses on one high-tech industry in the scientific sector, the global pharmaceutical industry. Since the pharmaceutical industry is made up of both specialized pharmaceutical firms and more diversified, mainly chemical, conglomerates, we controlled for a pharmaceutical firm's degree of diversification by coding the firm as 1 if it is a 
specialized company $(1=$ Pharma Firm $)$ and 0 otherwise. Specialized pharmaceutical firms are those active in SIC 2834 (Pharmaceutical Preparations Manufacturing), whereas a conglomerate might engage, for instance, in both SIC 2834 and SIC 2890 (Chemical Products Manufacturing). About half of the firms in the sample are fully specialized $(46 \%)$.

Over time, patenting frequency may increase or decrease for all firms. To control for such time-varying effects, we included year fixed effects for each year, with 2000 being the reference year.

\subsection{ESTIMATION}

As the dependent variable of this study, the number of patents applied for and received by firms, is a count variable taking only non-negative integer values, we employ various count panel data models - the multiplicative distributed lag model and the dynamic linear feedback model — to investigate the relationship between patenting and internal R\&D activity of firms in the global pharmaceutical industry. For simplicity, all estimation methods to be used in our empirical analysis will only be sketched here. The relevant models and the associated moment conditions to be solved are described in Appendix 2B (see GMM I and PSM I for the estimation of Model (1), the multiplicative distributed lag model, and GMM II and PSM II for estimating Model (2), the dynamic linear feedback model).

\subsubsection{Multiplicative Distributed Lag Model}

The conditional mean for a standard multiplicative distributed lag model is specified as

$$
\begin{aligned}
& E\left(P_{i t} \mid \log R D_{i t}, \operatorname{logRD} D_{i t-1}, \ldots, \log R D_{i t-\tau}, s_{i}, w_{t}, \eta_{i}\right) \\
& =\exp \left(\beta_{0}+\beta_{1} \log R D_{i t}+\ldots+\beta_{\tau+1} \log R D_{i t-\tau}+s_{i}^{\prime} \theta_{i}+w_{t}^{\prime} \theta_{t}+\eta_{i}\right)
\end{aligned}
$$

where $P_{i t}$ is the number of patents applied for and received by firm i in period t, $\mathrm{RD}_{\text {it }}$ denotes annual R\&D expenditures, $\mathrm{s}_{\mathrm{i}}$ is a vector of observable firm-specific effects (such as firm size, firm nationality, and Pharma firm), ${ }^{14} \mathrm{w}_{\mathrm{t}}$ is a vector of time-specific variables (i.e., year fixed effects), and $\eta_{\mathrm{i}}$ represents unobserved individual fixed effects, which are commonly modeled multiplicatively in count panel data models.

The basic reference for estimating the above model is the Poisson and negative binomial estimations (Hausman et al., 1984). Both random- and fixed-effects

\footnotetext{
${ }^{14}$ The firm-specific effects $S_{i}$ are only included in the random-effects specifications.
} 
specifications are used in this study to control for unobserved individual fixed effects, $\eta_{i}$, in the Poisson and negative binomial estimations. The problem with the random (uncorrelated) effects formulation is that it is inconsistent when $\eta_{i}$ is correlated with the regressors of interest. ${ }^{15}$ Conditional fixed-effects specification, however, allows for such correlations (Hall et al., 1986; Hausman et al., 1984). It is also important to note that, on account of the overdispersed nature of patent counts, the negative binomial estimation provides a better fit for our data than the Poisson estimation since the assumption of the equality of conditional mean and variance may not hold (Hall et al., 1986; Hausman et al., 1984).

The consistency of the standard estimators presented above relies on the strict exogeneity of the explanatory variables. As previously discussed, new patents may depend on additional R\&D expenditures in the future for their full development, the series of current and lagged R\&D expenditures is therefore weakly exogenous or predetermined in our estimation models. As an alternative, Chamberlain (1992) and Wooldridge (1997) propose a quasi-differenced GMM estimator that relaxes the strict exogeneity assumption. More specifically, they provide a transformation strategy that eliminates the unobserved fixed effects and then use valid moment conditions to obtain consistent estimation. In this study, we follow Wooldridge's (1997) quasi-differencing transformation and use the instruments $\left(z_{i t}\right)$ as below, which require a restricted serial correlation of the residuals. ${ }^{16}$

$\mathrm{z}_{\mathrm{it}}=\left(1, \log \mathrm{RD}_{\mathrm{it}-(\tau+1)}, \ldots, \log \mathrm{RD}_{\mathrm{i} 1}, \mathrm{P}_{\mathrm{it}-(\tau+2)}, \ldots, \mathrm{P}_{\mathrm{i} 1}, \mathrm{w}_{\mathrm{t}}^{\prime}\right)$

On the other hand, the GMM estimator is subject to some problems, namely small sample bias and imprecision, particularly when economic series is highly persistent as the instruments are then weak predictors of the endogenous changes (Blundell et al., 1995, 2002). As an alternative, Blundell et al. (2002) propose a presample mean (PSM) estimator that replaces the unobserved fixed effect by the presample mean of the dependent variable. In view of the highly persistent R\&D series in our study, as will be exhibited in Table 2.2, we also use the PSM estimator.

${ }^{15}$ There are reasons to believe that in many circumstances such correlations may exist. For instance, firms that have a higher propensity to patent for unobserved reasons may invest more in R\&D as the return from R\&D is higher than that from other investment projects (Montalvo, 1997).

${ }^{16}$ The GMM estimation is inconsistent if the requirement on the instruments $\left(z_{i t}\right)$ is not satisfied (see Crépon and Duguet, 1997). Alternatively, the instruments $S_{\text {it }}$, as shown below, can be used, for which a restricted serial correlation of the residuals is not required.

$$
\mathrm{S}_{\text {it }}=\left(1, \log R \mathrm{D}_{\text {it }-(\tau+1)}, \log R \mathrm{D}_{\text {it }-(\tau+2)}, \ldots, \log R \mathrm{D}_{\mathrm{i} 1}, \mathrm{w}_{\mathrm{t}}^{\prime}\right)
$$

The difference between these two sets of instruments is that the latter could lose efficiency in the presence of a restricted serial correlation of the residuals. We used $\mathrm{S}_{\text {it }}$ as well and the estimation results were basically similar. 


\subsubsection{Dynamic Linear Feedback Model}

An additional complication to the highly persistent $R \& D$ series is that the current and lagged R\&D terms in the multiplicative distributed lag model [i.e., Model (1)] are collinear. To solve this problem, Blundell et al. (2002) develop a dynamic linear feedback model by explicitly introducing the dynamics of the count process itself in panel data. In contrast with Model (1), in the dynamic linear feedback model [i.e., Model (2)], the lagged dependent variable enters the conditional mean specification linearly, which corresponds to the following: ${ }^{17}$

$\mathrm{E}\left(\mathrm{P}_{\mathrm{it}} \mid \mathrm{P}_{\mathrm{it}-1}, \log \mathrm{RD} \mathrm{it}_{\mathrm{it}}, \mathrm{w}_{\mathrm{t}}, \eta_{\mathrm{i}}\right)=\gamma \mathrm{P}_{\mathrm{it}-1}+\exp \left(\alpha_{0}+\alpha_{1} \operatorname{logRD_{it}}+\mathrm{w}_{\mathrm{t}}^{\prime} \theta_{\mathrm{t}}+\eta_{\mathrm{i}}\right)$

where $1-\gamma$ estimates the depreciation factor, $\alpha_{1}$ and $(1-\gamma) \alpha_{1}$ are the long-run and short-run elasticities of patents with respect to internal $R \& D$, respectively (see Appendix 2B for an economic interpretation of the dynamic linear feedback model).

Following Blundell et al. (2002), we use two approaches to obtaining estimates for Model (2). The first is the GMM estimator, based on Wooldridge's (1997) quasi-differencing transformation and a choice of the instruments as follows:

$\mathrm{z}_{\mathrm{it}}=\left(1, \log \mathrm{R} \mathrm{D}_{\mathrm{it}-1}, \log \mathrm{RD} \mathrm{D}_{\mathrm{it}-2}, \ldots, \log \mathrm{RD} \mathrm{D}_{\mathrm{i} 1}, \mathrm{P}_{\mathrm{it}-2}, \ldots, \mathrm{P}_{\mathrm{i} 1}, \mathrm{w}_{\mathrm{t}}^{\prime}\right)$

A further estimation of Model (2) using the PSM estimator, as discussed earlier, includes pre-sample information on the number of patents to control for unobserved individual fixed effects. Both estimators are consistent in the presence of predetermined regressors and correlated fixed effects.

\section{$2.5 \quad$ RESULTS}

\subsubsection{Results for Hypothesis}

The main findings for Model (1), in which five lagged $\mathrm{R} \& \mathrm{D}$ terms are included, ${ }^{18}$ and Model (2) are presented in Table 2.3-a. Columns 1 through 4 give results from the standard Poisson and negative binomial estimations of Model (1). The coefficients on contemporaneous $(t)$ and the first lag $(t-1)$ of $R \& D$ are positive and significant across all the Poisson and negative binomial regression models. Moreover, a consistent pattern of a $U$-shaped lag structure is found, with the first $(t)$ and

\footnotetext{
${ }^{17}$ Blundell et al. (2002) suggest that inclusion of functions of the lagged dependent variable in the exponential function can lead to explosive series for patents or cause problems with transforming zero values.

${ }^{18}$ Following Hausman et al. (1984) and Pakes and Griliches (1984a), the multiplicative distributed lag model [i.e., Model (1)] is constructed with five lagged R\&D terms.
} 
last $(t-5)$ coefficients being larger than those in the middle, for the Poisson and negative binomial models in both the random-effects (RE) and fixed-effects (FE) specifications.

Table 2.3-a Estimates of the Knowledge Production Function from Patents

\begin{tabular}{|c|c|c|c|c|}
\hline Variable & $\begin{array}{l}\text { Poisson } \\
\text { (RE) }\end{array}$ & $\begin{array}{l}\text { Poisson } \\
\text { (FE) }\end{array}$ & $\begin{array}{l}\text { Negative } \\
\text { Binomial (RE) }\end{array}$ & $\begin{array}{l}\text { Negative } \\
\text { Binomial (FE) }\end{array}$ \\
\hline Constant & $\begin{array}{l}-0.0403 \\
(0.5779)\end{array}$ & & $\begin{array}{c}0.0048 \\
(0.3967)\end{array}$ & $\begin{array}{l}-0.5668^{*} \\
(0.2717)\end{array}$ \\
\hline Year Dummies & Included & Included & Included & Included \\
\hline European Firm & $\begin{array}{l}-0.0164 \\
(0.2054)\end{array}$ & & $\begin{array}{l}-0.3471^{*} \\
(0.1527)\end{array}$ & \\
\hline U.S. Firm & $\begin{array}{l}0.7599^{* * *} \\
(0.2000)\end{array}$ & & $\begin{array}{c}0.1390 \\
(0.1584)\end{array}$ & \\
\hline Pharma Firm & $\begin{array}{l}-0.6679^{* * *} \\
(0.1700)\end{array}$ & & $\begin{array}{l}-0.5137^{* * *} \\
(0.1187)\end{array}$ & \\
\hline LogEquity & $\begin{array}{l}-0.1412 \dagger \\
(0.0764)\end{array}$ & & $\begin{array}{l}-0.1523^{*} \\
(0.0621)\end{array}$ & \\
\hline $\log R \& D_{t}$ & $\begin{array}{l}0.3654^{* * *} \\
(0.0362)\end{array}$ & $\begin{array}{l}0.3813^{* * *} \\
(0.0363)\end{array}$ & $\begin{array}{c}0.2517^{* *} \\
(0.0943)\end{array}$ & $\begin{array}{r}0.2392^{*} \\
(0.1028)\end{array}$ \\
\hline $\log R \& D_{t-1}$ & $\begin{array}{l}0.2493^{* * *} \\
(0.0500)\end{array}$ & $\begin{array}{l}0.2449^{* * *} \\
(0.0499)\end{array}$ & $\begin{array}{c}0.2937^{*} \\
(0.1330)\end{array}$ & $\begin{array}{r}0.2432 \dagger \\
(0.1415)\end{array}$ \\
\hline $\log R \& D_{t-2}$ & $\begin{array}{c}0.0365 \\
(0.0533)\end{array}$ & $\begin{array}{c}0.0445 \\
(0.0533)\end{array}$ & $\begin{array}{l}-0.0164 \\
(0.1383)\end{array}$ & $\begin{array}{l}-0.0416 \\
(0.1464)\end{array}$ \\
\hline $\log R \& D_{t-3}$ & $\begin{array}{c}0.1122^{*} \\
(0.0536)\end{array}$ & $\begin{array}{c}0.1154^{*} \\
(0.0536)\end{array}$ & $\begin{array}{c}0.0578 \\
(0.1379)\end{array}$ & $\begin{array}{l}-0.0223 \\
(0.1439)\end{array}$ \\
\hline $\log R \& D_{t-4}$ & $\begin{array}{l}-0.0522 \\
(0.0516)\end{array}$ & $\begin{array}{l}-0.0493 \\
(0.0516)\end{array}$ & $\begin{array}{l}-0.0948 \\
(0.1325)\end{array}$ & $\begin{array}{l}-0.0854 \\
(0.1374)\end{array}$ \\
\hline $\log R \& D_{t-5}$ & $\begin{array}{l}0.2383^{* * *} \\
(0.0372)\end{array}$ & $\begin{array}{l}0.2520^{* * *} \\
(0.0373)\end{array}$ & $\begin{array}{r}0.2080^{*} \\
(0.0934)\end{array}$ & $\begin{array}{r}0.1926^{*} \\
(0.0956)\end{array}$ \\
\hline $\begin{array}{l}\text { Sum of } \\
\text { R\&D Elasticity }\end{array}$ & 0.9495 & 0.9888 & 0.7000 & 0.5257 \\
\hline Log Likelihood & -4498.0885 & -3888.3712 & -3327.3603 & -2713.6075 \\
\hline Chi Square & $2339.20^{* * *}$ & $2212.43^{* * *}$ & $368.04^{* * *}$ & $226.49^{* * *}$ \\
\hline
\end{tabular}

Notes:

Firm size, firm nationality, and pharma firm, as observable firm-specific effects, are only included in the random-effects (RE) estimation so as to alleviate a potential endogeneity problem caused by the correlation between unobserved individual fixed effects and the regressors of interest (Hall et al., 1986; Hausman et al., 1984).

The significant, positive, and large coefficient on the last lag ( $t-5)$ of $R \& D$ could be due to the correlation of the last $R \& D$ variable with earlier left-out R\&D. If this is the case, a U-shaped lag structure is solid evidence for a lag truncation effect in the distributed lag of R\&D on patents (Hall et al., 1986; Pakes and Grili- 
ches, 1984a). To explore this idea further, we performed autoregressive regressions on the R\&D series. As shown in Table 2A-1 (see Appendix 2A), an AR (2) process can be accepted at $5 \%$ significance level. Nonetheless, the first lag coefficients are close to one and the second lag coefficients are relatively small, which implies that it is difficult to reject a random walk process. Hence, the R\&D series of this study conforms to a random walk or an AR (2) process and suggests the existence of a lag truncation effect. On the other hand, the fairly large coefficient on the last lagged R\&D may also be caused by correlated fixed effects, i.e., the correlation between the permanent patenting propensity of firms and their investments in internal R\&D (Hall et al., 1986; Pakes and Griliches, 1984a). We then used fixedeffects models that allow for such correlations, and a U-shaped lag structure was identified as well in the fixed effects formulation. This finding suggests that correlated fixed effects do not bias the estimated results and there is indeed a lag truncation effect in the distributed lag relationship between patenting and R\&D expenditures. By contrast, previous work is inconclusive about the lag structure of the patents-R\&D relationship. Hausman et al. (1984) and Hall et al. (1986) found a Ushaped lag structure for the Poisson and negative binomial random-effects models, but only a contemporaneous relationship was identified in their conditional fixedeffects models. In the recent study by Gurmu and Pérez-Sebastián (2008), a Ushaped lag structure was found for the random- and fixed-effects Poisson models but no evidence of it in the case of negative binomial models.

Results for Model (1) using the less constrained GMM and PSM estimators, which relax the strict exogeneity assumption, are reported in columns GMM I and PSM I, respectively (see Table 2.3-b). ${ }^{19}$ In the GMM estimation, a Sargan Difference test is used to check for overidentifying restrictions, and $\mathrm{m} 1$ and $\mathrm{m} 2$ are tests for first- and second-order serial correlations. As shown in column GMM I, the Sargan test does not reject the null hypothesis that the additional moment conditions are valid. In addition, the first- and second-order serial correlation tests are consistent with the serially uncorrelated error term (i.e., significant $\mathrm{m} 1$ and insignificant $\mathrm{m} 2$ ). The specification tests thus do not indicate misspecification in GMM I. Comparison of the results from GMM I to those from the Poisson and negative binomial estimations shows that there are still strong contemporaneous and lag effects of R\&D, with significant positive coefficients on $\mathrm{t}(p<0.001), \mathrm{t}-1$ ( $p<$ $0.001)$, and $\mathrm{t}-5(p<0.05)$. However, a negative and significant $(p<0.001)$ effect is found at the second lag $(t-2)$ of $R \& D$. Although this is not as expected, similar cases also occur in previous studies (see Gurmu and Pérez-Sebastián, 2008; Mon-

${ }^{19}$ We are thankful for Frank Windmeijer's ExpEnd program for Gauss to obtain estimates for Models (1) and (2) using the GMM and PSM estimators (see Windmeijer, 2002). 
talvo, 1997). ${ }^{20}$ The puzzling estimated form of the lag structure in GMM I possibly arises from a problem of weak instruments, as the R\&D series in our data set is highly persistent over time (the first order autocorrelation is about 0.99 as displayed in Table 2.2) and the instruments are only weakly correlated with the endogenous regressors in the differenced model (Blundell et al., 1995, 2002; Bond and Windmeijer, 2005).21

In column PSM I, results are given from the PSM estimator for the estimation of Model (1). The pre-sample mean of patents is positive and statistically significant $(p<0.001)$, indicating that it is important to control for the unobserved differences in the capabilities for knowledge production with which firms entered the sample. With regard to the influence of internal $\mathrm{R} \& \mathrm{D}$, both the contemporaneous $(t)$ and first lagged $(t-1) R \& D$ terms retain their signs, though with reduced level of significance $(p<0.10)$. The significant effect of the last lag $(t-5)$ of $R \& D$, however, no longer appears in the PSM I version. The explanation lies in the fact that the information contained in the pre-sample mean becomes close to that reflected by the $R \& D$ series when the $R \& D$ process is highly persistent. Thus, the separate estimation of the parameters on $\mathrm{R} \& \mathrm{D}$ and the pre-sample mean is problematic due to multicollinearity (Blundell et al., 2002). Since the variance of the fixed effect (proxied by the pre-sample mean) is relatively large, the parameter on the pre-sample mean variable will get a larger weight, leading to a downward bias in the parameters for the R\&D series. ${ }^{22}$

To give a brief summary of Model (1), based on the various estimations presented above, in all cases the results suggest that there are lag effects of internal R\&D as well as a significant contemporaneous relationship between patents and $R \& D$. Consistent with prior literature, the impact of contemporaneous $(t) R \& D$ on patents is rather strong. However, our study differs substantively from previous

\footnotetext{
${ }^{20}$ In Montalvo (1997), the estimated coefficient on contemporaneous R\&D was barely different from zero, whereas the first lag of $R \& D$ was positive and significant. Likewise, puzzling results were also found in the study by Gurmu and Pérez-Sebastián (2008), where a negative and significant effect was identified at the fourth lag of R\&D.

${ }^{21}$ To give an indication of the extent of the weak instrument problem, we used a log-log functional form to model the relationship between patents and R\&D expenditures (see Pakes and Griliches, 1984a). After differencing the log-log model, we obtained several statistics, provided by Stata, for weak instruments test under GMM estimation. The values for $F$ statistic, with a minimum of 0.773 and a maximum of 3.727 , are much lower than 10. Stock et al. (2002) suggest that the $F$ statistic should exceed 10 for inference. Other statistics for weak instruments test include: (1) The Kleibergen-Paap rk Wald F statistic $=0.056$; (2) The Cragg-Donald Wald F statistic $=0.037$; (3) The minimum eigenvalue $=0.056$; (4) Shea's partial $R^{2}$ report a range of $0.004-0.018$ and Shea's adjusted partial $R^{2}$ turn out to be negative values. Taken together, the rather low values of various statistics suggest that the instruments are (very) weakly correlated with the endogenous regressors in our model.

22See Blundell et al. (2002), the PSM estimator performs better in Monte-Carlo simulations in comparison to the GMM estimator. However, there is an increase in the bias and root mean squared error for the PSM estimator of $\beta$ when the R\&D series becomes very persistent.
} 
work in that the estimation results exhibit direct evidence on lagged R\&D effects, with the first lag $(t-1)$ of $R \& D$ being significant in all distributed lag specifications. More importantly, a U-shaped lag structure of the patents-R\&D relationship is identified across the various estimations of Model (1) (except for PSM I), suggesting a potential long-run effect of internal R\&D investments on firm patenting.

Table 2.3-b Estimates of the Knowledge Production Function from Patents

\begin{tabular}{|c|c|c|c|c|}
\hline Variable & $\begin{array}{l}\text { GMM } \\
\text { I }\end{array}$ & $\begin{array}{l}\text { PSM } \\
\text { I }\end{array}$ & $\begin{array}{l}\text { GMM } \\
\text { II }\end{array}$ & $\begin{array}{c}\text { PSM } \\
\text { II }\end{array}$ \\
\hline Constant & & $\begin{array}{l}3.7630^{* * *} \\
(0.1001)\end{array}$ & & $\begin{array}{l}1.7962^{* * *} \\
(0.3536)\end{array}$ \\
\hline Year Dummies & Included & Included & Included & \\
\hline Log Pre-sample Mean & & $\begin{array}{l}0.6121^{* * *} \\
(0.0660)\end{array}$ & & $\begin{array}{c}0.3797^{* *} \\
(0.1383)\end{array}$ \\
\hline Patent $t_{\mathrm{t}-1}$ & & & $\begin{array}{l}0.2130^{* * *} \\
(0.0172)\end{array}$ & $\begin{array}{l}0.9003^{* * *} \\
(0.0439)\end{array}$ \\
\hline $\log R \& D_{t}$ & $\begin{array}{l}0.4443^{* * *} \\
(0.0629)\end{array}$ & $\begin{array}{r}0.3058 \dagger \\
(0.1583)\end{array}$ & $\begin{array}{l}0.7276^{* * * *} \\
(0.0315)\end{array}$ & $\begin{array}{l}0.4995^{* *} \\
(0.1529)\end{array}$ \\
\hline $\log R \& D_{t-1}$ & $\begin{array}{l}0.2664^{* * *} \\
(0.0703)\end{array}$ & $\begin{array}{r}0.1646 \dagger \\
(0.0981)\end{array}$ & & \\
\hline $\log R \& D_{t-2}$ & $\begin{array}{l}-0.2992^{* * *} \\
(0.0884)\end{array}$ & $\begin{array}{l}-0.0866 \\
(0.1393)\end{array}$ & & \\
\hline $\log R \& D_{t-3}$ & $\begin{array}{c}0.0248 \\
(0.0734)\end{array}$ & $\begin{array}{c}0.1394 \\
(0.1224)\end{array}$ & & \\
\hline $\log R \& D_{t-4}$ & $\begin{array}{c}0.1140 \\
(0.0699)\end{array}$ & $\begin{array}{l}-0.1456 \\
(0.0940)\end{array}$ & & \\
\hline $\log R \& D_{t-5}$ & $\begin{array}{c}0.1698^{*} \\
(0.0683)\end{array}$ & $\begin{array}{l}-0.0707 \\
(0.1611)\end{array}$ & & \\
\hline $\begin{array}{l}\text { Sum of } \\
\text { R\&D Elasticity }\end{array}$ & 0.7201 & 0.3069 & & \\
\hline Sargan $[p$-value $]$ & $\begin{array}{c}55.5390 \\
{[0.1139]}\end{array}$ & & $\begin{array}{c}69.0116 \\
{[0.1991]}\end{array}$ & \\
\hline $\mathrm{m} 1[p$-value $]$ & $\begin{array}{l}-2.5497 \\
{[0.0108]}\end{array}$ & & $\begin{array}{l}-4.0400 \\
{[0.0001]}\end{array}$ & \\
\hline $\mathrm{m} 2[p$-value $]$ & $\begin{array}{l}-1.2863 \\
{[0.1983]}\end{array}$ & & $\begin{array}{c}0.0049 \\
{[0.9961]}\end{array}$ & \\
\hline
\end{tabular}

\section{Notes:}

1) Standard errors are in parentheses. Year dummies are included but not shown, except that in PSM (II) estimation, we could not achieve convergence with inclusion of fixed year effects.

2) $† p<0.10, * p<0.05, * * p<0.01, * * * p<0.001$.

3) The diagnostic tests for GMM (I) and GMM (II) include: Sargan $=$ the Sargan test for overidentifying restrictions, $\mathrm{m} 1=$ first-order serial correlation, $\mathrm{m} 2=$ second-order serial correlation; $p$-values are in brackets.

4) The pre-sample mean variable is only included in the PSM estimation of Models (1) and (2). 
We now turn to the estimation of Model (2), the dynamic linear feedback model, which essentially allows for the dynamics of the count process itself. Results for Model (2) using the GMM and PSM estimators are reported in columns GMM II and PSM II, respectively (see Table 2.3-b). As seen in GMM II, the specification tests provide no evidence against the model. The estimated coefficients on the lagged dependent variable and R\&D equal to $0.21(\gamma)$ and $0.73\left(\alpha_{1}\right)$. This implies that the contribution of internal R\&D investments depreciates exponentially at the rate of approximately $1-\gamma=79 \%$, with the short-run elasticity of patents with respect to R\&D of about $(1-\gamma) \alpha_{1}=0.57$ and the long-run elasticity of about $\alpha_{1}=0.73$. These results provide evidence for the lag effects of R\&D expenditures on patents, though at a relatively fast moving process. The suspicion is still that, as in the case of GMM I, the GMM estimator is subject to small sample bias and the weak instrument problem, particularly when the R\&D series is highly persistent over time (Blundell et al., 1995, 2002; Bond and Windmeijer, 2005).

The estimates from PSM II show a rather different picture, with a fairly low depreciation rate of approximately $10 \%$ and the long-run elasticity of patents with respect to $\mathrm{R} \& \mathrm{D}$ of about 0.50 , which is substantially larger than the short-run elasticity, 0.05. Therefore, PSM II implies a much slower moving process and accordingly an overall long-run effect of in-house R\&D on firm patenting. In this vein, the estimation results from Model (2) coincide with those from Model (1), indicating not only lag effects from more recent R\&D (i.e., the first lag $(t-1)$ of R\&D) but, in support of our main hypothesis, also a potential long-run effect of internal R\&D investments in the distant past on a firm's knowledge production or innovation process.

\subsubsection{Robustness of Results}

We acknowledge that firms' knowledge production or innovation could arise from both their internal and external R\&D investments. ${ }^{23}$ As a robustness test, we also ran all the model estimations by including firms' external R\&D investments, through $\mathrm{R} \& \mathrm{D}$ alliances and $\mathrm{R} \& \mathrm{D}$ acquisitions. $\mathrm{R} \& \mathrm{D}$ alliances, as registered in the CATI (Cooperative Agreements and Technology Indicators) database, are measured as the number of alliances between incumbent pharmaceutical firms and new biotechnology companies, in which a combined innovative activity or an exchange of technology is involved. Likewise, R\&D acquisitions, as registered in the SDC (Securities Database Corporation) Platinum database of Thomson Financial, are measured as the number of acquisitions undertaken by incumbent pharmaceutical

\footnotetext{
${ }^{23}$ The focus in our paper is on the role of internal $R \& D$ as a basis for sustainable innovative capabilities of firms. An in-depth analysis of the impact of external R\&D strategies such as R\&D alliances and $\mathrm{R} \& \mathrm{D}$ acquisitions is beyond the scope of this study.
} 
firms, which targeted new biotechnology companies for their R\&D capabilities. A one-year lag is employed on both variables to alleviate a potential simultaneity bias. We found that inclusion of external R\&D does not alter the estimation results, including the lagged R\&D effects and the U-shaped lag structure of the patents-R\&D relationship, across the various estimations of models (1) and (2). An exception is GMM I, in which the Sargan test rejects the null hypothesis and indicates that the model is misspecified.

Furthermore, apart from the book value of equity in year 2000, we used the logarithm of the annual values of equity to control for firm size. Since a very few firm-year values of equity are negative, we changed the negative value into 0.000001 (million dollars) before taking the logarithms. In addition, firm revenues and net income were included in the regression equations to allow for firm performance. A one-period lag is employed on the above control variables. The estimated results remained largely unchanged.

\subsection{DISCUSSION AND CONCLUSIONS}

The principal purpose of this study is to revisit the classic research question regarding the lag structure of the patents-R\&D relationship through an examination of the impact of internal $\mathrm{R} \& \mathrm{D}$ on firm patenting in the context of the global pharmaceutical industry during 1986-2000. Our empirical analysis shows that, although the results are somewhat sensitive to different estimation methods, the total elasticity of patents with respect to $\mathrm{R} \& \mathrm{D}$ varies from 0.3 to 0.9 , indicating decreasing returns to scale in internal R\&D. Consistent with prior research, the impact of contemporaneous ( $t$ ) $R \& D$ on patents is rather strong, accounting for over $36 \%$ of the overall R\&D elasticity. However, our study differs from previous work that examines the patents-R\&D relationship in three aspects. First, our estimation results exhibit direct evidence on lagged $R \& D$ effects, with the first lag ( $t-$ 1) of $R \& D$ being significant in all distributed lag specifications. Evidence for the contribution of the first lag of R\&D to the current year's patent counts is of more than $25 \%$ of the total R\&D elasticity. Second, a U-shaped lag structure of the patents-R\&D relationship is identified across the various estimations of the multiplicative distributed lag model (except for PSM I). This finding suggests a potential long-run effect of internal R\&D investments on firm patenting. Finally, the estimation results for the dynamic linear feedback model, especially from the PSM estimator, coincide with those from the multiplicative distributed lag model, with a fairly low depreciation rate of approximately $10 \%$ of internal R\&D investments over time and accordingly an overall long-run effect of internal R\&D on firm patenting. In short, our empirical findings, from both the multiplicative distributed lag model and the dynamic linear feedback model, provide evidence for not only 
lag effects from more recent $\mathrm{R} \& \mathrm{D}$ but, in support of our main hypothesis, also a potential long-run effect of internal $R \& D$ investments in the distant past on the knowledge production or innovation process of incumbent pharmaceutical firms.

To summarize, our results illustrate a cumulative knowledge production or innovation process of incumbent pharmaceutical firms, with current patent production being historically dependent on past investments in internal R\&D. These results are consistent with prior research which suggests that not only recent knowledge is important for new knowledge creation, but that older knowledge in knowledge stock accruing from long past R\&D investments may also be valuable for firm innovativeness (Katila, 2002; Nerkar, 2003). This finding echoes the real options logic for managing R\&D investment strategies of firms (McGrath, 1997; McGrath and Nerkar, 2004), according to which early R\&D investments by firms in a new area with technical uncertainty may be influential in their knowledge production or innovation process over a long-term horizon. Subsequent R\&D investments in the same area can further reduce technical uncertainty and reinforce the value of options opened earlier. Alternatively, firms may choose to wait or even exit the area they invested before. In this way, the earlier investments in R\&D can still serve as part of the firms' stock of knowledge, which may contribute substantially to their later innovations when conditions favor its use.

From a managerial perspective, our study offers important insights into the cumulative knowledge production or innovation process of firms. In addition to emphasizing recent investments in internal R\&D to stay abreast of the latest, cutting edge technologies, decision-makers in firms should also adopt a long-term perspective for organizing $R \& D$ investment strategies. Through periodically reviewing and recombining older, useful but under-utilized knowledge, firms can increase their creation of new knowledge (Garud and Nayyar, 1994; Nerkar, 2003). However, it is noteworthy that older knowledge tends to be lost over time due to lack of adequate organizational memory, inaccurate recording, and turnover in R\&D personnel (Argote, 1999). As a consequence, for firms to effectively transfer knowledge across time, they need to build up the 'transformative capacity' which pertains to the choice of knowledge for future use, its maintenance over time, and the reactivation and synthesis of such knowledge when required (Garud and Nayyar, 1994; Nerkar, 2003). In this way, by making better use of older knowledge and actively maintaining stock of knowledge for future use, firms can enhance their returns from internal $\mathrm{R} \& \mathrm{D}$ investments.

Our study is subject to some limitations which suggest avenues for future research. The restriction of the sample to a single industrial context raises the question of the generalizability of our findings, thus further efforts could be made to conduct research in other high-technology industries. In addition, as the proportion of research (' $R$ ') in $R \& D$ expenditures is the main contributor to patents 
(Czarnitzki et al., 2009; Griliches, 1990), future work directed towards a finegrained analysis of disaggregating ' $\mathrm{R}$ ' and ' $\mathrm{D}$ ' would contribute to a better understanding of the overall lag structure of the patents-R\&D relationship. 


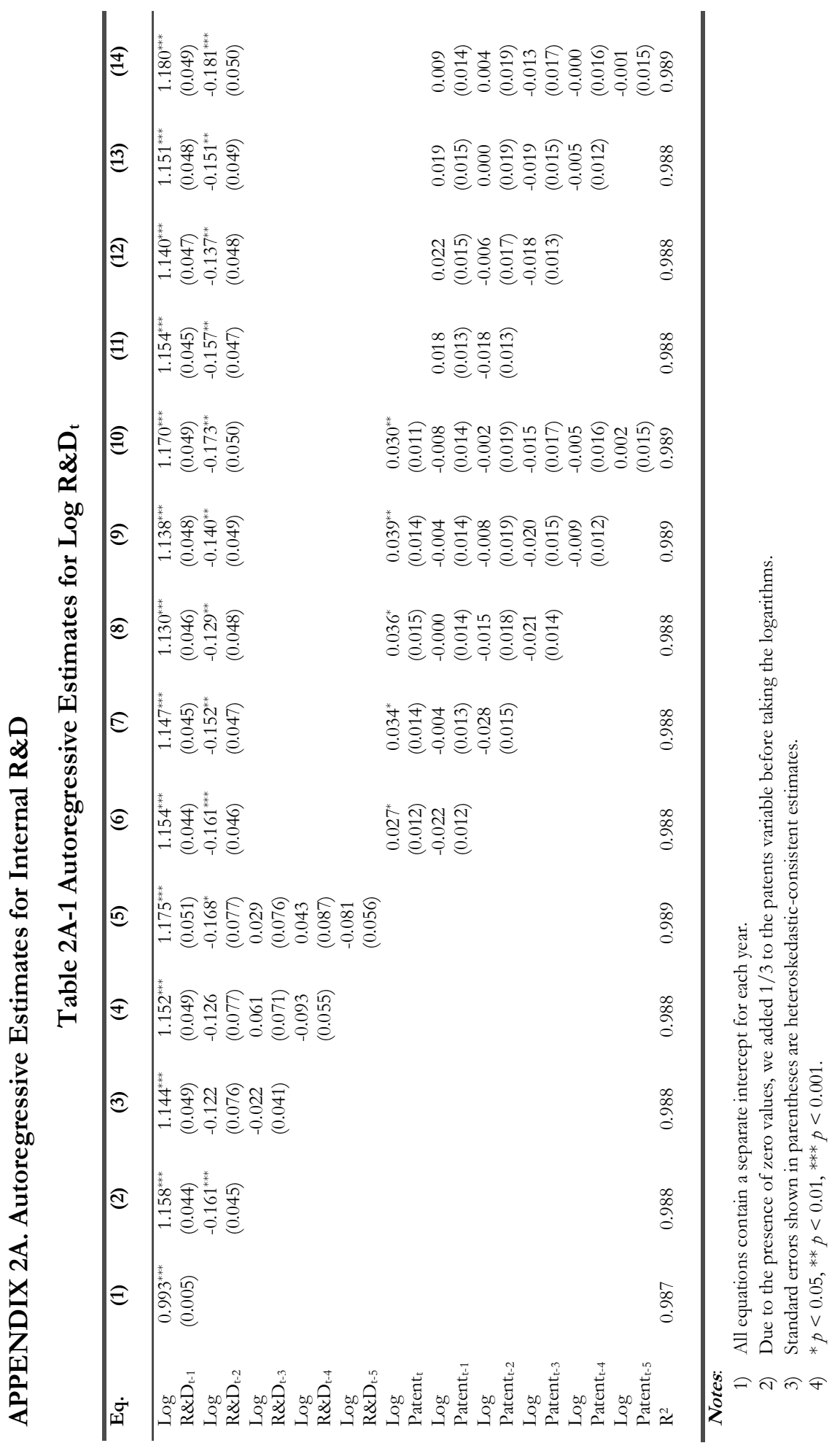




\section{APPENDIX 2B. Estimation Models and the Moment Conditions}

\section{B-1 Multiplicative Distributed Lag Model [Model (1)]}

The conditional mean for a standard multiplicative distributed lag model for count panel data is: ${ }^{24}$

$\mathrm{E}\left(\mathrm{y}_{\mathrm{it}} \mid \mathrm{X}_{\mathrm{it}}, \eta_{\mathrm{i}}\right)=\exp \left(\mathrm{X}_{\mathrm{it}}^{\prime} \beta+\eta_{\mathrm{i}}\right)=\mu_{\mathrm{it}} \nu_{\mathrm{i}}$

where $\mu_{i t}=\exp \left(X_{i t}^{\prime} \beta\right)$, and $\nu_{i}=\exp \left(\eta_{i}\right)$ is a permanent scaling factor for the individual specific mean. In our study, the innovation model is written as,

$X_{i t}^{\prime} \beta=\beta_{0}+\beta_{1} x_{i t}+\beta_{2} x_{i t-1}+\ldots+\beta_{\tau+1} x_{i t-\tau}+\operatorname{control}^{\prime} \theta$

where $y_{i t}$ is the number of patents applied for and received by firm $\mathrm{i}$ in period $\mathrm{t}(\mathrm{i}=$ $1, \ldots, \mathrm{N} ; \mathrm{t}=1, \ldots, \mathrm{T}), \mathrm{x}_{\mathrm{it}}$ denotes the natural logarithm of annual R\&D expenditures, and control is a vector of control variables.

\section{GMM I}

In our study, the generalized method of moment (GMM) estimator applies the Wooldridge's (1997) quasi-differencing transformation: ${ }^{25}$

$\mathrm{q}_{\mathrm{it}}=\mathrm{y}_{\mathrm{it}} / \mu_{\mathrm{it}}-\mathrm{y}_{\mathrm{it}-1} / \mu_{\mathrm{it}-1}$

When $\mathrm{x}_{\mathrm{it}}, \mathrm{x}_{\mathrm{it}-1}, \ldots, \mathrm{x}_{\mathrm{it}-\tau}$ are predetermined, the following moment conditions hold, ${ }^{26}$

$\mathrm{E}\left(\mathrm{q}_{\mathrm{it}} \mid \mathrm{x}_{\mathrm{i} 1}, \mathrm{x}_{\mathrm{i} 2}, \ldots, \mathrm{x}_{\mathrm{it}-1}\right)=0$.

\section{PSM I}

The pre-sample mean (PSM) estimator solves the following moment conditions when estimating the multiplicative distributed lag model:

$\sum_{\mathrm{i}=1}^{\mathrm{N}} \sum_{\mathrm{t}=\tau+1}^{\mathrm{T}} z_{\mathrm{it}}\left(\mathrm{y}_{\mathrm{it}}-\exp \left(\beta_{0}^{*}+\beta_{1} \mathrm{x}_{\mathrm{it}}+\ldots+\beta_{\tau+1} \mathrm{x}_{\mathrm{it}-\tau}+\operatorname{control}^{\prime} \theta+\phi \log \bar{y}_{\mathrm{ip}}\right)\right)=0$

${ }^{24}$ The Cobb-Douglas knowledge production function is applied in this model.

${ }^{25} \mathrm{An}$ alternative is the Chamberlain (1992) quasi-differencing transformation:

$$
\mathrm{s}_{\mathrm{it}}=\mathrm{y}_{\mathrm{it}} \frac{\mu_{\mathrm{it}-1}}{\mu_{\mathrm{it}}}-\mathrm{y}_{\mathrm{it}-1}
$$

${ }^{26} \mathrm{z}_{\mathrm{it}}=\left(1, \mathrm{x}_{\mathrm{it}-(\mathrm{s}+1)}, \mathrm{x}_{\mathrm{it}-(\mathrm{s}+2)}, \ldots, \mathrm{x}_{\mathrm{i} 1}\right.$, control $)$ is used as the instruments, where $\mathrm{s}(=0, \ldots, \tau)$ represents the extent to which the $z_{\text {it }}$ are weakly exogenous, i.e., $s=0(s=1, \ldots, \tau)$ means that $\mathrm{x}_{\mathrm{it}-1}\left(\mathrm{x}_{\mathrm{it}-2}, \ldots, \mathrm{x}_{\mathrm{it}-(\tau+1)}\right)$ in the $\mathrm{z}_{\mathrm{it}}($ Cincera, 1997). 
where $\bar{y}_{\mathrm{ip}}=\frac{1}{\mathrm{TP}} \sum_{\mathrm{r}=0}^{\mathrm{TP}-1} \mathrm{y}_{\mathrm{i} 0-\mathrm{r}}$ is the pre-sample mean of $\mathrm{y}$, TP is the number of presample observations, and $z_{i t}=\left(1, x_{i t}, x_{i t-1}, \ldots, x_{i t-\tau}\right.$, control', $\left.\log \bar{y}_{i p}\right)$.

\section{B-2 Dynamic Linear Feedback Model27 [Model (2)]}

\section{Dynamic linear feedback model in the patents- $R \& D$ relationship: An economic interpretation}

Instead of using Cobb-Douglas knowledge production function, R\&D expenditures are combined through a specific parameterization of the CES knowledge production function to produce knowledge stock:

$Q_{i t}=k\left(R D_{i t}^{\beta}+(1-\delta) R_{i t-1}^{\beta}+\ldots\right)^{\psi / \beta} v_{i}$

where $\mathrm{Q}_{\mathrm{it}}$ is some latent measure of technological output of firm $\mathrm{i}$ in period $\mathrm{t}, \mathrm{k}$ is a positive constant, $\mathrm{R} \& \mathrm{D}$ investment depreciates exponentially at rate $\delta$, and $\mathrm{v}_{\mathrm{i}}$ captures the firm specific propensity to patents.

As observed patents are a noisy indicator of a firm's technological output, we write

$\mathrm{P}_{\mathrm{it}}=\mathrm{Q}_{\mathrm{it}}+\varepsilon_{\mathrm{it}}$

where $\mathrm{P}_{\text {it }}$ are the number of patents applied for and received by firm $\mathrm{i}$ in period $\mathrm{t}$, and $\mathrm{E}\left(\varepsilon_{\mathrm{it}} \mid \mathrm{RD}_{\mathrm{it}}, \mathrm{RD}_{\mathrm{it}-1}, \ldots, \mathrm{v}_{\mathrm{i}}\right)=0$.

Setting the returns to scale parameter $\psi$ equal to $\beta$ in (B6) and using (B7) results in,

$P_{i t}=k\left(R D_{i t}^{\beta}+(1-\delta) R D_{i t-1}^{\beta}+\ldots\right) v_{i}+\varepsilon_{i t}$

Ignoring any feedback from patents to R\&D expenditures, the long run steady state for firm i may be written as

$\mathrm{P}_{\mathrm{i}}=\frac{\mathrm{k}}{\delta} \mathrm{RD}_{\mathrm{i}}^{\beta} \mathrm{v}_{\mathrm{i}}$

thus $\beta$ may be interpreted as the long run elasticity of patents with respect to $R \& D$, and $\delta * \beta$ is the short run elasticity.

Inverting (B8) results in,

$$
\begin{aligned}
\mathrm{P}_{\mathrm{it}} & =(1-\delta) \mathrm{P}_{\mathrm{it}-1}+\mathrm{kRD}_{\mathrm{it}}^{\beta} \mathrm{v}_{\mathrm{i}}+\mathrm{u}_{\mathrm{it}} \\
& =(1-\delta) \mathrm{P}_{\mathrm{it}-1}+\exp \left(\log \mathrm{k}+\beta \log \mathrm{RD}_{\mathrm{it}}\right) \mathrm{v}_{\mathrm{i}}+\mathrm{u}_{\mathrm{it}}
\end{aligned}
$$

with $E\left(u_{i t} \mid P_{i t-1}, R_{i t}, v_{i}\right)=0$. 
From (B10), the conditional mean in the dynamic linear feedback model is defined as,

$\mathrm{E}\left(\mathrm{y}_{\mathrm{it}} \mid \mathrm{y}_{\mathrm{it}-1}, \mathrm{X}_{\mathrm{it}}, \mathrm{v}_{\mathrm{i}}\right)=\gamma \mathrm{y}_{\mathrm{it}-1}+\exp \left(\mathrm{X}_{\mathrm{it}}^{\prime} \alpha\right) \mathrm{v}_{\mathrm{i}}=\gamma \mathrm{y}_{\mathrm{it}-1}+\mu_{\mathrm{it}} \nu_{\mathrm{i}}$

where

$$
\begin{gathered}
\mathrm{X}_{\mathrm{it}}^{\prime} \alpha=\alpha_{0}+\alpha_{1} \mathrm{x}_{\mathrm{it}}+\text { control }^{\prime} \theta \\
\gamma=1-\delta \\
\alpha_{1}=\beta
\end{gathered}
$$

$y_{i t}$ are the number of patents applied for and received by firm $i$ in period $t(i=$ $1, \ldots, \mathrm{N} ; \mathrm{t}=1, \ldots, \mathrm{T}), \mathrm{x}_{\mathrm{it}}$ denotes the natural logarithm of annual R\&D expenditures, and control is a vector of control variables.

\section{GMM II}

In this study the generalized method of moment (GMM) estimator applies the Wooldridge's (1997) quasi-differencing transformation: ${ }^{28}$

$\mathrm{q}_{\mathrm{it}}=\left(\mathrm{y}_{\mathrm{it}}-\gamma \mathrm{y}_{\mathrm{it}-1}\right) / \mu_{\mathrm{it}}-\left(\mathrm{y}_{\mathrm{it}-1}-\gamma \mathrm{y}_{\mathrm{it}-2}\right) / \mu_{\mathrm{it}-1}$

When $x_{i t}$ is predetermined, the following moment conditions hold

$\mathrm{E}\left(\mathrm{q}_{\mathrm{it}} \mid \mathrm{y}_{\mathrm{i} 1}, \mathrm{y}_{\mathrm{i} 2}, \ldots, \mathrm{y}_{\mathrm{it}-2}, \mathrm{x}_{\mathrm{i} 1}, \mathrm{x}_{\mathrm{i} 2}, \ldots, \mathrm{x}_{\mathrm{it}-1}\right)=0$.

\section{PSM II}

The pre-sample mean (PSM) estimator solves the following moment conditions when estimating the dynamic linear feedback model:

$\sum_{\mathrm{i}=1}^{\mathrm{N}} \sum_{\mathrm{t}=2}^{\mathrm{T}} \mathrm{z}_{\mathrm{it}}\left(\mathrm{y}_{\mathrm{it}}-\gamma \mathrm{y}_{\mathrm{it}-1}-\exp \left(\alpha_{0}^{*}+\alpha_{1} \mathrm{x}_{\mathrm{it}}+\operatorname{control}^{\prime} \theta+\phi \log \overline{\mathrm{y}}_{\mathrm{ip}}\right)\right)=0$

where $\bar{y}_{\text {ip }}=\frac{1}{\mathrm{TP}} \sum_{\mathrm{r}=0}^{\mathrm{TP}-1} \mathrm{y}_{\mathrm{i} 0-\mathrm{r}}$ is the pre-sample mean of $\mathrm{y}$, TP is the number of presample observations, and $z_{i t}=\left(1, y_{i t-1}, x_{i t}\right.$, control', log $\left.\bar{y}_{i p}\right)$.

${ }^{28} \mathrm{An}$ alternative is the Chamberlain's (1992) quasi-differencing transformation as follows:

$$
\mathrm{s}_{\mathrm{it}}=\left(\mathrm{y}_{\mathrm{it}}-\gamma \mathrm{y}_{\mathrm{it}-1}\right) \frac{\mu_{\mathrm{it}-1}}{\mu_{\mathrm{it}}}-\left(\mathrm{y}_{\mathrm{it}-1}-\gamma \mathrm{y}_{\mathrm{it}-2}\right)
$$





\section{CHAPTER 3}

\section{IS THERE COMPLEMENTARITY OR SUBSTITUTABILITY BETWEEN INTERNAL AND EXTERNAL R\&D STRATEGIES? ${ }^{29 *}$}

\subsection{INTRODUCTION}

Recent years have witnessed more and more firms pursuing an 'open innovation' (Chesbrough, 2003) approach by leveraging internal and external knowledge development in parallel so as to build and hone their innovative capabilities. Concurrent with the open innovation approach, a rather voluminous literature has emerged that examines the relationship between internal and external R\&D strategies. At the heart of this literature is the discussion of the complementarity or substitutability between internal and external R\&D strategies for managing innovation, a debate that has been accompanied by mixed empirical evidence. ${ }^{30}$ On one hand, a number of recent studies have demonstrated that internal R\&D and external technology sourcing are complementary innovation activities, suggesting their interrelatedness in improving a firm's innovative performance (see e.g., Cassiman and Veugelers, 2006; Lokshin et al., 2008; Rothaermel and Hess, 2007; Schmiedeberg, 2008). On the other hand, another stream of empirical studies investigating the relationship between internal and external sources of innovation have found substitutability (or, no complementarity) between these activities (Hess and Rothaermel, 2011; Laursen and Salter, 2006; Vega-Jurado et al., 2009). The various strands of extant empirical research are thus inconclusive about the complementarity or substitutability between different innovation mechanisms.

Building on the above literature, our study seeks to provide empirical evidence on the complementarity or substitutability between internal and external R\&D strategies in the context of the global pharmaceutical industry. In particular,

\footnotetext{
${ }^{29 *}$ This chapter is based on Hagedoorn, J. and Wang, N. 2012. Is there complementarity or substitutability between internal and external R\&D strategies? Research Policy 41(6): 1072-1083.

${ }^{30}$ Complementarity (substitutability) is assumed to exist between two activities if an increase in one activity can actually enhance (reduce) the marginal return to the other (Cassiman and Veugelers, 2006; Milgrom and Roberts, 1990, 1995; Topkis, 1998). We take a firm-level view of the complementarity or substitutability between internal and external R\&D strategies of firms. A project-level analysis is beyond the scope of this study.
} 
we focus on incumbent pharmaceutical firms, examining the interactive effects of their internal and external R\&D activities on innovative performance. With the emergence of biotechnology in the mid-1970s, the pharmaceutical industry has undergone disruptive technological change for incumbent pharmaceutical firms, which were traditionally organic chemistry based (Powell et al., 1996; Stuart et al., 1999). In adapting to the new biotechnology-based technological regime, incumbent pharmaceutical firms have engaged significantly in external R\&D strategies, such as R\&D alliances with or R\&D acquisitions of new biotechnology companies, to supplement their in-house R\&D efforts (Eisenhardt and Martin, 2000; Rothaermel, 2001; Rothaermel and Hess, 2007). Such a simultaneous pursuit of internal and external R\&D investments exemplifies the open innovation approach and hence makes the pharmaceutical industry an especially appropriate context in which to investigate the relationship between internal and external R\&D strategies in predicting a firm's innovative output.

Using a panel sample of 83 incumbent pharmaceutical firms covering the period 1986-2000, our empirical analysis suggests that, instead of a clear-cut answer to the question whether internal and external R\&D are complementary or substitutive innovation activities, there appears to be a contingent relationship between internal and external R\&D strategies in shaping a firm's innovative output. The results from our study indicate that the level of in-house R\&D investments, characterized by decreasing marginal returns, is a contingency variable that critically influences the association between internal and external R\&D strategies. More specifically, internal $R \& D$ and external $R \& D$, through either $R \& D$ alliances or R\&D acquisitions, are complementary innovation activities at higher levels of inhouse R\&D investments, whereas at lower levels of in-house R\&D efforts, internal and external R\&D turn out to be substitutive strategic options. These findings highlight the complexity of understanding the relationship between internal and external R\&D strategies, where the existence of a potential complementarity is contingent. As suggested by Cassiman and Veugelers (2006), understanding under what conditions innovation activities may in fact be complementary is more important than determining what activities are complementary per se. Given the scarcity of prior work on this line of research (exceptions are Cassiman and Veugelers, 2006; Hess and Rothaermel, 2011), we contribute to the existing empirical literature by advancing and testing the role of a firm's in-house R\&D efforts in determining the condition under which there may actually be complementarity or substitutability between its various R\&D strategies.

The paper proceeds as follows. In Section 3.2, after an overview of the growing literature on internal and external $R \& D$ strategies of firms, we formulate the hypotheses to be tested. We then describe the sample, the model, and the estimation techniques in Section 3.3. The empirical results are presented in Section 3.4, 
followed by a variety of robustness tests. Section 3.5 provides a discussion of the main findings and their implications, together with some directions for future research.

\subsection{THEORY AND HYPOTHESES}

To the extent that internal R\&D (often measured as R\&D expenditures) is an important, and perhaps even the most important, contributor to productivity growth and innovation (Griliches, 1979; Scherer, 1982), the impact of R\&D expenditures on firm innovation has attracted enormous attention in the literature. Researchers have found quite a strong relationship between R\&D expenditures and patents in their attempt to validate patents as an economic indicator of firm innovative output (Acs and Audretsch, 1989; Bound et al., 1984; Hall et al., 1986; Pakes and Griliches, 1984a; Scherer, 1983). A related research question in the relationship of patents to internal R\&D activity is: are there decreasing marginal returns to R\&D? Evidence from a large body of empirical studies (Cincera, 1997; Crépon and Duguet, 1997; Guo and Trivedi, 2002; Gurmu and Perez-Sebastian, 2008; Hall et al., 1986; Hausman et al., 1984; Montalvo, 1997) suggests that firms experience diminishing marginal returns as the level of $R \& D$ expenditures increases, with the overall elasticity of patents with respect to internal $R \& D$ varying from 0.26 to 0.90 .

The reasons behind decreasing returns to scale in $R \& D$ expenditures are multifaceted. One reason is that large firms appear to be less efficient than small firms, ${ }^{31}$ receiving a relatively smaller number of patents per R\&D dollar. As firms grow in size, more formalization and bureaucratic controls are required, which result in more rigid and standardized managerial behavior. This contributes to organizational inertia and reduced managerial commitment to innovation, thereby leading to lower innovative efficiency of firms (Hitt and Hoskisson, 1990). Another explanation for diminishing returns, in terms of patents received, to increasing levels of $\mathrm{R} \& \mathrm{D}$ expenditures is that technological and inventive opportunities are being exhausted over time within firms (Griliches, 1990; Hausman et al., 1984). In their seminal work on the patents-R\&D relationship, Hausman et al. (1984) suggest that, rather than the propensity to patent just declining exogenously over time, firms are obtaining less patents from their more recent (internal) R\&D investments, implying a decline in the innovative effectiveness. However, the fact that the relevant $\mathrm{R} \& \mathrm{D}$ is measured with error (Griliches, 1990) casts doubt on the real

\footnotetext{
${ }^{31}$ Griliches (1990) also suggests that the reason why small firms appear to be more efficient than large firms is that small firms are likely to be doing relatively more informal $R \& D$, reporting less of it, and thus providing the appearance of more patents per reported R\&D dollar. However, this is not the case in the present study as our sample is composed of large, established pharmaceutical firms which engage mostly in formal $R \& D$ investments.
} 
characteristics of the relationship between patents and internal R\&D. Empirical evidence shows that the proportion of research ('R') in $R \& D$ expenditures is the main contributor to patents, whereas the bulk of development ('D') costs lead more to new products and processes (Czarnitzki et al., 2009). Given that the 'D' part of $R \& D$ expenditures, relative to ' $R$ ', is mostly the larger one, the estimated patents-R\&D elasticity would be biased downwards when development costs are of minor relevance for patent production (Czarnitzki et al., 2009; Griliches, 1990).

In the present study, we choose to examine decreasing marginal returns to $R \& D$ expenditures within the context of the pharmaceutical industry, which is actually among the most research-intensive sectors with a very large share of ' $R$ ' (CBO Study, 2006). As such, studying the pharmaceutical industry may alleviate the problem that the relevant $R \& D$ is measured with error in the patents-R\&D relationship. Previous studies in the pharmaceutical industry have provided empirical evidence on the existence of decreasing marginal returns to R\&D expenditures (see e.g., Demirkan and Demirkan, 2012; Graves and Langowitz, 1993; Rothaermel and Hess, 2007). The above leads us to a baseline hypothesis on the effect of internal R\&D on firm innovation, which is to be seen as a starting point for our analysis of the simultaneous interactions between internal and external R\&D strategies.

Hypothesis 1: There are decreasing returns to scale in internal R\&D: a firm's innovative output increases with its investment in internal R\&D, this rate of increase diminishes at bigher levels of internal R\&D investments though.

The openness of firms to external knowledge sources is another key element for knowledge creation and innovation. In view of the increasing complexity and multidisciplinarity of research, even the largest and most self-contained organizations cannot keep abreast of all the relevant technological advances solely through their internal R\&D efforts (Teece, 1988; Veugelers, 1997). As Powell et al. (1996) point out, in industries characterized by complex and rapidly expanding knowledge bases, the locus of innovation lies in a broad 'network' of learning rather than within the boundaries of individual firms (also see Powell, 1998). As a consequence, incumbent firms frequently need to engage in external $R \& D$ strategies to source new technology and capabilities in order to survive in a regime of encompassing technological change (Bettis and Hitt, 1995; Kranenburg and Hagedoorn, 2008; Nicholls-Nixon and Woo, 2003; Rothaermel and Hess, 2007). Previous research suggests that interfirm $R \& D$ alliances and $R \& D$ acquisitions are alternative manifestations of external $\mathrm{R} \& \mathrm{D}$ strategies that firms can use to source knowledge externally so as to supplement their in-house R\&D capabilities (Hagedoorn and 
Duysters, 2002a; Vanhaverbeke et al., 2002). R\&D alliances allow incumbent firms to gain access to their partners' specialized knowledge and to explore new technological opportunities, which enable them not only to adapt but also to innovate successfully (Hagedoorn, 2002; Park et al., 2002; Rothaermel, 2001). Alternatively, managers of incumbent firms can engage in R\&D acquisitions by means of outright buying smaller, research-intensive firms to integrate, reconfigure, and gain new resource configurations to match the rapidly changing technological environment (Eisenhardt and Martin, 2000; Ranft and Lord, 2002).

In recent decades, more and more firms have been pursuing an 'open innovation' (Chesbrough, 2003) approach through a simultaneous pursuit of internal and external R\&D strategies. This open innovation approach echoes the notion of 'absorptive capacity' introduced by Cohen and Levinthal $(1989,1990)$, who argue that the two roles of internal R\&D are reflected in directly generating new knowledge and indirectly contributing to absorptive capacity of firms. The central idea behind absorptive capacity is that significant investments in internal $R \& D$ are necessary for firms to effectively appraise, assimilate, and apply new external knowledge (Cohen and Levinthal, 1990). Ample theoretical and empirical evidence exists on the role of absorptive capacity in the capability of firms to combine internal and external knowledge development and to exploit the potential synergies between them (Arora and Gambardella, 1990, 1994; Beneito, 2006; Caloghirou et al., 2004; Higgins and Rodriguez, 2006; Nicholls-Nixon, 1995; Veugelers, 1997). More importantly, absorptive capacity is essential for firms to capitalize on the complementarity between internal and external R\&D strategies. Complementarity is herein understood as that undertaking more of one strategy increases the marginal return to the other (Cassiman and Veugelers, 2006; Milgrom and Roberts, 1990, 1995; Topkis, 1998). The crucial role of absorptive capacity, induced by inhouse $\mathrm{R} \& \mathrm{D}$ efforts, in fostering the complementarity between internal and external R\&D strategies of firms is mainly two-fold. On the one hand, firms' own internal R\&D will increase the marginal return to their external R\&D. Significant absorptive capacity enables firms to effectively scan the external knowledge landscape, evaluate the quality of technological know-how possessed by alliance partners or acquisition targets, and thus conduct more productive investments in external R\&D. On the other hand, access to external R\&D can be leveraged to enhance the efficiency of internal $R \& D$, assuming that a firm exhibits a willingness to be open to external ideas and it overcomes the not-invented-here syndrome (Allen, 1986; Laursen and Salter, 2006). A firm's absorptive capacity facilitates assimilation, transformation, and exploitation of externally acquired knowledge, which in turn enriches the firm's internal knowledge base and strengthens its capabilities to innovate. 
A number of recent empirical studies demonstrate that internal R\&D and external technology sourcing are complementary innovation activities, suggesting their interrelatedness in improving a firm's innovative performance (see e.g., Cassiman and Veugelers, 2006; Lokshin et al., 2008; Rothaermel and Hess, 2007; Schmiedeberg, 2008). ${ }^{32}$ Cassiman and Veugelers (2006) analyze the choice between internal R\&D ('make') and external knowledge acquisition ('buy') by firms in Belgian manufacturing industry and find that they are complementary innovation activities. Likewise, Schmiedeberg (2008) tests for complementarity of different innovation activities - internal $\mathrm{R} \& \mathrm{D}, \mathrm{R} \& \mathrm{D}$ contracting, and $\mathrm{R} \& \mathrm{D}$ cooperationusing cross-sectional firm level data of the German manufacturing sector. His empirical analysis finds evidence for a significant complementarity between internal $R \& D$ and $R \& D$ cooperation, but calls into question the complementarity between internal and contracted R\&D. In their dynamic panel study of Dutch manufacturing firms, Lokshin et al. (2008) show that combining internal and external R\&D contributes significantly to productivity growth. Their results provide evidence of complementarity between internal and external R\&D, with a positive impact of external R\&D only evident in case of sufficient internal R\&D. Using a multilevel analytic approach, Rothaermel and Hess (2007) investigate how pharmaceutical firms can build and refine their dynamic capabilities to adapt to radical technological change. Their study indicates that a firm's internal R\&D capability and its biotechnology alliances complement each other when pursued in parallel, but no complementarity is found between a firm's internal R\&D and its biotechnology acquisitions. Taken together, these empirical findings suggest that internal and external R\&D activities are expected to be complementary and hence positively reinforce each other in raising a firm's innovative output.

Hypothesis 2a: Internal and external ReDD strategies complement each other, such that the interaction between internal and external R\&D is positive and hence increases a firm's innovative output.

Complementarity is but one case of how internal and external $\mathrm{R} \& \mathrm{D}$ strategies interact, different innovation activities within firms may interact as substitutes as well. Substitutability between two activities implies that an increase in one activity

\footnotetext{
${ }^{32}$ Some earlier empirical studies (e.g., Arora and Gambardella, 1990; Audretsch et al., 1996; Blonigen and Taylor, 2000; Colombo and Garrone, 1996; Veugelers, 1997) have examined the cooccurrence of internal R\&D and external knowledge sourcing. Their results suggest complementarity (substitutability) through a positive (negative) correlation between internal and external R\&D activities. This, however, does not suffice to test for complementarity or substitutability between the various $R \& D$ activities. Such inconsistency in defining and measuring complementarity or substitutability possibly leads to some of the contradictory empirical findings.
} 
reduces the marginal benefit of investing in the other (Cassiman and Veugelers, 2006; Milgrom and Roberts, 1990, 1995; Topkis, 1998). Previous studies suggest that a potential substitutability may arise between internal and external $\mathrm{R} \& \mathrm{D}$ activities due to switching costs (Rothaermel and Hess, 2007) or diseconomies of scope (Hess and Rothaermel, 2011). Since investments in the various innovation mechanisms tend to be path dependent, firms prefer to leverage the innovation mechanism in which they have accumulated sufficient skills and capabilities (Cohen and Levinthal, 1990; Pennings and Harianto, 1992). This could lead to substantial switching costs between different modes of innovation, thereby making the use of more than one mode cost prohibitive (Levinthal and March, 1993). In this respect, the simultaneous pursuit of different innovation activities may reduce a firm's innovative output, at least at the margin (Rothaermel and Hess, 2007). Moreover, different innovation activities can result in similar outcomes of innovation and thus exhibit some element of equifinality, suggesting the potential diseconomies of scope associated with using different innovation mechanisms concurrently (Hess and Rothaermel, 2011).

Although there is relatively little empirical evidence on substitutability, several studies investigating the relationship between internal and external sources of innovation find no complementarity between these activities, or suggest that they are substitutive strategic options (Hess and Rothaermel, 2011; Laursen and Salter, 2006; Vega-Jurado et al., 2009). Vega-Jurado et al. (2009) examine the effects of different external knowledge sourcing strategies on product and process innovation and to what extent these effects are influenced by in-house R\&D. Based on a sample of Spanish manufacturing firms, their analysis finds no support for the complementarity between internal R\&D and external sourcing strategies, even though internal R\&D activities are associated with a greater use of external scientific knowledge sources. In an investigation into the role of openness in explaining innovative performance across U.K. manufacturing firms, Laursen and Salter (2006) find that R\&D intensity negatively moderates the relationship between external search strategies (with respect to search breath and search depth) and a firm's innovative performance, indicating a substitution effect between internal R\&D and openness to external knowledge sources. More recently, Hess and Rothaermel (2011) address the question regarding when combinations of value chain activities are substitutive or complementary through investigating the impact of specific activity combinations on a firm's innovative performance. Focusing on two mechanisms-recruitment and retention of star scientists and engagement in strategic alliances-that are central to combining resources for innovation in the pharmaceutical industry, their study suggests that innovation activities that link the same segment of the value chain (i.e., star scientists and upstream alliances) are substitutes. Conversely, activities that focus on different aspects of the value chain 
(i.e., star scientists and downstream alliances) complement each other. From the above discussion, we are faced with a competing hypothesis:

Hypothesis 2b: Internal and external R\&D strategies substitute for each other, such that the interaction between internal and external R\&D is negative and hence decreases a firm's innovative output.

A substantial body of research literature has examined the relationship between internal R\&D and external technology sourcing strategies, so far focusing mainly on either complementarity or substitutability. Nonetheless, understanding under what conditions different R\&D strategies may in fact be complementary is more important than merely determining what activities are complementary per se (Cassiman and Veugelers, 2006). In their study of firm innovation in Belgian manufacturing industry, Cassiman and Veugelers (2006) identify 'basic R\&D reliance', a proxy for a firm's basic R\&D capabilities, as a contextual variable that influences the strength of complementarity between internal R\&D ('make') and external knowledge acquisition ('buy'). Since basic R\&D capabilities often constitute absorptive capacity, firms with basic R\&D capabilities are more likely engaged in combining internal and external innovation activities because their higher absorptive capacity increases the marginal returns from 'make' in the presence of 'buy', and vice versa (Cassiman and Veugelers, 2006). In short, the potential benefits from complementarity between different innovation activities are context specific, particularly sensitive to a firm's absorptive capacity. Inspired by Cassiman and Veugelers (2006), in this study we take a closer look at the critical role of a firm's absorptive capacity, induced by its in-house R\&D efforts (Cohen and Levinthal, 1989, 1990), in the relationship between internal and external R\&D activities. We argue that absorptive capacity not only affects the strength of complementarity but also determines the condition under which there may actually be complementarity or substitutability between internal and external $R \& D$ strategies of incumbent pharmaceutical firms.

It has been shown that a minimum level of internal $R \& D$ investments is required for effectively incorporating external R\&D (Catozzella and Vivarelli, 2007; Lokshin et al., 2008). Within the empirical setting of our research, new biotechnology companies possess strong competences in drug discovery and developmentan upstream value chain activity, whereas incumbent pharmaceutical firms are more experienced at regulatory management, marketing, and distribution-all downstream value chain activities (Rothaermel and Boeker, 2008). Under such conditions, incumbent pharmaceutical firms may build their new technological competencies through engagement into two types of R\&D alliances (Rothaermel, 
2001). On the one hand, an established pharmaceutical firm can enter into 'exploitation alliances' (Rothaermel, 2001), in which it can leverage its existing downstream capabilities to gain access to the technological competencies of new biotechnology companies (Teece, 1986, 1992; Tripsas, 1997). In this case it is, however, often difficult for a pharmaceutical firm to assess the quality of untested technological competences possessed by the new biotechnology entrants (Colombo et al., 2006; Pisano, 1997b). Pisano (1997b) suggests that a potential 'lemons' problem exists in $R \& D$ alliance partnerships due to asymmetric information about the true quality of biotechnology R\&D projects. The biotechnology ventures have a tendency to offer inferior $R \& D$ projects for collaboration, while maintaining the more promising projects in-house for solo development. One way for an established pharmaceutical firm to reduce its exposure to the lemons problem is to put strong efforts into in-house $\mathrm{R} \& \mathrm{D}$ so as to better evaluate the $\mathrm{R} \& \mathrm{D}$ projects offered by collaborative partners (Arora and Gambardella, 1990; Pisano, 1997b). Put it differently, a sufficient level of absorptive capacity enables incumbent pharmaceutical firms to more adequately assess the true value of their partners' technological competencies.

On the other hand, an incumbent pharmaceutical firm can enter 'exploration' alliances to learn the new technology directly from its partners, allowing it to build up new upstream capabilities (Rothaermel, 2001). In this context, both incumbent pharmaceutical firms and new biotechnology entrants operate in the upstream value chain and thus act as competitors rather than collaborators. As a consequence, the risk of a 'learning race' may arise, where each firm seeks for a maximum absorption of distinctive competencies from its partner and tries to protect its own core resources and capabilities (Hamel, 1991; Kale et al., 2000; Khanna et al., 1998). Different absorptive capacity, amongst other factors, explains why firms may win or lose the learning race (Quintana-Garcia and Benavides-Velasco, 2004). Therefore, incumbent pharmaceutical firms with higher levels of internal R\&D investments, which are conducive to higher absorptive capacity, may learn and appropriate key technologies and know-how from their competitive partners (Dushnitsky and lenox, 2005a, 2005b). In contrast, at lower levels of internal R\&D efforts, incumbent pharmaceutical firms tend to be exploited by the new biotechnology entrants, who have absorbed as much as possible while giving as little as possible. In a worst scenario, an established pharmaceutical firm may end up with damaging its own core competencies, especially when unintended knowledge spillovers or leakages emerge (Gilsing and Nooteboom, 2006; Sampson, 2004), thereby leading to a reduced marginal return of in-house $R \& D$.

In the case of the other strategic choice of external $R \& D-R \& D$ acquisitions, an acquiring firm's absorptive capacity also plays a key role in evaluating as well as integrating the acquired technological know-how of the target company. In their 
study of R\&D-directed acquisitions in the pharmaceutical industry, Higgins and Rodriguez (2006) document how pharmaceutical firms engage in serial acquisitions of new biotechnology ventures to overcome their deteriorating internal $R \& D$ productivity. As knowledge-based assets are generally more difficult to assess than tangible ones, for incumbent pharmaceutical firms to avoid overbidding, they need to draw upon their internal $R \& D$ capabilities to better evaluate the underlying value of the target. Moreover, a minimum level of absorptive capacity is required for pharmaceutical firms to effectively integrate the acquired research into their own R\&D (Higgins and Rodriguez, 2006). Conversely, insufficient absorptive capacity could lead to ineffective integration processes, which may harm internal innovation efforts, particularly if they draw attention and resources from such efforts (Hitt et al., 1996), thereby resulting in a reduced marginal return of internal $\mathrm{R} \& \mathrm{D}$.

Taken together, more in-house $\mathrm{R} \& \mathrm{D}$ investments are conducive to higher absorptive capacity which increases a firm's synergistic benefits (e.g., access to and joint development of new technological competencies) between internal and external $R \& D$ activities and, meanwhile, decreases the costs and risks (such as the lemons problem, the risk of losing a learning race, and integration costs) associated with doing external R\&D in the presence of internal R\&D. Hence, at higher levels of in-house $\mathrm{R} \& \mathrm{D}$ investments, a complementary relationship exists between internal and external R\&D strategies as the synergistic benefits outweigh the associated costs and risks, whereas at lowers levels of in-house R\&D efforts, a substitutive relationship emerges in which the costs and risks would actually outweigh the synergistic benefits. Overall, a contingent relationship is expected to exist between internal $R \& D$ and external $R \& D$, through either $R \& D$ alliances or $R \& D$ acquisitions, in shaping a firm's innovative output. We therefore propose,

Hypothesis 3: There is a contingent relationship between internal and external ReD strategies in shaping a firm's innovative output: internal and external R\&D strategies are complementary innovation activities at higher levels of in-house R\&D investments, whereas at lower levels of in-house R\&D investments, they are substitutive innovation activities.

\subsection{METHODOLOGY}

\subsubsection{Data and Sample}

The research setting for testing the postulated hypotheses is the global pharmaceutical industry. During the last one and a half decades of the twentieth century, the pharmaceutical industry can be characterized as a high-tech sector with a strong dual market structure, which is largely determined by a small group of incumbent 
pharmaceutical firms and a large group of entrepreneurial biotechnology companies (Hagedoorn et al., 2008). In particular, our analytic focus is on incumbent pharmaceutical firms that are defined as pharmaceutical firms that were in existence prior to the emergence of biotechnology. These incumbents, such as Bayer, Hoffmann-La Roche, Merck, and Pfizer, are generally mature and very large firms which have dominated the industry since the 1940s. In the mid-1970s, the advent of biotechnology led to significant scientific and technological breakthroughs in genetic engineering (recombinant DNA, 1973) and hybridization (monoclonal antibodies, 1975). These advances have been altering the drug discovery process profoundly in the following decades, accompanied by the upsurge of numerous new dedicated biotechnology firms which possess strong competences in drug discovery and development in the field of biotechnological research. The new biotechnology is considered competence destroying for incumbent pharmaceutical firms, which were traditionally organic chemistry based (Powell et al., 1996; Stuart et al., 1999). In adapting to the new technological regime and an attempt to build up biotechnology competencies, incumbent pharmaceutical firms have engaged significantly in external R\&D strategies, such as $R \& D$ alliances or R\&D acquisitions, to supplement their in-house R\&D efforts (Eisenhardt and Martin, 2000; Rothaermel, 2001; Rothaermel and Hess, 2007). Such a simultaneous pursuit of internal and external R\&D investments exemplifies the open innovation approach and thus makes the pharmaceutical industry an interesting arena in which to study the relationship between internal and external R\&D strategies of firms.

We used data from several major sources. (1) The source for the patent data is the Technology Profile Report maintained by the U.S. Patent and Trademark Office (USPTO), an agency of the U.S. Department of Commerce. We obtained detailed data comprising the population of all biotechnology patents granted to global pharmaceutical firms annually since the emergence of biotechnology. ${ }^{33}$ (2) The data on biotechnology R\&D alliances of incumbent pharmaceutical firms were mainly retrieved from the MERIT-CATI database, ${ }^{34}$ which is developed and main-

\footnotetext{
${ }^{33}$ The complete set of biotechnology patents refers to the granted patents of incumbent pharmaceutical firms, as identified by the USPTO, in the patent classes as follows: 424 [Drug, bio-affecting and body treating compositions (424/9.1-424/9.2, 424/9.34-424/9.81, 424/85.1-424/94.67, 424/130.1-424/283.1, 424/520-424/583, 424/800-424/832) ], 435 [Chemistry: Molecular biology and microbiology (435/1.1-435/7.95, 435/40.5-435/261, 435/317.1-435/975) ], 436 [Chemistry: Analytical and immunological testing (436/500-436/829) ], 514 [Drug, bio-affecting and body treating compositions (514/2-514/22, 514/44, 514/783) ], 530 [Chemistry: Natural resins or derivatives; peptides or proteins; lignins or reaction products thereof (530/300-530/427, 530/800-530/868) ], 536 [Organic compounds (536/1.11-536/23.74, 536/25.1-536/25.2)], 800 [Multi-cellular living organisms and unmodified parts thereof and related processes], 930 [Peptide or protein sequence], PLT [Plants].

${ }^{34}$ The collection of R\&D alliance data was supplemented by two biotechnology-orientated sources, BioScan and Recombinant Capital.
} 
tained by researchers at the Maastricht Economic Research Institute on Innovation and Technology (MERIT). The CATI (Cooperative Agreements and Technology Indicators) database provides information on cooperative technology agreements ${ }^{35}$ and some information on companies participating in these agreements. (3) Data on R\&D acquisitions of new biotechnology companies by incumbent pharmaceutical firms were obtained from the SDC (Securities Database Corporation) Platinum database of Thomson Financial. This database contains information on the year an acquisition was made, with details on the (parent) acquirer, the (parent) target, and a brief description of the acquisition transaction. (4) Financial data were crosstracked through the Compustat and Datastream (Thomson Financial) databases. All financial data were first converted to U.S. dollars by year-end exchange rates provided by Compustat, and then inflation-adjusted to year 2000 U.S. dollars using U.S. CPI.

To mitigate a potential survivor bias, we started with a comprehensive set of global pharmaceutical firms that were in existence as of 1986 according to various industry sources. ${ }^{36}$ In this manner we identified 89 incumbent pharmaceutical firms, defined as pharmaceutical firms that were founded prior to the emergence of biotechnology in the mid-1970s. We then proceeded with a family tree analysis ${ }^{37}$ on each of the 89 pharmaceutical firms for the period of observation, from 1986 until 2000. Through this analytical process, six horizontal mergers and acquisitions (M\&As) were identified among the incumbent pharmaceutical firms. As a horizontal M\&A took place, we added to the survivor the historical data of the acquired firm and then tracked the surviving entity forward. ${ }^{38}$ Such scrutiny procedure ultimately rendered an unbalanced panel sample of 83 firms covering the 15 -year period from 1986 to 2000 .

\footnotetext{
${ }^{35}$ The CATI database only collects cooperative agreements in which a combined innovative activity or an exchange of technology is undertaken by at least two independent, industrial partners. See more details of the CATI data collection in Hagedoorn (1993) and Duysters and Hagedoorn (1993).

${ }^{36}$ To draw the sample for this study, we tracked Compustat, Datastream, Amadeus, SIC reports, Ernst and Young's Annual Biotech Industry Reports, Scrip's Pharmaceutical Yearbook, amongst others.

${ }^{37}$ See Rothaermel and Hess (2007) for the rationale of constructing family trees. Once sample firms were acquired by outsiders before the end of our study period, they were still included as unbalanced data. A variety of industry sources were checked throughout the family tree analysis, including Compustat/Standard and Poor's, Encyclopedia, and company homepage.

${ }^{38}$ In the Compustat database, the treatment of mergers and acquisitions seeks to preserve historical data for the acquiring firm whenever possible. It is rare that a new firm is added as a result of a merger. There are usually no changes to the surviving firm's firm-level identifiers, whereas the acquired firm becomes inactive in the database the month following the merger or acquisition. Two basic accounting methods are used to account for mergers and acquisitions, the "purchase method" and the "pooling of interest method". In this study, we primarily followed the "purchase method" since it is the way that the majority of mergers and acquisitions are accounted for. In June 2001, the Financial Accounting Standard Board eliminated the "pooling of interest method" and required that all business combinations be accounted for by the "purchase method" (FASB Statement 141).
} 


\subsubsection{Dependent Variable}

The dependent variable is measured as the number of annual biotechnology patents (Biotechnology Patents) granted to an incumbent pharmaceutical firm to proxy for its innovative output within the new biotechnology regime (also see NichollsNixon and Woo, 2003; Rothaermel and Hess, 2007). Our measure of Biotechnology Patents is based on successful patent applications, i.e., granted patents. The application date of a patent is only reported when the patent is successfully granted. On average it may take three years for the USPTO to grant a patent after it was originally applied for by an inventing firm. In contrast, there is essentially no lag time between the completed invention and the patent application date, which is on average no more than three months (Darby and Zucker, 2010). Thus, the patent application date is closely tied to the timing of the new knowledge creation and it should be used as the relevant time placer for patents (Hall et al., 2001; Trajtenberg, 1990). Accordingly, we assigned a granted biotechnology patent to the particular year in which the patent was originally applied for. For instance, a biotechnology patent applied for in 2000 but granted in 2003 is considered a 2000 patent. ${ }^{39}$ Since patents can be assigned to both the parent firm and its various levels of subsidiaries, we identified all subsidiaries of firms in the sample, using D\&Bs Who Owns Whom, and then aggregated the number of granted patents to the parent level or the entire corporate level (Ahuja, 2000a; Sampson, 2007). Further, we used USPTO patent data for both U.S. and non-U.S. firms. Although U.S. patent data could imply a bias against non-U.S. firms, it is mentioned in the literature that, given the importance of the U.S. market, the patent protection offered by U.S. authorities, and the level of technological sophistication of the U.S. market, it is inevitable that non-U.S. firms, especially leading large firms, file their patents in the USA (Hagedoorn and Cloodt, 2003; Patel and Pavitt, 1991). Moreover, as suggested by Ahuja and Katila (2001), to maintain a certain level of consistency, reliability and comparability, choosing one patenting system is preferred to using several patenting systems across nations.

Annual patent counts are generally accepted as one of the most appropriate indicators that enable researchers to compare the inventive or innovative performance of companies in terms of new technologies, new processes, and new products (Hagedoorn and Cloodt, 2003). Patents are directly related to inventiveness (Walker, 1995), and represent an externally validated measure of technological novelty (Griliches, 1990). Moreover, prior research suggests that a raw count of patents is highly correlated with other indicators of innovative output such as citation-weighted patents and counts of new product announcements (Hagedoorn and

\footnotetext{
${ }^{39} \mathrm{It}$ is important to note that while we collected patent data until the end of 2003, we purposefully ended the study in 2000 to overcome a potential right truncation bias.
} 
Cloodt, 2003; Stuart, 2000). It is also important to note that, despite their desirable properties, patent counts are an imperfect measure of a firm's innovative output. Since some inventions are not patentable and others are not patented for strategic reasons (Griliches, 1990), patents account for only a fraction of a firm's innovative output and the fraction may vary considerably across industries (Hall et al., 1986). Limiting our study to a single industrial sector-the pharmaceutical industry which is characterized by high $\mathrm{R} \& \mathrm{D}$ intensity and high propensity to patent-minimizes problems related to inter-sectoral differences in patenting propensity.

\subsubsection{Independent Variables}

Internal R\&D. We measured an incumbent pharmaceutical firm's internal R\&D investments by its RひD expenditures. Previous studies show that R\&D expenditures are primarily taken as an input indicator of a firm's efforts in internal R\&D that might eventually lead to innovative output (Griliches, 1990, 1998; Hitt et al., 1997). In addition, proxying internal $R \& D$ investments by $R \& D$ expenditures is preferred over R\&D intensity (R\&D expenditures divided by firm revenues) in that in the latter measure, significant uncertainty exists as to whether any observed effects on innovation are due to the numerator, as hoped for, or due to the denominator (Rothaermel and Hess, 2007). To accurately identify the magnitude of R\&D expenditures incurred by the global pharmaceuticals, we excluded in-process R\&D spending, ${ }^{40}$ which is subsumed within $\mathrm{R} \& \mathrm{D}$ expenditures in the Compustat database. Meanwhile, the quadratic term of internal R\&D, R\&D expenditures squared, is enclosed in the regression analysis so as to test for decreasing returns to scale in internal R\&D (Graves and Langowitz, 1993; Griliches, 1990; Hagedoorn and Duysters, 2002a; Hausman et al., 1984; Lokshin et al., 2008; Rothaermel and Hess, 2007).

External R\&D. We included a dummy variable of external R\&D, indicating whether or not an incumbent pharmaceutical firm pursued external R\&D strategies, as firms which use external R\&D may be qualitatively different from those not doing so (see e.g., Cassiman and Veugelers, 2006; Schmiedeberg, 2008). ${ }^{41}$ This dummy variable takes on the value of 1 if a pharmaceutical firm sourced R\&D externally through either $R \& D$ alliances or $R \& D$ acquisitions $(1=R \& D$ sourced

\footnotetext{
${ }^{40}$ Acquisition-related in-process $R \& D$ charges are defined in the Compustat database as the portion of R\&D considered to be 'purchased' and are written off immediately upon acquisition if the R\&D items are deemed not to have any alternative use.

${ }^{41}$ The average of this dummy variable is 0.43 in our sample. We appreciate the insights provided by Boris Lokshin about the potential problems with using a dummy variable in a complementarity test. Alternatively, as to be shown in one of the robustness tests, we used a count variable of external $R \& D$ strategies, measured as the number of $R \& D$ alliances and $R \& D$ acquisitions undertaken by pharmaceutical firms.
} 
externally through R\&D alliances or R\&D acquisitions), ${ }^{42}$ and 0 if the firm solely undertook internal R\&D. For analytic clarity and focus, R\&D alliances are defined as interfirm agreements in which a combined innovative activity or an exchange of technology is engaged between independent, industrial firms. ${ }^{43}$ We identified R\&D alliances through a detailed content analysis of each alliance incumbent pharmaceutical firms entered since 1986 into biotechnology, 3362 alliances in total, of which 1205 alliances pertained to a clear R\&D component and thus were counted as $\mathrm{R} \& \mathrm{D}$ alliances. Likewise, we focused merely on $\mathrm{R} \& \mathrm{D}$ acquisitions (Ahuja and Katila, 2001; Higgins and Rodriguez, 2006), for which the business description of the acquisition transactions as registered in SDC Platinum suggested that the acquired biotechnology company was indeed targeted for its R\&D capabilities. Through this process, we identified $638 \mathrm{R} \& \mathrm{D}$ acquisitions undertaken by incumbent pharmaceutical firms for the study period 1986-2000.

\subsubsection{Control Variables}

Pre-sample Innovation. In all models we attempted to capture the unobserved heterogeneity in firm innovation. As stressed by Blundell et al. (1995), the 'permanent' capabilities of firm innovation should be reflected in the pre-sample history of innovative output. Hence, we included both the pre-sample average patent count (i.e., Pre-sample Mean, the average number of biotechnology patents by a pharmacentical firm in the period from 197444 to 1985) and a pre-sample dummy (1 = if the firm had ever innovated prior to 1986$)^{45}$ to proxy for the unobserved heterogeneity in the innovation models of incumbent pharmaceutical firms (Blundell et al., 1995, 2002).

Firm Merged. The global pharmaceutical industry has witnessed a continuing trend of consolidation and concentration, especially in the late 1990s. To account for horizontal mergers and acquisitions among sample firms, as mentioned previously, we conducted a detailed family tree analysis by tracking all incumbent pharmaceutical firms in existence as of 1986 forward. Along with this analytical approach, a dummy variable was also included indicating whether or not a sample firm was the outcome of a horizontal merger or acquisition over the study period from 1986 to 2000 (1 = Firm Merged).

\footnotetext{
${ }^{42}$ The dummy variable of External R\&D takes on the value of 1 only in the particular year a pharmaceutical firm entered either R\&D alliances or R\&D acquisitions.

${ }^{43}$ If an interfirm R\&D alliance involves more than two industrial firms, it still accounts for one $R \& D$ alliance. $R \& D$ alliances primarily include joint research pacts, joint development agreements, $R \& D$ contracts, $R \& D$ joint ventures and research corporations.

${ }^{44}$ In accordance with the emergence of the new biotechnology in the mid-1970s.

${ }^{45}$ The dummy variable captures the fact that firms which sometimes innovate may be qualitatively different from those not doing so (Blundell et al., 1995).
} 
Pharmacentical Firm. The global pharmaceutical industry is made up of both specialized pharmaceutical firms and more diversified, mainly chemical, conglomerates. A firm's level of diversification indicates its previous experience in entering new businesses (Chang and Singh, 1999; Yip, 1982), which may influence the degree to which it attempts to innovate within the new biotechnology regime. Thus, we controlled for a pharmaceutical firm's level of diversification by coding the firm as 1 if it is a specialized pharmaceutical company $(1=$ Pharma Firm $)$, and 0 otherwise. Specialized pharmaceutical companies are firms that are active in SIC 2834 (Pharmaceutical Preparations Manufacturing), whereas a conglomerate might engage, for instance, in both SIC 2834 and SIC 2890 (Chemical Products Manufacturing). About one half (45\%) of the firms in the sample are fully specialized.

Firm Nationality. To control for country-specific institutional configurations that are significant in shaping patenting propensities (Jaffe and Trajtenberg, 1999) as well as internal and external R\&D strategies of firms, we included two indicator variables based upon the location of firm headquarters. One indicator variable is coded as 1 if a pharmaceutical firm is headquartered in the United States $(1=$ U.S. Firm), and the other indicator variable is coded as 1 if a pharmaceutical firm is headquartered in Europe ( 1 = European Firm), with a Japanese location as the reference category. The global representation of the sample is reflected in the fact that $36 \%$ of the firms are U.S. based, $28 \%$ are European based, with the remaining $36 \%$ headquartered in Japan.

Firm Size. Firm size has been shown to exert a direct effect on innovative output (Acs and Audretsch, 1988; Freeman and Soete, 1997). Previous studies have also examined how factors associated with firm size impact on a firm's incentive to invest in R\&D (Cohen and Klepper, 1996; Cohen and Levinthal, 1989; Schumpeter, 1942; Teece, 1982, 1992). Moreover, researchers observe that small firms are more likely to restrict themselves to a simple innovation strategy, whereas large firms tend to combine various R\&D sources (Beneito, 2006; Cassiman and Veugelers, 1999). To control for these effects, we included firm size, proxied by the total number of employees (Employees), in the regression equations.

Firm Performance. We allowed for the financial status of incumbent pharmaceutical firms by including variables of Net Income and Total Revenues. In addition, explicitly controlling for firm revenues is necessary to isolate the impact of R\&D expenditures on patenting rate (Rothaermel and Hess, 2007).

Year Fixed Effects. Innovative output may increase or decrease with timevarying factors which can influence for all sample firms. To control for such period effects, we included a series of year dummies, 2000 being the reference year. 


\subsubsection{Estimation Technique}

The dependent variable of our study, innovative output, as measured by biotechnology patent counts, is a count variable taking only non-negative integer values. To model count data, the linear exponential or log-link family is a good alternative (Cameron and Trivedi, 1986). On account of the overdispersion phenomenon displayed by patent counts, namely the preponderance of zero and small values of firm patenting, the negative binomial estimation provides a better fit for our data than the more restrictive Poisson model (Hausman et al., 1984).

The common first moment condition for the negative binomial model is,

$$
\lambda_{\text {it }}=E\left(Y_{\text {it }}\right)=\exp \left(X_{\text {it }}^{\prime} \beta\right)
$$

In our innovation model, we write as

$$
\begin{aligned}
\mathrm{X}_{\mathrm{it}}^{\prime} \beta=\theta_{0} & +\theta_{1} \mathrm{RD}_{\mathrm{I}_{\mathrm{it}-1}}+\theta_{2} \mathrm{RD}_{\mathrm{I}_{\mathrm{it}-1}}^{2}+\theta_{3} \mathrm{RD}_{\mathrm{E}_{\mathrm{it}-1}}+\theta_{13} \mathrm{RD}_{\mathrm{I}_{\mathrm{it}-1}} \mathrm{RD}_{\mathrm{E}_{\mathrm{it}-1}} \\
& +\theta_{23} \mathrm{RD}_{\mathrm{I}_{\mathrm{it}-1}}^{2} \mathrm{RD}_{\mathrm{E}_{\mathrm{it}-1}}+\sum \gamma_{\mathrm{n}} \operatorname{Control}_{\mathrm{n}_{\mathrm{it}-1}}
\end{aligned}
$$

where $\lambda_{\text {it }}$ is the mean value of biotechnology patents for firm $i$ in period $t ; R D_{I}$ and $R D_{I}{ }^{2}$ are $R \& D$ expenditures and $R \& D$ expenditures squared, respectively; $R D_{E}$ represents a dummy variable of external $R \& D$ strategies through $R \& D$ alliances and R\&D acquisitions; Control $_{\mathrm{n}}$ denotes control variables; the parameters $\beta, \theta, \gamma$ are coefficients of various explanatory variables. A one-period lag is employed on all explanatory variables to alleviate a potential simultaneity bias. In the above equation, inclusion of the quadratic term of internal R\&D (see e.g., Hagedoorn and Duysters, 2002a; Rothaermel and Hess, 2007) is to detect whether there is a nonlinear relationship between internal R\&D and firm patenting. Furthermore, our model includes the interaction terms of internal and external R\&D so as to explore the complementarity or substitutability between various $R \& D$ strategies, in which a firm's internal R\&D efforts are expected to act as a contingency variable.

As our estimation model is a nonlinear model with interaction terms, an explanatory variable's model coefficient cannot be used to infer the true nature of the relationship between an explanatory variable and the dependent variable, and hence the focus of our analysis is on the value of an explanatory variable's marginal effect (Hoetker, 2007; Wiersema and Bowen, 2009). The marginal effect of internal $\mathrm{R} \& \mathrm{D}$ on firm patenting frequency can be calculated by taking the first derivative of $\lambda_{\text {it }}$ with respect to $R D_{I}$,

$\frac{\partial \lambda_{i t}}{\partial \mathrm{RD}_{\mathrm{I}_{\mathrm{it}-1}}}=\left(\theta_{1}+2 \theta_{2} \mathrm{RD}_{\mathrm{I}_{\mathrm{it}-1}}+\theta_{13} \mathrm{RD}_{\mathrm{E}_{\mathrm{it}-1}}+2 \theta_{23} \mathrm{RD}_{\mathrm{I}_{\mathrm{it}-1}} \mathrm{RD}_{\mathrm{E}_{\mathrm{it}-1}}\right) \exp \left(\mathrm{X}_{\mathrm{it}}^{\prime} \beta\right)$ 


$$
=\left(\theta_{1}+2 \theta_{2} \mathrm{RD}_{\mathrm{I}_{\mathrm{it}-1}}+\theta_{13} \mathrm{RD}_{\mathrm{E}_{\mathrm{it}-1}}+2 \theta_{23} \mathrm{RD}_{\mathrm{I}_{\mathrm{it}-1}} \mathrm{RD}_{\mathrm{E}_{\mathrm{it}-1}}\right) \lambda_{\mathrm{it}}
$$

Eq. (3) measures the change in the mean value of biotechnology patents, induced by a marginal increase in internal $\mathrm{R} \& \mathrm{D}$, holding the value of other explanatory variables constant. As seen in Eq. (3), the marginal effect of internal R\&D depends on the value of $X_{i t}^{\prime} \beta$ and varies with the value of all model variables. In this situation, it is more common, and simpler, to consider the relative change (Winkelmann, 2008: 70) in the mean value of biotechnology patents associated with a marginal increase in internal R\&D. Dividing both sides of Eq. (3) by $\lambda_{i t}$, we obtain the marginal effect of internal R\&D under relative change:

$\frac{\partial \lambda_{\text {it }} / \partial \mathrm{RD}_{\mathrm{I}_{\mathrm{it}-1}}}{\lambda_{\mathrm{it}}}=\theta_{1}+2 \theta_{2} \mathrm{RD}_{\mathrm{I}_{\mathrm{it}-1}}+\theta_{13} \mathrm{RD}_{\mathrm{E}_{\mathrm{it}-1}}+2 \theta_{23} \mathrm{RD}_{\mathrm{I}_{\mathrm{it}-1}} \mathrm{RD}_{\mathrm{E}_{\mathrm{it}-1}}$

Eq. (4) herein gives the percentage change in the mean value of biotechnology patents arising from a marginal increase in internal R\&D, all else held constant.

To identify whether there are increasing or decreasing returns to scale in internal R\&D, as postulated in Hypothesis 1, we differentiate Eq. (4) with respect to $\mathrm{RD}_{\mathrm{I}}$ a second time, ${ }^{46}$

$\frac{\partial\left(\left(\partial \lambda_{\mathrm{it}} / \partial \mathrm{RD}_{\mathrm{I}_{\mathrm{it}-1}}\right) / \lambda_{\mathrm{it}}\right)}{\partial \mathrm{RD}_{\mathrm{I}} \mathrm{it}_{1}}=2 \theta_{2}+2 \theta_{23} \mathrm{RD}_{\mathrm{E}_{\mathrm{it}-1}}= \begin{cases}2 \theta_{2} & \text { when } \mathrm{RD}_{\mathrm{E}_{\mathrm{it}-1}}=0 \\ 2 \theta_{2}+2 \theta_{23} & \text { when } \mathrm{RD}_{\mathrm{E}_{\mathrm{it}-1}}=1\end{cases}$

The above equation examines, from a relative change perspective (Winkelmann, 2008), whether firm innovativeness increases or decreases with increasing levels of internal R\&D investments. In other words, the percentage change in the mean value of biotechnology patents, per unit change in internal R\&D, may increase or decrease as the level of internal R\&D investments rises. From Eq. (5) we can conclude that there are increasing marginal returns to internal $R \& D$ when $2 \theta_{2}>0$ or $2 \theta_{2}+2 \theta_{23}>0$, or decreasing marginal returns to internal R\&D when $2 \theta_{2}<0$ or $2 \theta_{2}+2 \theta_{23}<0$.

Furthermore, to test for complementarity or substitutability between internal and external R\&D strategies, as postulated in Hypotheses $2 \mathrm{a}, 2 \mathrm{~b}$, and 3, we estimate the interactive effects between internal and external R\&D so as to infer how the effect of $\mathrm{RD}_{\mathrm{I}}$ on $\lambda_{\text {it }}$ depends on the existence (or the magnitude) of $\mathrm{RD}_{\mathrm{E}}$ and

\footnotetext{
${ }^{46}$ Alternatively, the second derivative of $\lambda_{\text {it }}$ with respect to $\mathrm{RD}_{\mathrm{I}}$, as shown below, would depend on the value of all model variables.$$
\begin{aligned}
\frac{\partial\left(\partial \lambda_{\mathrm{it}} / \partial \mathrm{RD}_{\mathrm{I}_{\mathrm{it}-1}}\right)}{\partial \mathrm{RD}_{\mathrm{I}_{\mathrm{it}-1}}}= & \left(\theta_{1}+2 \theta_{2} \mathrm{RD}_{\mathrm{I}_{\mathrm{it}-1}}+\theta_{13} \mathrm{RD}_{\mathrm{E}_{\mathrm{it}-1}}+2 \theta_{23} \mathrm{RD}_{\mathrm{I}_{\mathrm{it}-1}} \mathrm{RD}_{\mathrm{E}_{\mathrm{it}-1}}\right)^{2} \exp \left(\mathrm{X}_{\mathrm{it}}^{\prime} \beta\right) \\
& +\left(2 \theta_{2}+2 \theta_{23} \mathrm{RD}_{\mathrm{E}_{\mathrm{it}-1}}\right) \exp \left(\mathrm{X}_{\mathrm{it}}^{\prime} \beta\right)
\end{aligned}
$$ 
vice versa. Due to the nonlinear structure of our estimation model, the interactive effect is not given by the model coefficient on the interactive term, but given by the cross-partial derivative (or, cross-partial difference in case of a discrete rather than a continuous variable) of $\lambda_{\text {it }}$ first with respect to $\mathrm{RD}_{\mathrm{I}}$ and then with respect to RDE (Ai and Norton, 2003; Brambor, et al., 2006; Hoetker, 2007; Wiersema and Bowen, 2009). Given a dummy variable of $\mathrm{RD}_{\mathrm{E}}$ (see Appendix $3 \mathrm{~A}$ for $\mathrm{RD}_{\mathrm{E}}$ as a count variable) and our analytical focus on the relative change in $\lambda_{\text {it }}$, the interactive effect between $\mathrm{RD}_{\mathrm{I}}$ and $\mathrm{RD}_{\mathrm{E}}$ can be calculated by differencing Eq. (4) with respect to $\mathrm{RD}_{\mathrm{E}},{ }^{47}$

$\left\{\frac{\partial \lambda_{\mathrm{it}} / \partial \mathrm{RD}_{\mathrm{I}_{\mathrm{it}-1}}}{\lambda_{\mathrm{it}}} \mid \mathrm{RD}_{\mathrm{E}_{\mathrm{it}-1}}=1\right\}-\left\{\frac{\partial \lambda_{\mathrm{it}} / \partial \mathrm{RD}_{\mathrm{I}}}{\lambda_{\mathrm{it}-1}} \mid \mathrm{RD}_{\mathrm{E}_{\mathrm{it}-1}}=0\right\}=\theta_{13}+2 \theta_{23} \mathrm{RD}_{\mathrm{I}_{\mathrm{it}-1}}$

Eq. (6) clarifies the sense in which internal and external R\&D strategies are considered (strict) complementary when the interactive effect between $\mathrm{RD}_{\mathrm{I}}$ and $\mathrm{RD}_{\mathrm{E}}$ is positive (i.e., when $\theta_{13}+2 \theta_{23} \mathrm{RD}_{\mathrm{I}_{\mathrm{it}-1}}>0$ ), whereas internal and external $\mathrm{R} \& \mathrm{D}$ are considered (strict) substitutive when the interactive effect is negative (i.e., when $\left.\theta_{13}+2 \theta_{23} \mathrm{RD}_{\mathrm{I}_{\mathrm{it}-1}}<0\right) \cdot{ }^{48}$

In estimating our count panel data model, either fixed- or random-effects specification can, in theory, be used to control for firm-specific unobserved heterogeneity (Greene, 2003; Gujarati, 2003). One difficulty with the random-effects specification is its underlying assumption that time invariant unobserved heterogeneity is uncorrelated with regressors of interest. This specification thus rules out the existence of time invariant unobserved factors which influence both a firm's R\&D strategies and its innovative output. However, some unobserved firm characteristics (e.g., firm propensity to patent and managerial capabilities) are expected to be correlated with R\&D strategic choices and may influence subsequent innovative performance, thereby leading to a potential endogeneity bias (Hamilton and Nickerson, 2003; Leiblein et al., 2002). To alleviate such endogeneity bias, we used the fixed-effects specification so as to estimate the model parameters consistently

\footnotetext{
${ }^{47}$ Mullahy (1999) discusses the difficulties that will arise if interactive effects in nonlinear models are defined in terms of absolute, rather than relative, change. In our model the interactive effects under absolute change would otherwise be as complicated as follows, $\left\{\partial \lambda_{\text {it }} / \partial \mathrm{RD}_{\mathrm{I}_{\mathrm{it}-1}} \mid \mathrm{RD}_{\mathrm{E}_{\mathrm{it}-1}}=1\right\}-\left\{\partial \lambda_{\mathrm{it}} / \partial \mathrm{RD}_{\mathrm{I}_{\mathrm{it}-1}} \mid \mathrm{RD}_{\mathrm{E}_{\mathrm{it}-1}}=0\right\}$ $=\left\{\left(\theta_{1}+2 \theta_{2} \mathrm{RD}_{\mathrm{I}_{\mathrm{it}-1}}+\theta_{13}+2 \theta_{23} \mathrm{RD}_{\mathrm{I}_{\mathrm{it}-1}}\right) \exp \left(\theta_{1} \mathrm{RD}_{\mathrm{I}_{\mathrm{it}-1}}+\theta_{2} \mathrm{RD}_{\mathrm{I}_{\mathrm{it}-1}}^{2}+\theta_{3}+\theta_{13} \mathrm{RD}_{\mathrm{I}_{\mathrm{it}-1}}+\theta_{23} \mathrm{RD}_{\mathrm{I}_{\mathrm{it}-1}}^{2}\right.\right.$ $\left.\left.+\sum \gamma_{\mathrm{n}} \operatorname{Control}_{\mathrm{n}_{\mathrm{it}-1}}\right)\right\}-\left\{\left(\theta_{1}+2 \theta_{2} \mathrm{RD}_{\mathrm{I}_{\mathrm{it}-1}}\right) \exp \left(\theta_{1} \mathrm{RD}_{\mathrm{I}_{\mathrm{it}-1}}+\theta_{2} \mathrm{RD}_{\mathrm{I}_{\mathrm{it} t-1}}^{2}+\sum \gamma_{\mathrm{n}} \operatorname{Control}_{\mathrm{n}_{\mathrm{it}-1}}\right)\right\}$

${ }^{48} \mathrm{In}$ other words, when the interactive effect between $\mathrm{RD}_{\mathrm{I}}$ and $\mathrm{RD}_{\mathrm{E}}$ is positive, the percentage change in $\lambda_{i t}$ associated with a marginal increase in $\mathrm{RD}_{\mathrm{I}}$ is higher in the presence of $\mathrm{RD}_{\mathrm{E}}$. Conversely, when the interactive effect between $\mathrm{RD}_{\mathrm{I}}$ and $R \mathrm{RD}_{\mathrm{E}}$ is negative, the percentage change in $\lambda_{\text {it }}$ associated with a marginal increase in $\mathrm{RD}_{\mathrm{I}}$ is lower in the presence of $\mathrm{RD}_{\mathrm{E}}$.
} 
(Winkelmann, 2008).49 In addition, following Blundell et al. (1995, 2002), we also allowed for time invariant unobserved heterogeneity by explicitly taking into account the pre-sample history of firm innovativeness.

\subsection{RESULTS}

\subsubsection{Results for Hypotheses}

Table 3.1 shows the descriptive statistics and the bivariate correlation matrix. The bivariate correlations are, with the exception of R\&D expenditures and employees, ${ }^{50}$ low and thus indicate sound validity. In particular, the correlation between the key explanatory variables, $R \& D$ expenditures and external $R \& D$, is quite low ( $r$ $=0.33$ ). Moreover, to assess the severity of multicollinearity, we computed variance inflation factors (VIFs), with an average VIF value of 2.19 and a maximum VIF value of 5.29, which are well below the cut-off point of 10 (Cohen et al., 2003), indicating that multicollinearity does not pose a problem to our estimation models. ${ }^{51}$

Table 3.2 provides results for all models using fixed-effects negative binomial estimation. Model 1 is the baseline specification including only the control variables. Model 2 estimates R\&D expenditures and the quadratic term thereof. Model 3 presents the full model with the interactive effects between internal and external R\&D. Each subsequent model demonstrates a significant $(p<0.001)$ improvement over the baseline specification. We use the full model, i.e., Model 3, to discuss the regression results of the hypothesis tests. Overall, the estimated coefficients suggest a curvilinear relationship between $\mathrm{R} \& \mathrm{D}$ expenditures and biotechnology patenting. The estimated second derivative, $2 \theta_{2}$ when $\mathrm{RD}_{\mathrm{E}}=0$ [see Eq. (5)], is negative and statistically significant $(p<0.001)$. Moreover, when $\mathrm{RD}_{\mathrm{E}}=1$, the estimated second derivative, $2 \theta_{2}+2 \theta_{23}$ [see Eq. (5)], becomes less negative (marginally

\footnotetext{
${ }^{49}$ Besides the fixed-effects negative binomial specification (Ahuja, 2000a; Rothaermel and Hess, 2007; Vanhaverbeke et al., 2009), we also ran the negative binomial estimation with cluster-robust standard errors (Whittington et al., 2009) for an additional robustness test. The results from these two estimations produce fairly similar patterns except for some control variables.

${ }^{50}$ Factors associated with firm size, proxied by the number of employees in our analysis, tend to influence a firm's incentive to invest in R\&D (Cohen and Levinthal, 1989; Schumpeter, 1942; Teece, 1982, 1992). In addition, Employees and Total Revenues, as close measures of firm size, are also highly correlated in our dataset $(\mathrm{r}=0.80)$.

${ }^{51} \mathrm{As}$ an additional test, we centered the independent variables before creating their squares and cross products (Cohen et al., 2003). The estimated coefficients demonstrate a similar pattern as our main results in Table 3.2. Besides, even if multicollinearity does not bias coefficient estimates, it may affect the stability of the estimated coefficients. In this sense, omitting even a few observations can change the sign or the significance of the affected variables (Greene, 2003). Thus, to ensure the robustness of our results, we performed a sensitivity analysis by drawing random samples of $90 \%$ of the total observations and estimating the full model for each of these random samples (Ahuja and Katila, 2001). The corresponding results are quite similar to the main results shown in Table 3.2.
} 


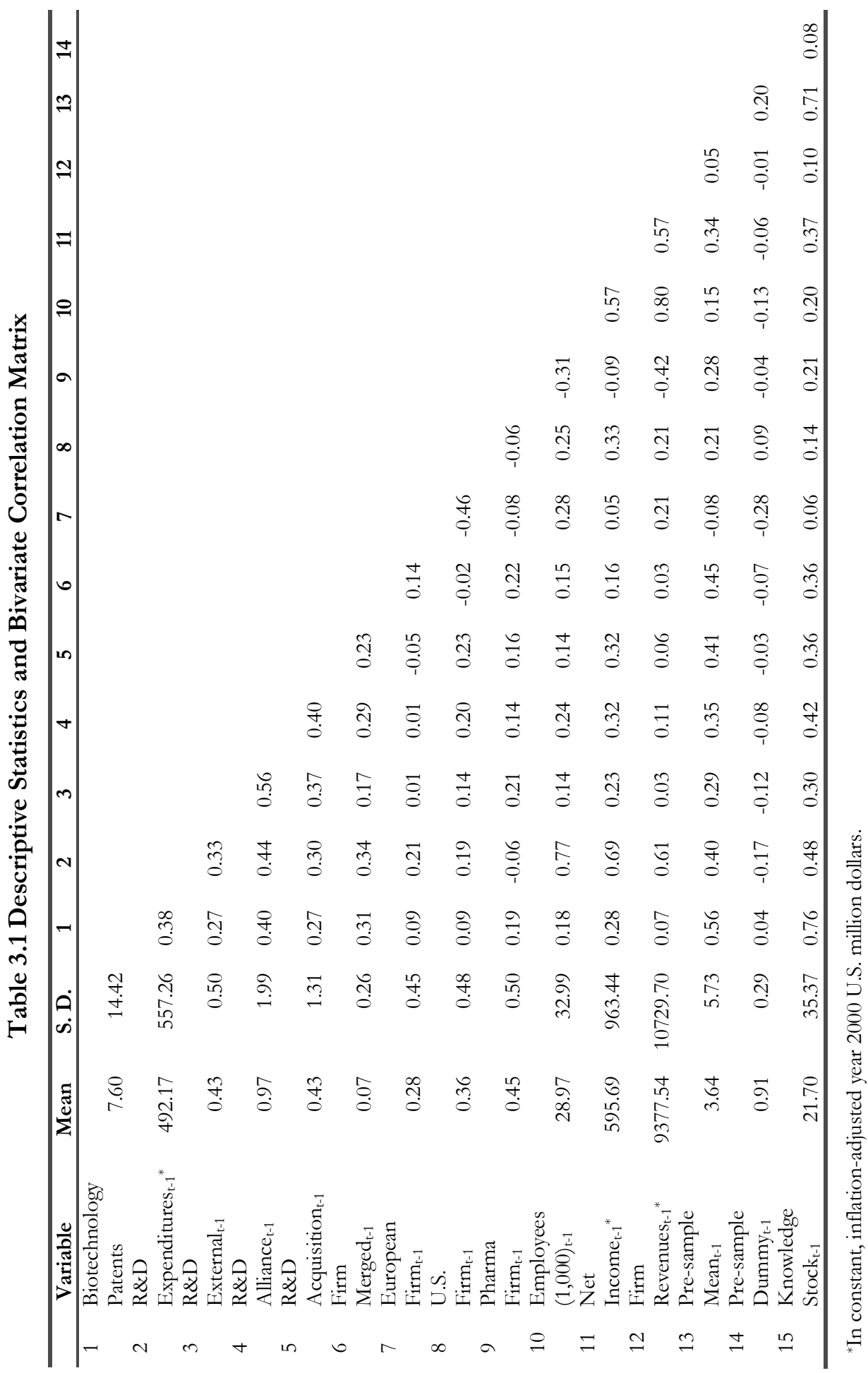


Table 3.2 Fixed-Effects Negative Binomial Regression Predicting Biotechnology Patents

\begin{tabular}{|c|c|c|c|}
\hline Variable & Model 1 & Model 2 & Model 3 \\
\hline Constant & $\begin{array}{c}0.1134 \\
(0.3374)\end{array}$ & $\begin{array}{l}-0.0927 \\
(0.3473)\end{array}$ & $\begin{array}{l}-0.2953 \\
(0.3545)\end{array}$ \\
\hline Year Fixed Effects & Included & Included & Included \\
\hline Firm Merged t-1 $_{\mathrm{t}}$ & $\begin{array}{l}-0.9764^{* * *} \\
(0.2746)\end{array}$ & $\begin{array}{l}-1.1353^{* * *} \\
(0.2669)\end{array}$ & $\begin{array}{l}-1.1584^{* * *} \\
(0.2650)\end{array}$ \\
\hline European Firm $_{\mathrm{t}-1}$ & $\begin{array}{l}-1.3036^{* * *} \\
(0.2726)\end{array}$ & $\begin{array}{l}-1.2720^{* * *} \\
(0.2803)\end{array}$ & $\begin{array}{l}-1.2603^{* * *} \\
(0.2828)\end{array}$ \\
\hline U.S. Firmt-1 & $\begin{array}{l}-0.8015^{* *} \\
(0.2764)\end{array}$ & $\begin{array}{l}-0.9207^{* *} \\
(0.2854)\end{array}$ & $\begin{array}{l}-0.9156^{* *} \\
(0.2865)\end{array}$ \\
\hline Pharma Firm $\mathrm{t}_{-1}$ & $\begin{array}{c}0.0839 \\
(0.2270)\end{array}$ & $\begin{array}{l}-0.0305 \\
(0.2232)\end{array}$ & $\begin{array}{c}0.0153 \\
(0.2236)\end{array}$ \\
\hline Employees $_{t-1}$ & $\begin{array}{l}0.0166^{* * *} \\
(0.0034)\end{array}$ & $\begin{array}{l}0.0076^{*} \\
(0.0039)\end{array}$ & $\begin{array}{c}0.0079^{*} \\
(0.0038)\end{array}$ \\
\hline Net Income $_{t-1}$ & $\begin{array}{c}1.49 \mathrm{E}-05 \\
(4.05 \mathrm{E}-05)\end{array}$ & $\begin{array}{l}-1.32 \mathrm{E}-05 \\
(3.90 \mathrm{E}-05)\end{array}$ & $\begin{array}{l}-1.40 \mathrm{E}-05 \\
(3.93 \mathrm{E}-05)\end{array}$ \\
\hline Revenues $_{\mathrm{t}-1}$ & $\begin{array}{l}-3.91 \mathrm{E}-05^{* *} \\
(1.25 \mathrm{E}-05)\end{array}$ & $\begin{array}{l}-4.77 \mathrm{E}-05^{* * *} \\
(1.34 \mathrm{E}-05)\end{array}$ & $\begin{array}{l}-4.93 \mathrm{E}-05^{* * *} \\
(1.32 \mathrm{E}-05)\end{array}$ \\
\hline Pre-sample Mean $\mathrm{t}_{\mathrm{t}-1}$ & $\begin{array}{l}0.0528^{* *} \\
(0.0161)\end{array}$ & $\begin{array}{l}0.0291 t \\
(0.0171)\end{array}$ & $\begin{array}{l}0.0321 \dagger \\
(0.0176)\end{array}$ \\
\hline Pre-sample Dummyt-1 & $\begin{array}{l}1.3161^{* * *} \\
(0.2733)\end{array}$ & $\begin{array}{l}1.3288^{* * *} \\
(0.2920)\end{array}$ & $\begin{array}{l}1.3900^{* * *} \\
(0.2911)\end{array}$ \\
\hline R\&D Expenditures $t_{t-1}$ & & $\begin{array}{l}1.70 \mathrm{E}-03^{* * *} \\
(3.33 \mathrm{E}-04)\end{array}$ & $\begin{array}{l}2.30 \mathrm{E}-03^{* * *} \\
(3.81 \mathrm{E}-04)\end{array}$ \\
\hline$R \& D$ Expenditures Squared ${ }_{t-1}$ & & $\begin{array}{l}-4.07 \mathrm{E}-07^{* * *} \\
(1.14 \mathrm{E}-07)\end{array}$ & $\begin{array}{l}-6.99 \mathrm{E}-07^{* * *} \\
(1.49 \mathrm{E}-07)\end{array}$ \\
\hline R\&D External $\mathrm{t}_{\mathrm{t}-1}$ & & & $\begin{array}{r}0.2555^{*} \\
(0.0993)\end{array}$ \\
\hline $\begin{array}{l}\text { R\&D Expenditures } \times \\
\text { R\&D External } t \text {-1 }\end{array}$ & & & $\begin{array}{l}-9.36 \mathrm{E}-04^{* *} \\
(2.82 \mathrm{E}-04)\end{array}$ \\
\hline $\begin{array}{l}\text { R\&D Expenditures Squared } \times \\
\text { R\&D External } l_{t-1}\end{array}$ & & & $\begin{array}{l}4.36 \mathrm{E}-07^{* *} \\
(1.41 \mathrm{E}-07)\end{array}$ \\
\hline $\mathrm{N}$ & 1125 & 1125 & 1125 \\
\hline Log Likelihood & -2273.8789 & -2258.3008 & -2252.8549 \\
\hline Chi Square & $286.36^{* * *}$ & $337.51^{* * *}$ & $351.57^{* * *}$ \\
\hline
\end{tabular}

Notes: Standard errors are in parentheses; year dummies are included but not shown. The fixedeffects specification eliminates one firm which never patents, thereby reducing the effective sample to 1,125 firm-year observations. Two tailed-tests significant at: $\dagger p<0.10,{ }^{*} p<0.05,{ }^{* *} p<0.01$, *** $p$ $<0.001$. 
significant at $p<0.10$ ), implying that marginal returns to internal $\mathrm{R} \& \mathrm{D}$ decrease less in the presence of external R\&D. Taken together, these results provide strong support for Hypothesis 1, indicating that there are decreasing returns to scale in internal R\&D. In other words, a firm's innovative output increases with its investment in internal $R \& D$, yet this rate of increase diminishes at higher levels of internal $R \& D$ spending. This finding is consistent with previous studies which clearly suggest diseconomies of scale in internal R\&D (Graves and Langowitz, 1993; Hagedoorn and Duysters, 2002a; Lokshin et al., 2008; Rothaermel and Hess, 2007).

To analyze the relationship between internal and external R\&D strategies in shaping a firm's innovative output (Hypotheses 2a, 2b, and 3), we tested the interactive effect between internal and external R\&D through examining the sign and statistical significance of the value of Eq. (6), $\theta_{13}+2 \theta_{23} R D_{I_{i t-1}}$. To this purpose, a graphical analysis, as exhibited in Figure 3.1, was conducted to manifest the nature and significance of the interactive effect by plotting its value over the range of internal R\&D investments by incumbent pharmaceutical firms (Ai and Norton, 2003; Hoetker, 2007; Wiersema and Bowen, 2009). In Figure 3.1, the middle scattered line (i.e., the solid symbols) depicts values of the estimated interactive effect between internal and external R\&D, varying from -0.0009 to 0.0016 , with a mean value of -0.0005 . The upper and lower scattered lines (i.e., the hollow symbols) are plotted with 90\% confidence intervals. As shown in Figure 3.1, the sign, magnitude, and statistical significance of the interactive effect vary with the level of in-house R\&D investments. More specifically, the interactive effect takes on both negative and positive values over the range of internal $R \& D$ investments $\left[0.30<\mathrm{RD}_{\mathrm{I}}<\right.$ 2,869.31 million dollars (MM\$) in our sample], with a zero value when internal $\mathrm{R} \& \mathrm{D}$ is at the level of $1,073.39 \mathrm{MM}$ (i.e., $\mathrm{RD}_{\mathrm{I}}=1,073.39 \mathrm{MM} \$$ is the threshold value). The interactive effect is negative and marginally significant $(p<0.10)$ when internal $\mathrm{R} \& \mathrm{D}$ is less than $886.14 \mathrm{MM} \$$, suggesting a substitutive relationship between internal and external $\mathrm{R} \& \mathrm{D}$. In contrast, the interactive effect is positive and marginally significant $(p<0.10)$ when internal $R \& D$ is larger than $1,364.34 \mathrm{MM} \$$, indicative of a complementary relationship between internal and external $R \& D$ strategies. The interactive effect is not statistically significant, however, when the $90 \%$ confidence intervals overlap zero, with internal R\&D ranging from 886.14 to 1,364.34 MM\$. Taken together, the above findings highlight the complexity of understanding the relationship between internal and external R\&D strategies in predicting a firm's innovative performance. A clear-cut result, either complementarity (Hypothesis 2a) or substitutability (Hypothesis 2b), is not validated. In contrast to conventional wisdom, our overall findings provide support for Hypothesis 3, i.e., at higher levels of in-house $R \& D$ investments, internal and external $R \& D$ are complementary innovation activities, while at lower levels of in-house R\&D investments, they are substitutive innovation activities. 


\section{Figure 3.1 Interactive Effects between Internal and External R\&D Under Relative Change}

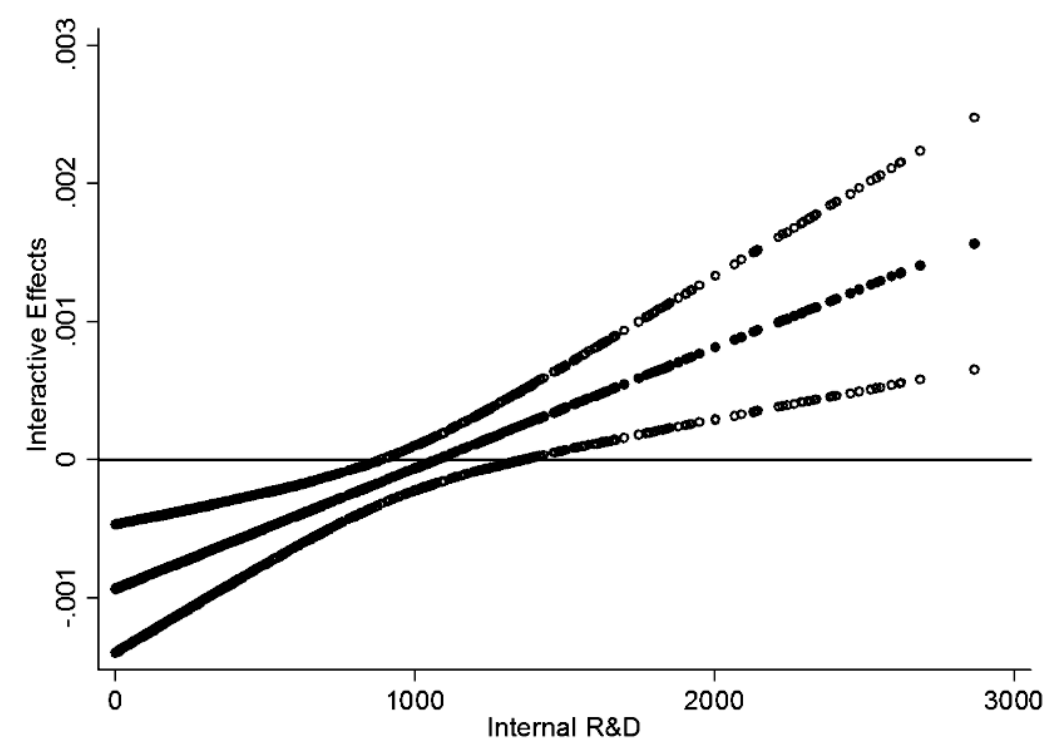

Turning to the effects of control variables, we found largely consistent results across various models. The pre-sample patent variables, i.e., the pre-sample mean and the dummy, are both positive and statistically significant $(p<0.10$ and $p<$ 0.001 , respectively), indicating that it is important to control for the unobserved differences in the innovative capabilities with which firms entered the sample. The number of employees, as a measure of firm size, is positively and significantly $(p<$ $0.05)$ associated with patenting frequency. The implied gains from large horizontal mergers or acquisitions, however, have not been identified. ${ }^{52}$ The estimated coefficient of firm revenues is significant $(p<0.001)$ but in a negative direction. With regard to the year fixed effects (included but not shown), the year dummies for 1993-1999 are positive and significant, while all the other calendar year indicators are not statistically significant, relative to the reference year 2000.

\footnotetext{
${ }^{52} \mathrm{One}$ possible explanation is that pharmaceutical firms with relatively weak innovative capabilities and poor potential for biotechnology patenting are more likely to engage in mergers and acquisitions. Alternatively, in the year immediately after a merger and acquisition, a firm has undergone various organizational changes and might not concentrate on innovation activities, thus the gains from mergers and acquisitions could not unfold till some years later. We are thankful for two anonymous referees' advice on this issue.
} 


\subsubsection{Robustness of Results}

It is readily apparent that firms do not randomly choose a specific way to organize $R \& D$, either rely exclusively on in-house R\&D or systematically combine it with $R \& D$ alliances or $R \& D$ acquisitions. The firm-specific unobserved effects that drive firms to ex ante choose a specific R\&D strategy towards superior performance outcomes, when not corrected for, would introduce a serious endogeneity bias (Hamilton and Nickerson, 2003; Leiblein et al., 2002). ${ }^{53}$ Possible remedies are available if such firm-specific unobserved effects are time invariant, for which one can estimate the model parameters consistently by fixed effects panel data methods (Winkelmann, 2008). Accordingly we used the fixed-effects specification in our models. Moreover, to ensure the robustness of our estimation results, we also ran models including a measure of firm knowledge stock ${ }^{54}$ to correct for firm-specific unobserved effects that are not fixed throughout time (Blundell et al., 1995, 2002; Dushnitsky and Lenox, 2005b). Since firm knowledge stock, effectively a lagged dependent variable, is predetermined, we used the pre-sample mean (PSM) estimator which is a good alternative to standard estimators when there are predetermined regressors (Blundell et al., 1995, 2002). ${ }^{55}$ The results under PSM estimation are reported in the first and third columns of Table 3.3 These estimated results set a very similar pattern as shown in Table 3.2. The additional message is that pharmaceutical firms with higher knowledge stock exhibit a significantly $(p<0.001)$ greater number of biotechnology patents. Yet the strong effects of the pre-sample dummy and horizontal M\&As on firm innovation are driven into insignificance in this dynamic analysis.

Furthermore, we disaggregated external $R \& D$ into the count number of $R \& D$ alliances and R\&D acquisitions so as to capture the scale of different types of external R\&D strategies undertaken by pharmaceutical firms (see e.g., Rothaermel and Hess, 2007; Hess and Rothaermel, 2011). The bivariate correlations between $R \& D$ expenditures and $R \& D$ alliances $(r=0.44$, see Table 3.1$)$, and between $R \& D$

\footnotetext{
${ }^{53}$ Another concern is the sample selection bias. A varied set of sample selection models are available in econometric literature to deal with such self-selection bias-the foremost model being Heckman two-stage approach. However, while Heckman and similar approaches are most commonly used within the domain of continuous-response models, they are not appropriate for count response models (Cameron and Trivedi, 1998; Hilbe, 2007). The development of a methodology for correcting for sample selection bias in count panel data models is, unfortunately, still an open task (Winkelmann, 2008).

${ }^{54}$ See Blundell et al. (1995), knowledge stock $\left(\mathrm{K}_{\mathrm{it}}\right)$ is the depreciated sum of past innovations, defined as $\mathrm{K}_{\mathrm{it}}=\mathrm{Y}_{\mathrm{it}}+(1-\delta) \mathrm{K}_{\mathrm{it}-1}$, where the depreciation rate $\delta$ is taken to be $30 \%$ (also see Keil et al., $2008)$ and $Y_{\text {it }}$ is the count number of biotechnology patents in our models.

${ }^{55} \mathrm{An}$ alternative to PSM for estimating models in the presence of predetermined regressors is a generalized method of moments (GMM) estimator. However, the GMM estimator is subject to some problems, namely small sample bias and imprecision, particularly when economic series is highly persistent as the instruments are then weak predictors of the endogenous changes (Blundell et al., 1995, 2002).
} 
Table 3.3 Robustness of Results

\begin{tabular}{|c|c|c|c|}
\hline \multirow{2}{*}{ Variable } & \multirow{2}{*}{$\frac{\text { External R\&D (dummy) }}{\text { PSM }}$} & \multicolumn{2}{|c|}{ External R\&D (count) } \\
\hline & & Negative Binomial & $\overrightarrow{\text { PSM }}$ \\
\hline \multirow[t]{2}{*}{ Constant } & 0.2136 & -0.1925 & 0.1899 \\
\hline & $(0.4545)$ & $(0.3504)$ & $(0.4184)$ \\
\hline Year Fixed Effects & Included & Included & Included \\
\hline \multirow[t]{2}{*}{ Firm Merged ${ }_{t-1}$} & -0.0527 & $-1.1806^{* * *}$ & -0.0431 \\
\hline & $(0.1908)$ & $(0.2712)$ & $(0.1693)$ \\
\hline \multirow[t]{2}{*}{ European Firmt } & 0.0996 & $-1.2490^{* * *}$ & 0.0370 \\
\hline & $(0.2470)$ & $(0.2752)$ & $(0.2322)$ \\
\hline \multirow[t]{2}{*}{ U.S. Firm ${ }_{\mathrm{t}-1}$} & -0.1470 & $-0.9321^{* *}$ & -0.2045 \\
\hline & $(0.2339)$ & $(0.2807)$ & $(0.2249)$ \\
\hline \multirow[t]{2}{*}{ Pharma Firm ${ }_{\mathrm{t}-1}$} & -0.0883 & -0.0282 & -0.1152 \\
\hline & $(0.1932)$ & $(0.2258)$ & $(0.1870)$ \\
\hline \multirow[t]{2}{*}{ Employeest $-1_{1}$} & $0.0086^{*}$ & $0.0100^{*}$ & $0.0087^{*}$ \\
\hline & $(0.0040)$ & $(0.0040)$ & $(0.0042)$ \\
\hline \multirow{2}{*}{ Net Income $\mathrm{t}_{-1}$} & $-3.20 \mathrm{E}-06$ & $-8.15 \mathrm{E}-06$ & $3.73 \mathrm{E}-05$ \\
\hline & $(6.82 \mathrm{E}-05)$ & (3.88E-05) & $(5.84 \mathrm{E}-05)$ \\
\hline \multirow[t]{2}{*}{ Revenues $_{\mathrm{t}-1}$} & $-3.61 \mathrm{E}-05^{* *}$ & $-5.08 \mathrm{E}-05^{* * *}$ & $-3.66 \mathrm{E}-05^{* *}$ \\
\hline & $(1.28 \mathrm{E}-05)$ & $(1.33 \mathrm{E}-05)$ & $(1.32 \mathrm{E}-05)$ \\
\hline \multirow[t]{2}{*}{ Pre-sample Mean $\mathrm{t}_{\mathrm{t}-1}$} & $0.0393^{* *}$ & $0.0394^{*}$ & $0.0469^{* *}$ \\
\hline & $(0.0137)$ & $(0.0178)$ & $(0.0147)$ \\
\hline \multirow[t]{2}{*}{ Pre-sample Dummyt-1 } & -0.0623 & $1.2789^{* * *}$ & 0.0276 \\
\hline & $(0.2749)$ & $(0.2935)$ & $(0.2806)$ \\
\hline \multirow[t]{2}{*}{ Knowledge Stock $\mathrm{t}_{\mathrm{t}-1}$} & $0.0098^{* * *}$ & & $0.0094^{* * *}$ \\
\hline & $(0.0017)$ & & $(0.0017)$ \\
\hline \multirow[t]{2}{*}{ R\&D Expenditures $t_{t-1}$} & $2.12 \mathrm{E}-03^{* * *}$ & 1.93E-03 $3^{* * *}$ & $1.97 \mathrm{E}-03^{* * *}$ \\
\hline & (6.31E-04) & (3.58E-04) & $(5.32 \mathrm{E}-04)$ \\
\hline R\&D Expenditures & $-9.52 \mathrm{E}-07^{* * *}$ & $-5.57 \mathrm{E}-07^{* * *}$ & $-8.60 \mathrm{E}-07^{* * *}$ \\
\hline Squared $_{\mathrm{t}-1}$ & $(2.56 \mathrm{E}-07)$ & $(1.25 \mathrm{E}-07)$ & (2.07E-07) \\
\hline $\mathrm{R} \& \mathrm{D}$ External $_{\mathrm{t}-1}$ & $0.6121^{* *}$ & & \\
\hline R\&D Expenditures & $\begin{array}{l}(0.2191) \\
-1.22 \mathrm{E}_{-} 03^{*}\end{array}$ & & \\
\hline$\times$ R\&D External $\mathrm{t}_{-1}$ & $(5.64 \mathrm{E}-04)$ & & \\
\hline R\&D Expenditures Squared & $6.28 \mathrm{E}-07^{*}$ & & \\
\hline$\times \mathrm{R} \& \mathrm{D}$ External $_{\mathrm{t}-1}$ & $(2.67 \mathrm{E}-07)$ & & \\
\hline \multirow[t]{2}{*}{ R\&D Alliance $_{\mathrm{t}-1}$} & & $0.1120^{* *}$ & $0.1964^{* * *}$ \\
\hline & & $(0.0390)$ & $(0.0561)$ \\
\hline R\&D Expenditures & & $-2.05 \mathrm{E}-04^{* *}$ & $-3.02 \mathrm{E}-04^{*}$ \\
\hline$\times \mathrm{R} \& \mathrm{D}$ Alliance $\mathrm{t}_{-1}$ & & $(6.15 \mathrm{E}-05)$ & $(1.17 \mathrm{E}-04)$ \\
\hline R\&D Expenditures Squared & & $9.11 \mathrm{E}-08^{* * *}$ & $1.27 \mathrm{E}-07^{* *}$ \\
\hline$\times \mathrm{R} \& \mathrm{D}$ Alliance $\mathrm{t}_{\mathrm{t}}$ & & $(2.35 \mathrm{E}-08)$ & (4.68E-08) \\
\hline \multirow[t]{2}{*}{$\mathrm{R} \& \mathrm{D}$ Acquisition $\mathrm{t}-1$} & & 0.1076 & $0.3139^{* *}$ \\
\hline & & $(0.0736)$ & $(0.0995)$ \\
\hline R\&D Expenditures & & $-2.04 \mathrm{E}-04 t$ & $-5.56 \mathrm{E}-04^{* * *}$ \\
\hline$\times$ R\&D Acquisition $_{\mathrm{t}-1}$ & & $(1.19 \mathrm{E}-04)$ & $(1.64 \mathrm{E}-04)$ \\
\hline R\&D Expenditures Squared & & $7.88 \mathrm{E}-08 \mathrm{t}$ & $2.03 \mathrm{E}-07^{* *}$ \\
\hline$\times$ R\&D Acquisition ${ }_{t-1}$ & & $(4.74 \mathrm{E}-08)$ & $(6.73 \mathrm{E}-08)$ \\
\hline $\mathrm{N}$ & 1139 & 1125 & 1139 \\
\hline Log Likelihood & & -2247.5532 & \\
\hline Chi Square & & $360.39^{* * *}$ & \\
\hline
\end{tabular}


expenditures and $\mathrm{R} \& \mathrm{D}$ acquisitions $(\mathrm{r}=0.30$, see Table 3.1$)$, are quite low. The corresponding regression results are shown in the last two columns of Table 3.3. Both estimation methods-fixed-effects negative binomial and PSM-produce fairly close findings to those presented before. The robust empirical patterns overall suggest that the complementarity or substitutability between internal R\&D and $\mathrm{R} \& \mathrm{D}$ alliances, or between internal $\mathrm{R} \& \mathrm{D}$ and $\mathrm{R} \& \mathrm{D}$ acquisitions, is contingent on the level of in-house $R \& D$ investments by incumbent pharmaceutical firms. In sum, these results corroborate our main findings from the more parsimonious models presented in Table 3.2.

\subsection{DISCUSSION AND CONCLUSIONS}

With few notable exceptions (Cassiman and Veugelers, 2006; Hess and Rothaermel, 2011), there is a dearth of empirical work that has examined under what conditions internal and external innovation activities may actually complement each other. The present study fills this research gap through an examination of the interactive effects between internal and external R\&D strategies of incumbent pharmaceutical firms on their innovative output within the new biotechnology regime. Our empirical analysis suggests that the level of in-house R\&D investments is a contingency variable that critically influences the association between internal and external R\&D strategies. More specifically, internal R\&D and external R\&D, through either $\mathrm{R} \& \mathrm{D}$ alliances or R\&D acquisitions, are complementary innovation activities at higher levels of in-house $R \& D$ investments, whereas at lower levels of in-house R\&D efforts, internal and external R\&D turn out to be substitutive strategic options. Our study therefore underscores the contingency role of a firm's in-house R\&D efforts, as a critical source of absorptive capacity, in determining the condition under which there is complementarity or substitutability between its various innovation strategies.

\subsubsection{Managerial Implications: A Simulation Analysis}

To give an intuitive illustration of our empirical findings, we pursued a simulation analysis in which the estimated mean value of biotechnology patents of a hypothetical pharmaceutical firm in year 1993 (the mid-year of our study period) is calculated based on Model 3 in Table 3.2 with varying levels of internal and external R\&D investments, while the other independent variables are set to equal the sample medians. In this simulation analysis, we define $\lambda\left(\mathrm{RD}_{\mathrm{I}}, \mathrm{RD}_{\mathrm{E}}\right)$ as the estimated mean value of biotechnology patents with the firm's investments in both internal and external $R \& D$ in year $1992,{ }^{56} \lambda\left(R_{\mathrm{I}}, 0\right)$ and $\lambda\left(0, \mathrm{RD}_{\mathrm{E}}\right)$ as the estimated mean value

\footnotetext{
${ }^{56} \mathrm{~A}$ one-year lag is employed on all explanatory variables to alleviate a potential simultaneity bias.
} 
of biotechnology patents when the firm only invests in either internal or external $\mathrm{R} \& \mathrm{D}$ in 1992 , and $\lambda(0,0)$ as an indication of firm innovative output without any $\mathrm{R} \& \mathrm{D}$ investment in 1992, being it internal or external. As $\mathrm{RD}_{\mathrm{I}}$ and $\mathrm{RD}_{\mathrm{E}}$ are considered complementary (substitutive) when the interactive effect between internal and external R\&D, as shown in Eq. (6), is positive (negative), we identified the magnitudes of the impact of complementarity (substitutability) on firm patenting frequency by looking at,

$$
\left(\Delta_{2}-\Delta_{1}\right) / \Delta_{1}{ }^{57}
$$

where

$\Delta_{11}=\lambda\left(R D_{I}, 0\right)-\lambda(0,0)$, the net increase in the mean value of biotechnology patents arising exclusively from a firm's internal $\mathrm{R} \& \mathrm{D}$ investment;

$\Delta_{12}=\lambda\left(0, \mathrm{RD}_{\mathrm{E}}\right)-\lambda(0,0)$, the net increase in the mean value of biotechnology patents arising exclusively from a firm's external R\&D investment;

$\Delta_{1}=\Delta_{11}+\Delta_{12}$, the net increase in the mean value of biotechnology patents arising from a firm's investments in internal and external $\mathrm{R} \& \mathrm{D}$, presuming $\mathrm{RD}_{\mathrm{I}}$ and $\mathrm{RD}$ E are not interactively related innovation activities;

$\Delta_{2}=\lambda\left(\mathrm{RD}_{\mathrm{I}}, \mathrm{RD}_{\mathrm{E}}\right)-\lambda(0,0)$, the net increase in the mean value of biotechnology patents arising from a firm's investments in internal and external $R \& D$;

$\left(\Delta_{2}-\Delta_{1}\right) / \Delta_{1}>0$, the magnitude of the impact of complementarity (i.e., a positive interactive effect exists when $\left.\Delta_{2}-\Delta_{1}>0\right)$ on firm patenting frequency; $\left(\Delta_{2}-\Delta_{1}\right) / \Delta_{1}<0$, the magnitude of the impact of substitutability (i.e., a negative interactive effect exists when $\Delta_{2}-\Delta_{1}<$ $0)$ on firm patenting frequency.

As suggested earlier by our empirical results, $\mathrm{RD}_{\mathrm{I}}$ and $\mathrm{RD}_{\mathrm{E}}$ are complements when the interactive effect between internal and external R\&D is positive and statistically significant (with $\mathrm{RD}_{\text {I }}$ ranging from $1,364.34$ to $2,869.31 \mathrm{MM} \$$ ), whereas $\mathrm{RD}_{\mathrm{I}}$ and $\mathrm{RD}_{\mathrm{E}}$ are substitutes when the interactive effect is negative and significant (with $\mathrm{RD}_{\mathrm{I}}$ ranging from 0.30 to $886.14 \mathrm{MM} \$$ ). Accordingly, Table 3.4 gives the simulation results for the impact of the interaction between internal and external $\mathrm{R} \& \mathrm{D}$ on firm patenting frequency under two situations: $\mathrm{RD}_{\mathrm{I}}=2,200 \mathrm{MM} \$$ $\left(1,364.34<\mathrm{RD}_{\mathrm{I}}<2,869.31\right)$ and $\mathrm{RD}_{\mathrm{I}}=200 \mathrm{MM} \$\left(0.30<\mathrm{RD}_{\mathrm{I}}<886.14\right)$, with the dummy variable of $\mathrm{RD}_{\mathrm{E}}$ taking the values of 0 and 1 . In the case of a higher level of in-house $R \& D, R_{I}=2,200 \mathrm{MM} \$$, the net increase in the mean value of bio-

57The interpretation of $\left(\Delta_{2}-\Delta_{1}\right) / \Delta_{1}$ is based upon the concepts of complementarity (supermodularity) and substitutability (submodularity) (see Milgrom and Roberts, 1990, 1995). Suppose there are two innovation activities, $\mathrm{RD}_{\mathrm{I}}$ and $\mathrm{RD}$. The function $\lambda\left(\mathrm{RD}_{\mathrm{I}}, \mathrm{RD}_{\mathrm{E}}\right)$ is supermodular and $R D_{I}$ and $R D_{E}$ are complements only if $\lambda\left(R D_{I}, R D_{E}\right)-\lambda\left(0, R D_{E}\right)>\lambda\left(R D_{I}, 0\right)-\lambda(0,0)$, i.e., adding an activity of $\mathrm{RD}_{\mathrm{I}}$, while the other activity of $\mathrm{RD}_{\mathrm{E}}$ is already being performed, has a higher incremental effect on firm patenting frequency than adding the activity of $\mathrm{RD}_{\mathrm{I}}$ in isolation. In contrast, the function $\lambda\left(R_{I}, R D_{E}\right)$ is submodular and $R D_{I}$ and $R D_{E}$ are substitutes when $\lambda\left(R_{I}, R D_{E}\right)-\lambda\left(0, R D_{E}\right)<$ $\lambda\left(\mathrm{RD}_{\mathrm{I}}, 0\right)-\lambda(0,0)$. 
technology patents arising from a firm's investments in internal and external $\mathrm{R} \& \mathrm{D}$, presuming $\mathrm{RD}_{\mathrm{I}}$ and $\mathrm{RD_{ \textrm {E } }}$ are not interactively related innovation activities, is $\Delta_{1}=$ 18.07. By contrast, the net increase in the mean value of biotechnology patents when the firm invests in internal and external $R \& D$ is $\Delta_{2}=24.42$. We therefore conclude that there is a positive interactive effect between internal and external $\mathrm{R} \& \mathrm{D}$, and that they reinforce each other in improving the firm's innovative performance by $\left(\Delta_{2}-\Delta_{1}\right) / \Delta_{1}=35.14 \%$. This is consistent with the result given by Eq. (6), a positive value of $9.83 \mathrm{E}-04$, indicating a complementary relationship between internal and external R\&D strategies. Instead, when the firm engages in a lower level of in-house $\mathrm{R} \& \mathrm{D}$ efforts, $\mathrm{RD}_{\mathrm{I}}=200 \mathrm{MM} \$$, a negative interactive effect is found between internal and external R\&D investments, leading to a reduction of up to $18.58 \%$ of the mean value of biotechnology patents. Consistently, Eq. (6) gives a negative value of $-7.61 \mathrm{E}-04$, suggesting that internal and external $\mathrm{R} \& \mathrm{D}$ are substitutive innovation activities. As a robustness check, we conducted a similar analysis of the impact of complementarity or substitutability on firm patenting frequency when external $R \& D$ is a count variable, measured as the number of $\mathrm{R} \& \mathrm{D}$ alliances or $\mathrm{R} \& \mathrm{D}$ acquisitions. When $\mathrm{RD}_{\mathrm{I}}=2,200 \mathrm{MM} \$$, a positive interactive effect exists between internal $R \& D$ and $R \& D$ alliances, and between internal $R \& D$ and $R \& D$ acquisitions, which improves firm innovative output by $53.11 \%$ and $8 \%$, respectively. However, at a lower level of in-house $R \& D, R_{I}=200$ $\mathrm{MM} \$$, the negative interaction between internal $R \& D$ and $R \& D$ alliances, and between internal $\mathrm{R} \& \mathrm{D}$ and $\mathrm{R} \& \mathrm{D}$ acquisitions, reduces firm biotechnology patenting by $8.51 \%$ and $9.44 \%$, respectively (see Table 3B-1 and Table 3B-2 in Appendix $3 \mathrm{~B}$ for the interactive effects between internal $\mathrm{R} \& \mathrm{D}$ and $\mathrm{R} \& \mathrm{D}$ alliances, and between internal $R \& D$ and $R \& D$ acquisitions).

Table 3.4 Simulation Results for Interactive Effects between Internal and External R\&D $\left(\mathrm{RD}_{\mathrm{I}}=200,2200 \mathrm{MM} \$ \mathrm{RD}_{\mathrm{E}}=0,1\right)$

\begin{tabular}{lclr}
\hline \multicolumn{1}{c}{$\boldsymbol{\lambda}\left(\mathbf{R} \mathbf{D}_{\mathbf{I}}, \mathbf{R} \mathbf{D}_{\mathbf{E}} \mathbf{)}\right.$} & $\begin{array}{c}\text { Estimated Mean } \\
\text { of Biotech Patents }\end{array}$ & \multicolumn{1}{c}{$\boldsymbol{\lambda}\left(\mathbf{R D}_{\mathbf{I}}, \mathbf{R} \mathbf{D}_{\mathbf{E}} \mathbf{)}\right.$} & $\begin{array}{c}\text { Estimated Mean } \\
\text { of Biotech Patents }\end{array}$ \\
\hline$\lambda(0,0)$ & 3.89 & $\lambda(0,0)$ & 3.89 \\
$\lambda(200,0)$ & 5.99 & $\lambda(2200,0)$ & 20.83 \\
$\lambda(0,1)$ & 5.02 & $\lambda(0,1)$ & 5.02 \\
$\lambda(200,1)$ & 6.52 & $\lambda(2200,1)$ & 28.31 \\
$\Delta_{11}=\lambda(200,0)-\lambda(0,0)$ & 2.10 & $\Delta_{11}=\lambda(2200,0)-\lambda(0,0)$ & 16.94 \\
$\Delta_{12}=\lambda(0,1)-\lambda(0,0)$ & 1.13 & $\Delta_{12}=\lambda(0,1)-\lambda(0,0)$ & 1.13 \\
$\Delta_{1}=\Delta_{11}+\Delta_{12}$ & 3.23 & $\Delta_{1}=\Delta_{11}+\Delta_{12}$ & 18.07 \\
$\Delta_{2}=\lambda(200,1)-\lambda(0,0)$ & 2.63 & $\Delta_{2}=\lambda(2200,1)-\lambda(0,0)$ & 24.42 \\
$\left(\Delta_{2}-\Delta_{1}\right) / \Delta_{1}$ & $-18.58 \%$ & $\left(\Delta_{2}-\Delta_{1}\right) / \Delta_{1}$ & $35.14 \%$ \\
Interactive Effect & $-7.61 \mathrm{E}-04<0$ & Interactive Effect & $9.83 \mathrm{E}-04>0$ \\
{$[$ Eq. $(6)]$} & Substitutability & {$[$ Eq. $(6)]$} & Complementarity \\
\hline
\end{tabular}


The above simulation results provide implications for established firms in organizing their internal and external R\&D strategies to match the rapidly changing technological environment. In order to continually update a firm's technological know-how and capabilities, managers often choose to pursue internal R\&D and external technology sourcing strategies in parallel, in hope of a potential complementarity between various innovation activities. Such complementarity, unfortunately, does not always exist. Our results show that it is contingent on the development of a firm's absorptive capacity, which is mainly determined by how much the firm would invest in its in-house R\&D. Taking the firm presented in Table 3.4 as an example, with sufficient in-house $R \& D$ investments (e.g., $R D_{I}=2,200 M M \$$ ), internal and external R\&D strategies complement each other and enhance the firm's innovative output by $35.14 \%$. In contrast, at a lower level of in-house R\&D efforts (e.g., $\mathrm{RD}_{\mathrm{I}}=200 \mathrm{MM} \$$ ), internal and external $\mathrm{R} \& \mathrm{D}$ activities substitute for each other and reduce the firm's innovative performance by $18.58 \%$. To summarize, in-house $\mathrm{R} \& \mathrm{D}$ efforts play a key role in the interrelationship between internal and external R\&D strategies to influence firms' innovative output. Managers who can leverage external sources of innovation to adapt to the relentlessly changing technological environment and, at the same time, lay emphasis on in-house R\&D endeavors will be most successful in building up sustainable innovative capabilities of firms.

\subsubsection{Limitations and Future Research}

Our study is subject to several limitations which suggest avenues for future research. The restriction of the sample to a single industrial context raises the question of the generalizability of our findings, thus further efforts could be made to conduct research in other high-technology industries. We also acknowledge that not only the level of in-house R\&D investments influences a firm's absorptive capacity, but that the various components of in-house R\&D may also have differential effects on absorptive capacity. For instance, within the empirical setting of our study, an incumbent pharmaceutical firm with a higher proportion of biotechnology-oriented internal research efforts, holding the level of internal R\&D investments constant, is more likely to have stronger absorptive capacity within the new biotechnology regime. Future research could probe deeply into the constituent structure of internal R\&D investments to yield additional insights into the contingency role of in-house R\&D in the complementarity between different innovation activities. Finally, absorptive capacity is a multidimensional construct. Zahra and George (2002) define absorptive capacity as four dimensions, i.e., acquisition, assimilation, transformation, and exploitation. They posit that acquisition and assimilation capabilities are dimensions of 'potential' absorptive capacity, and that trans- 
formation and exploitation capabilities are dimensions of 'realized' absorptive capacity. An investigation into the role of potential and realized absorptive capacity in the relationship between different innovation strategies could be a fruitful line of future inquiry. 


\section{APPENDIX 3A. Estimation Technique}

The common first moment condition for the negative binomial model is,

$$
\lambda_{\text {it }}=E\left(Y_{i t}\right)=\exp \left(X_{i t}^{\prime} \beta\right)
$$

In our innovation model, when $\mathrm{RD}_{\mathrm{E}}$ is disaggregated into two count variables, $\mathrm{R} \& \mathrm{D}$ alliances $\left(\mathrm{RD}_{\mathrm{All}}\right)$ and $\mathrm{R} \& \mathrm{D}$ acquisitions $\left(\mathrm{RD}_{\mathrm{Acq}}\right)$, we write as

$$
\begin{aligned}
\mathrm{X}_{\mathrm{it}}^{\prime} \beta=\theta_{0} & +\theta_{1} \mathrm{RD}_{\mathrm{I}_{\mathrm{it}-1}}+\theta_{2} \mathrm{RD}_{\mathrm{I}_{\mathrm{it}-1}}^{2}+\theta_{3} \mathrm{RD}_{\mathrm{All}_{\mathrm{it}-1}}+\theta_{13} \mathrm{RD}_{\mathrm{I}_{\mathrm{it}-1}} \mathrm{RD}_{\mathrm{All}_{\mathrm{it}-1}} \\
& +\theta_{23} \mathrm{RD}_{\mathrm{I}_{\mathrm{it}-1}}^{2} \mathrm{RD}_{\mathrm{All}_{\mathrm{it}-1}}+\theta_{4} \mathrm{RD}_{\mathrm{Acq}_{\mathrm{it}-1}}+\theta_{14} \mathrm{RD}_{\mathrm{I}_{\mathrm{it}-1}} \mathrm{RD}_{\mathrm{Acq}_{\mathrm{it}-1}} \\
& +\theta_{24} \mathrm{RD}_{\mathrm{I}_{\mathrm{it}-1}}^{2} \mathrm{RD}_{\mathrm{Acq}_{\mathrm{it}-1}}+\sum \gamma_{\mathrm{n}} \operatorname{Control}_{\mathrm{n}_{\mathrm{it}-1}}
\end{aligned}
$$

The marginal effect of internal R\&D under relative change is,

$$
\begin{aligned}
\frac{\partial \lambda_{\text {it }} / \partial \mathrm{RD}_{\mathrm{I}_{\mathrm{it}-1}}}{\lambda_{\mathrm{it}}}=\theta_{1} & +2 \theta_{2} \mathrm{RD}_{\mathrm{I}_{\mathrm{it}-1}}+\theta_{13} \mathrm{RD}_{\mathrm{All}}{ }_{\mathrm{it}-1}+2 \theta_{23} \mathrm{RD}_{\mathrm{I}_{\mathrm{it}-1}} \mathrm{RD}_{\mathrm{All}_{\mathrm{it}-1}} \\
& +\theta_{14} \mathrm{RD}_{\mathrm{Acq}_{\mathrm{it}-1}}+2 \theta_{24} \mathrm{RD}_{\mathrm{I}_{\mathrm{it}-1}} \mathrm{RD}_{\mathrm{Acq}_{\mathrm{it}-1}}
\end{aligned}
$$

The interactive effect between internal $R \& D$ and $R \& D$ alliances is as follows,

$$
\frac{\Delta\left(\left(\partial \lambda_{\mathrm{it}} / \partial \mathrm{RD}_{\mathrm{I}} \mathrm{it}-1\right) / \lambda_{\mathrm{it}}\right)}{\Delta \mathrm{RD}_{\mathrm{All}_{\mathrm{it}-1}}=1}=\theta_{13}+2 \theta_{23} \mathrm{RD}_{\mathrm{I}_{\mathrm{it}-1}} \quad\left\{\begin{array}{ll}
\text { when }>0 & \text { Complementarity } \\
\text { when }<0 & \text { Substitutability }
\end{array}\right\}
$$

The interactive effect between internal $R \& D$ and $R \& D$ acquisitions is as follows,

$$
\frac{\Delta\left(\left(\partial \lambda_{\mathrm{it}} / \partial \mathrm{RD}_{\mathrm{I}_{\mathrm{it}-1}}\right) / \lambda_{\mathrm{it}}\right)}{\Delta \mathrm{RD}_{\mathrm{Acq}_{\mathrm{it}-1}}=1}=\theta_{14}+2 \theta_{24} \mathrm{RD}_{\mathrm{I}_{\mathrm{it}-1}} \quad\left\{\begin{array}{ll}
\text { when }>0 & \text { Complementarity } \\
\text { when }<0 & \text { Substitutability }
\end{array}\right\}
$$




\section{APPENDIX 3B. Simulation Analysis}

Table 3B-1 Simulation Results for Interactive Effects between Internal R\&D and R\&D Alliances $\left(\mathrm{RD}_{\mathrm{I}}=200,2200 \mathrm{MM} \$ \mathrm{RD}_{\mathrm{E}-\mathrm{All}}=0,5\right)$

\begin{tabular}{lclc}
\hline \multicolumn{1}{c}{$\lambda\left(\mathbf{R D}_{\mathbf{I}}, \mathbf{R D}_{\mathrm{E}-\mathrm{All}}\right)$} & $\begin{array}{c}\text { Estimated Mean } \\
\text { of Biotech Patents }\end{array}$ & \multicolumn{1}{c}{$\boldsymbol{\lambda}\left(\mathbf{R D}_{\mathbf{I}}, \mathbf{R D}_{\mathrm{E}-\mathrm{All}}\right)$} & $\begin{array}{c}\text { Estimated Mean } \\
\text { of Biotech Patents }\end{array}$ \\
\hline$\lambda(0,0)$ & 4.05 & $\lambda(0,0)$ & 4.05 \\
$\lambda(200,0)$ & 5.83 & $\lambda(2200,0)$ & 19.16 \\
$\lambda(0,5)$ & 7.09 & $\lambda(0,5)$ & 7.09 \\
$\lambda(200,5)$ & 8.46 & $\lambda(2200,5)$ & 31.84 \\
$\Delta_{11}=\lambda(200,0)-\lambda(0,0)$ & 1.78 & $\Delta_{11}=\lambda(2200,0)-\lambda(0,0)$ & 15.11 \\
$\Delta_{12}=\lambda(0,5)-\lambda(0,0)$ & 3.04 & $\Delta_{12}=\lambda(0,5)-\lambda(0,0)$ & 3.04 \\
$\Delta_{1}=\Delta_{11}+\Delta_{12}$ & 4.82 & $\Delta_{1}=\Delta_{11}+\Delta_{12}$ & 18.15 \\
$\Delta_{2}=\lambda(200,5)-\lambda(0,0)$ & 4.41 & $\Delta_{2}=\lambda(2200,5)-\lambda(0,0)$ & 27.79 \\
$\left(\Delta_{2}-\Delta_{1}\right) / \Delta_{1}$ & $-8.51 \%$ & $\left(\Delta_{2}-\Delta_{1}\right) / \Delta_{1}$ & $53.11 \%$ \\
Interactive Effect & $-1.69 \mathrm{E}-04<0$ & Interactive Effect & $1.96 \mathrm{E}-04>0$ \\
[Eq. (A4.1)] & Substitutability & {$[$ Eq. (A4.1)] } & Complementarity \\
\hline
\end{tabular}

Notes: Table 3B-1 shows the estimated mean value of biotechnology patents of a hypothetical firm in 1993 (the mid-year of our sample period), which is calculated based on the fixed-effects Negative Binomial model in Table 3.3 with varying levels of internal $R \& D\left(R D_{I}=200,2200 \mathrm{MM} \$\right)$ and $R \& D$ Alliance $\left(R D_{\mathrm{E}-\mathrm{All}}=0,5\right)$, while other independent variables are set to equal the sample medians.

Table 3B-2 Simulation Results for Interactive Effects between Internal R\&D and R\&D Acquisitions $\left(\mathrm{RD}_{\mathrm{I}}=200,2200 \mathrm{MM} \$ \mathrm{RD}_{\mathrm{E}-\mathrm{Acq}}=0,5\right)$

\begin{tabular}{lclc}
\hline \multicolumn{1}{c}{$\lambda\left(\mathbf{R D}_{\mathbf{I}}, \mathbf{R D}_{\mathrm{E}-\mathrm{Acq}}\right)$} & $\begin{array}{c}\text { Estimated Mean } \\
\text { of Biotech Patents }\end{array}$ & \multicolumn{1}{c}{$\boldsymbol{\lambda}\left(\mathbf{R D}_{\mathbf{I}}, \mathbf{R} \mathbf{R D}_{\mathrm{E}-\mathrm{Acq}}\right)$} & $\begin{array}{c}\text { Estimated Mean } \\
\text { of Biotech Patents }\end{array}$ \\
\hline$\lambda(0,0)$ & 4.05 & $\lambda(0,0)$ & 4.05 \\
$\lambda(200,0)$ & 5.83 & $\lambda(2200,0)$ & 19.16 \\
$\lambda(0,5)$ & 6.93 & $\lambda(0,5)$ & 6.93 \\
$\lambda(200,5)$ & 8.27 & $\lambda(2200,5)$ & 23.48 \\
$\Delta_{11}=\lambda(200,0)-\lambda(0,0)$ & 1.78 & $\Delta_{11}=\lambda(2200,0)-\lambda(0,0)$ & 15.11 \\
$\Delta_{12}=\lambda(0,5)-\lambda(0,0)$ & 2.88 & $\Delta_{12}=\lambda(0,5)-\lambda(0,0)$ & 2.88 \\
$\Delta_{1}=\Delta_{11}+\Delta_{12}$ & 4.66 & $\Delta_{1}=\Delta_{11}+\Delta_{12}$ & 17.99 \\
$\Delta_{2}=\lambda(200,5)-\lambda(0,0)$ & 4.22 & $\Delta_{2}=\lambda(2200,5)-\lambda(0,0)$ & 19.43 \\
$\left(\Delta_{2}-\Delta_{1}\right) / \Delta_{1}$ & $-9.44 \%$ & $\left(\Delta_{2}-\Delta_{1}\right) / \Delta_{1}$ & $8.00 \%$ \\
Interactive Effect & $-1.72 \mathrm{E}-04<0$ & Interactive Effect & $1.43 \mathrm{E}-04>0$ \\
{$[$ Eq. (A4.2)] } & Substitutability & {$[$ Eq. (A4.2)] } & Complementarity \\
\hline
\end{tabular}

Notes: Table 3B-2 shows the estimated mean value of biotechnology patents of a hypothetical firm in 1993 (the mid-year of our sample period), which is calculated based on the fixed-effects Negative Binomial model in Table 3.3 with varying levels of internal $R \& D\left(R D_{I}=200,2200 \mathrm{MM} \$\right)$ and $R \& D$ Acquisition $\left(\mathrm{RD}_{\mathrm{E}-\mathrm{Acq}}=0,5\right)$, while other independent variables are set to equal the sample medians. 



\section{CHAPTER 4}

\section{BENEFITING FROM INTERFIRM R\&D ALLIANCES: NETWORK STRUCTURE AND INNOVATIVE OUTPUT}

\subsection{INTRODUCTION}

Studies in the innovation and interorganizational learning literatures suggest that R\&D alliances and the resultant network are key vehicles through which firms can gain access to external knowledge or technology sources (Hagedoorn, 1993, 2002; Hagedoorn and Duysters, 2002b; Hill and Rothaermel, 2003; Park et al., 2002; Powell et al., 1996; Rothaermel, 2001; Rothaermel and Hess, 2007; Teece, 1992; Walker et al., 1997). Interfirm alliance networks have frequently been considered to be network resources or social capital (Ahuja, 2000b; Burt, 1992, 1997; Koka and Prescott, 2002). Yet, despite the growing consensus on the facilitative role of alliance networks, there has been an ongoing debate over the relative efficacy of different forms of network structure-network closure (Coleman, 1988) vs. structural holes (Burt, 1992) - as critical determinants of firm innovation. The empirical evidence has produced a rather mixed picture of how firms should be structurally embedded in interfirm alliance networks to improve innovativeness (e.g., Ahuja, 2000a; Baum et al., 2000; McEvily and Zaheer, 1999; Schilling and Phelps, 2007). To reconcile these conflicting arguments and results, researchers have proposed a contingency perspective (Ahuja, 2000a; Burt, 2000). However, so far there are relatively few studies (exceptions are Koka and Prescott, 2008; Vanhaverbeke et al., 2012) that have employed such a contingency approach to examine the impact of interfirm network structure on a focal firm's innovative output. ${ }^{58}$

Relatedly, apart from network closure vs. structural holes as aforementioned, the role of indirect ties is another important aspect of alliance network structure

\footnotetext{
${ }^{58}$ The analytic focus in our study is on interfirm alliance network. A contingency approach has also been used at alternative levels of network analysis, such as interpersonal- and intraorganizational-level collaboration networks (see review by Phelps et al., 2012). For instance, Gargiulo et al. (2009) conduct an interpersonal-level analysis examining how the impact of network closure on a knowledge worker's performance depends on the predominant role this worker plays with his or her exchange partners, i.e., whether as an acquirer or a receiver of information in the relationships affected by that closure.
} 
relating to a focal firm's innovative output (Ahuja, 2000a). Although scholars have long studied the relationship between indirect ties and innovation, most research in this tradition has largely focused on the benefits from indirect ties associated with extending a focal actor's informational reach in interfirm alliance networks (Karamanos, 2012; Salman and Saives, 2005; Vanhaverbeke et al., 2012). However, as argued by Ahuja (2000a), indirect ties are essentially characterized by a dual role vis-a-vis the focal actor-both as sources of information and as competitors in terms of using similar information. Consequently, the degree to which indirect ties can provide information benefits will vary by factors such as the nature of the information and the relevant network, and the type of outcome being studied (Ahuja, 2000a). Nonetheless, until recently there is a scarcity of empirical work that has examined the conditions under which a focal firm's indirect ties may actually reinforce or reduce its innovative outcomes.

To fill the above research gaps, the goal of our study is to examine the impact of two aspects of interfirm network structure, i.e., structural holes and indirect ties, on a focal firm's innovative output. These two aspects of alliance network structure essentially capture a focal firm's alliance partners' alliance behavior in two ways: on the one hand, alliance partners can reach within a firm's ego network, increasing the degree of connectivity between each other and thereby reducing structural holes from the focal firm's perspective; on the other hand, they may reach beyond the ego network and extend the focal firm's informational reach through indirect ties. Both types of alliance behavior by alliance partners can influence the focal firm's innovative output. We utilize a contingency approach in this study by considering the various dimensions of a focal firm's innovative outputnew technology and new products - and identify their divergent requirements on the focal firm's network structure of interfirm R\&D alliances. A firm's new technology or technological novelty is often considered to be a merely intermediate output (Ahuja and Katila, 2001; Faems et al., 2005) from its upstream R\&D activity. What matters even more is the successful introduction of new products in the market, which result from the downstream R\&D activity and serve as a relatively direct measure of the commercial value generated by new technological innovations. Researchers usually limit their focus to the intermediate output, i.e., the new technology, and overlook the new products as the final innovative outcome (Ahuja and Katila, 2001; Nerkar, 2003; Rosenkopf and Nerkar, 2001). In the present study, we take a look at both types of innovative output and make two contingency arguments accordingly. First, the optimal network structure for firms to embed themselves in, either network closure or structural holes, is contingent on the various types of innovative output. For firms striving to enhance their creation of new technology, an R\&D alliance network rich in structural holes is more advantageous, whereas network closure is expected to be more beneficial for their development 
of new products in the market. Second, based upon the dual role of indirect ties, the number of indirect ties maintained by firms in an R\&D alliance network is positively related to their creation of new technology, whereas firms with more indirect ties may experience adverse effects on their innovative output in terms of new products.

The research setting for our study is the global pharmaceutical industry, characterized as a high-tech sector with a strong dual market structure which is largely determined by a small group of incumbent pharmaceutical firms and a large group of entrepreneurial biotechnology companies (Grabowski, 2011; Hagedoorn et al., 2008). Since the emergence of biotechnology in the mid-1970s, incumbent pharmaceutical firms have increasingly engaged in R\&D alliances with new biotechnology companies to gain access to their technological competences in the field of biotechnological research (Hagedoorn, 2002; Roijakkers and Hagedoorn, 2006). We therefore focus on incumbent pharmaceutical firms as the focal actors in the industry network of interfirm R\&D alliances. The empirical results confirm, to a great extent, our contingency framework, indicating that the impact of interfirm network structure on a focal firm's innovative output is contingent on the particular type of innovative outcomes being studied. More specifically, our findings on the relative efficacy of network closure vs. structural holes suggest that an R\&D alliance network rich in structural holes is more advantageous for incumbent pharmaceutical firms' creation of new technology, whereas a dense, interconnected network of interfirm R\&D alliances turns out to be more beneficial for their development of new products in the market. Concerning the dual role of indirect ties, our estimation results indicate that incumbent pharmaceutical firms with more indirect ties in an $\mathrm{R} \& \mathrm{D}$ alliance network are actually associated with reduced innovative output in terms of new products, while no significant effect is found in the case of new technology. Overall, our study contributes to a better understanding of under what conditions a focal firm mandates the distinct benefits provided by the different forms of alliance network structure. Moreover, as opposed to prior research that has predominately demonstrated the benefits from indirect ties as sources of information, the current study contributes to illuminating the dual role of indirect ties as potential competitors as well as information sources for a focal firm.

The paper proceeds as follows. In Section 4.2, we provide theoretical backgrounds to the network configuration of interfirm R\&D alliances and formulate the hypotheses to be tested. We then describe the sample, the model, and the estimation techniques in Section 4.3. The empirical results are reported in Section 4.4. Section 4.5 discusses the main findings and their implications, followed by some possible avenues for future research. 


\subsection{THEORETICAL BACKGROUNDS AND HYPOTHESES}

There are traditionally two competing theoretical perspectives about the optimal network structure of interfirm alliances (Walker et al., 1997). According to Coleman (1988), the appropriate network configuration is of a 'closure' form, in which a focal actor's partners are densely interconnected and structural holes (i.e., disconnections between alters that are linked to the focal actor) are absent. Such a dense or closed collaboration network provides collective social capital that can promote shared behavioral norms, trust, and cooperation among network members. This view runs contrary to Burt's (1992) structural hole theory, which claims that firms benefit from designing alliance networks to maximize efficiency by reducing redundant ties and maintaining only a limited set of ties that bridge structural holes. From Burt's (1992) standpoint, firms embedded in such sparse or open networks can obtain speedy access to diverse information. Moreover, firms bridging structural holes are awarded control benefits based on their ability to arbitrage nonredundant information exchanges between disconnected partners (or clusters).

In this debate, the empirical evidence represents a mixed picture of how firms should be structurally embedded in interfirm alliance networks to improve innovativeness. One set of studies indicates that network closure positively influences a focal firm's innovative output (Ahuja, 2000a; Schilling and Phelps, 2007). In his study of interfirm technological collaboration network in the international chemical industry, Ahuja (2000a) examines the impact of alliance network structure on firm innovation and finds that firms occupying many structural holes are associated with reduced innovative output. In support of Coleman's (1988) position, he concludes that firms connected via horizontal collaborative linkages benefit more from trust and cooperation provided by network closure than from information diversity provided by structural holes. Consistently, in a large-scale, industry-level network analysis, Schilling and Phelps (2007) find that the presence of structural holes in a firm's ego network has a significant negative effect on the firm's subsequent patenting rate. By contrast, a second set of studies shows that firms embedded in alliance networks rich in structural holes exhibit relatively higher levels of innovative output (Baum et al., 2000; McEvily and Zaheer, 1999).59 For instance, Baum et al. (2000) demonstrate how Canadian biotechnology startups raise their patenting rates by configuring them into a sparse (or an efficient) alliance network that provides access to diverse information and capabilities with minimum costs of redundancy. Similar arguments have also been made by McEvily and Zaheer (1999)

\footnotetext{
${ }^{59} \mathrm{Also}$ see Zaheer and Bell (2005) for the role of alliance network structure in determining a firm's financial performance. They investigate how the structure of collaboration networks in which Canadian mutual fund companies are embedded influences their market shares in the industry. Their results show that network structure construed as structural holes, rather than as closure, enhances a firm's financial performance.
} 
in their study that examines the role of bridging ties as a source of variation in competitive capabilities of firms within a geographic cluster. Their results reveal that structural holes (as measured by nonredundancy) in a firm's network of ties reinforce its acquisition of competitive capabilities and innovative performance.

Research efforts have been devoted to the reconciliation of these conflicting empirical findings. Rather than arguing for unconditional superiority of one form of network structure over the other, Burt (2000: 383-397) suggests that “...debate over network mechanisms responsible for social capital can be resolved in large part by understanding contingency; ... a study can show exclusive evidence of social capital from network closure or structural holes without calling either argument into question...". As such, Coleman's (1988) and Burt's (1992) versions of social capital provide different benefits and are useful for different strategic purposes (Rowley et al., 2000). The appropriate network structure is therefore contingent on what firms seek to enable through it, and it is important to identify the conditions under which firms mandate the distinct benefits provided by the different forms of network structure (Ahuja, 2000a; Rowley et al., 2000).

However, until recently there are relatively few studies that have employed such a contingency approach to explore the implications of the structure of interfirm alliance network for a focal firm's innovative output. Although not from the perspective of firm innovation, Rowley et al. (2000) provide early empirical evidence on the contingent value of interfirm network structure. Using alliance networks in the semiconductor and steel industries, Rowley et al. (2000) examine the conditions under which dense or sparse networks are positively related to firms' financial performance. They posit that the degree to which firm strategies are designed to exploit existing technologies or explore the environment for emerging opportunities influences the appropriate network configurations. Their results suggest that for firms operating in stable environments (i.e., the steel industry) which demand relatively high investments in exploitation, a dense network turns out to be more advantageous. However, the study finds no support for the argument that in uncertain environments (i.e., the semiconductor industry) demanding relatively high levels of exploration, a sparse network is more beneficial for firm performance. In contrast with the industry-dependent findings by Rowley et al. (2000), Koka and Prescott (2008) propose environmental change within an industry as one contingency factor that conditions the impact of alliance network structure on firm productivity. ${ }^{60}$ They find that following an environment-changing

\footnotetext{
${ }^{60}$ Environmental change is operationalized by using two events in the steel industry, the legislative event and the technology event (Koka and Prescott, 2008). Their results provide support for the contingent effect of environmental change triggered by the legislative event, but evidence is mixed in the case of the technology event. The other contingency factor in the study is the alliance strategy a firm pursues, i.e., whether an analyzer or a defender strategy.
} 
event, firms occupying many structure holes exhibit relatively higher levels of productivity, whereas firms situated in a group of densely interconnected partners experience adverse effects on their productivity.

The above two studies explore the contingent effect of interfirm network structure by looking at a firm's ex-ante innovation process, which involves its different learning activities, investments, or strategies in pursuing innovation (e.g., emphasizing either exploration or exploitation) under different environmental contexts. As such, it would be also interesting to examine the contingent value of alliance network structure from an ex-post outcome perspective, i.e., by relating different forms of network structure directly to a firm's various innovative outcomes. In this way, the manifestation of the relative efficacy of a certain network structure can be observed through examining a firm's increased innovative output affected by that network structure. In a study of interfirm technology alliances in the chemicals, automotive, and pharmaceutical industries, Vanhaverbeke et al. (2012) investigate how a firm's alliance network structure influences its innovative output with respect to the creation of core and non-core technologies. Their results indicate that a nonredundant network structure carries a positive effect on the creation of core technology, whereas no significant effect is found for the creation of non-core technology.

Building upon the above literature, we utilize a contingency approach in this study by considering the various dimensions of a focal firm's innovative outputnew technology and new products - and identify their differential requirements on the focal firm's network structure of interfirm R\&D alliances. Specifically, we focus on incumbent pharmaceutical firms as the focal actors in the industry network of interfirm R\&D alliances. To adapt to and capitalize on radical technological change, incumbent pharmaceutical firms not only strive for the creation of new technology - an upstream R\&D activity along the value chain, but also need to translate the new technology into profitable business models, leading to potentially successful introduction of new products in the market - the downstream R\&D activity along the value chain. To the extent that different $\mathrm{R} \& \mathrm{D}$ activities along the value chain can be conceptualized as either 'exploration' or 'exploitation' (March, 1991), the upstream R\&D activity is relatively exploratory, which provides input for the downstream activity to exploit (Gilsing and Nooteboom, 2006; Lavie and Rosenkopf, 2006; Li et al., 2008; Rothaermel and Deeds, 2004). In this sense, a firm's creation of new technology is more related to 'exploration' (March, 1991) or 'knowledge generation' (Spender, 1992), whereas the development of new products is mainly associated with 'exploitation' (March, 1991) or 'knowledge application' 
(Spender, 1992). ${ }^{61}$ Research has often portrayed exploration or exploitation as an innovation process, yet such process can be reflected in the exploratory or exploitative content of firm innovative output (Phelps, 2010). In this study, we introduce exploration and exploitation with reference to the various types of a firm's innovative output, ${ }^{62}$ with new technology being comparatively exploratory and new products more exploitative in nature. As will be argued, these different types of innovative output, i.e., new technology and new products, place divergent requirements on the appropriate network structure for incumbent pharmaceutical firms to embed themselves in.

\subsubsection{Structural Holes and Innovative Output}

In March (1991), exploration is defined as 'search, variation, risk-taking, experimentation, play, flexibility, discovery, and innovation', and exploitation as 'refinement, choice, production, efficiency, selection, implementation, and execution'. This broad definition is subject to various interpretations and later on restricted by Levinthal and March (1993) specifically to the knowledge domain (Lavie et al., 2010). They emphasize that exploration is associated with 'a pursuit of new knowledge, of things that might come to be known', whereas exploitation concerns 'the use and development of things already known'. In this paper, we draw on the latter concept of exploration and exploitation, focusing mainly on their distinction between 'knowledge generation' and 'knowledge application' (also see Spender, 1992).

A firm's exploration or knowledge generation typically involves the novel recombination of existing elements of knowledge, problems, or solutions (Fleming, 2001), or reconfiguring the ways knowledge elements are linked (Henderson and Clark, 1990). This often requires access to new and distinct information outside the

\footnotetext{
${ }^{61}$ There are three main functions along the value chain: science, technology, and products. Science or fundamental research is beyond the scope of this study. For each pair of functions, i.e., science vs. technology and technology vs. products, the earlier function is often considered to be exploration, based on which further exploitation takes place in the following function (Li et al., 2008). In the biotechnology and pharmaceutical industries, science or fundamental research is usually conducted within the network of academia and entrepreneurial biotechnology companies, and these biotechnology companies often act as the 'transfer channel' of new technology from science to incumbent pharmaceutical firms (Gilsing and Nooteboom, 2006).

${ }^{62}$ There is substantial inconsistency and ambiguity in the interpretation of exploration and exploitation as features of either the innovation process or the innovative outcomes ( $\mathrm{Li}$ et al., 2008). Some researchers consider exploration and exploitation as different forms of the innovation process which often involves technology search activities, investments, and strategies of firms (Gilsing and Nooteboom, 2006; He and Wong, 2004). Other studies, however, define exploration and exploitation through the lens of firms' innovative outcomes, for instance, radical vs. incremental innovations (Quintana-García and Benavides-Velasco, 2011; Sternitzke, 2010) and core vs. non-core technological innovations (Vanhaverbeke et al., 2009, 2012).
} 
sphere of a firm's existing knowledge base (Rowley et al., 2000). Such new and distinct information, or, information diversity, refers primarily to the heterogeneity of knowledge or resources that can usually be achieved through interfirm alliance networks (Ahuja, 2000b; Nooteboom, 2004; Rothaermel and Deeds, 2004), in which a focal firm can integrate complementary knowledge from its alliance partners and thus increase the potential for novelty creation (Gilsing and Duysters, 2008). Moreover, through accessing new and diverse sources of knowledge, a focal firm may develop multiple conceptualizations of problems and solutions and apply solutions from one domain to problems in another (Hargadon and Sutton, 1997; Phelps, 2010). In this respect, information diversity increases the number and variety of novel recombination of knowledge elements (Fleming, 2001; Gilsing and Duysters, 2008), thereby leading to the creation of exploratory innovations (Koka and Prescott, 2008; Rowley et al., 2000; Vanhaverbeke et al., 2009).

According to Burt (1992), firms bridging structural holes can enjoy timely access to novel and diverse information from disconnected parts of an alliance network. Consistently, Baum et al. (2000) demonstrate that a sparse alliance network provides firms with access to diverse information and capabilities with minimum costs of redundancy. In addition to information diversity, interfirm alliance networks rich in structural holes can serve as a screening device that allows news of technical breakthroughs, new insights to problems, or failed approaches to be brought to a focal actor's attention (Ahuja, 2000a; Leonard-Barton, 1984). This enables the focal actor to develop new understandings, especially regarding emergent technological opportunities and threats not possible to firms which do not bridge structural holes (Zaheer and Bell, 2005). By contrast, a dense network in which partners are tied to each other tends to provide highly redundant information (Burt, 1992). In other words, network closure prevents a focal actor from obtaining new and diverse information critical to its exploration by limiting the number of collaborative linkages in touch with emerging opportunities (Burt, 1992; Uzzi, 1996, 1997). Further, the collective social capital provided by network closure can limit firms' openness to alternative ways of doing things and produce forms of collective blindness (Coleman, 1988; Duysters and Lemmens, 2003; Nahapiet and Ghoshal, 1998), which would suppress their exploratory innovations. In a nutshell, the limitation of a dense, interconnected network is that new and diverse information may not be received, may be received more slowly, or may be subject to attenuation and blind-spot biases (Koka and Prescott, 2008). This is in vivid contrast to a structural-hole-rich network, which provides speedy access to diverse information that contributes substantially to firm exploration. Since the creation of new technology is a form of knowledge generation or exploration (Benner and Tushman, 2003; Rosenkopf and Nerkar, 2001), the above leads us to the following hypothesis that for firms striving to enhance the creation of new 
technology, an alliance network rich in structural holes is expected to be more advantageous, compared with a dense or closed network.

Hypothesis 1a: The more the structural holes spanned by a firm, the greater the firm's subsequent innovative output in terms of new technology.

As suggested earlier, the creation of new technology or exploratory innovations by firms often requires access to novel and diverse information, which is relatively broad and general in nature (Rowley et al., 2000). In contrast, firm exploitation or knowledge application entails gathering more specific information (Gilsing and Nooteboom, 2006; Rowley et al., 2000) to fully understand how to translate existing technologies into commercially viable products. Studies have shown that firms embedded in a densely interconnected network can, through triangulation among multiple and redundant sources, obtain valuable specific, finegrained information regarding particular technological innovations (Koka and Prescott, 2008; Rowley et al., 2000). In addition, a network of cohesive, redundant ties may enhance a focal firm's absorptive capacity and allow it to develop a richer understanding of the received information (Vanhaverbeke et al., 2009). Consequently, for the purpose of exploitation, a dense network assists a focal firm in obtaining and understanding relatively specific information in order to apply existing technologies to commercial ends.

Furthermore, a focal firm is likely to be subject to a heightened risk of partner opportunism in interfirm R\&D collaborations towards exploitative innovations (Pisano, 1997; Vanhaverbeke et al., 2009). Within the empirical setting of our study, incumbent pharmaceutical firms are more experienced at FDA regulatory management, marketing, and distribution, while new biotechnology companies possess strong technological capabilities in drug discovery (Roijakkers et al., 2005; Rothaermel, 2001; Rothaermel and Boeker, 2008). As a consequence, incumbent pharmaceutical firms usually look to R\&D alliances with new biotechnology companies to gain access to their technological competences (Rothaermel, 2001; Rothaermel and Hess, 2007). In this case it is often difficult for incumbent pharmaceuticals to assess the quality of untested technological competences possessed by new biotechnology companies (Colombo et al., 2006; Pisano, 1997). Pisano (1997) suggests that a potential 'lemons' problem exists in interfirm R\&D alliances due to asymmetric information about the true quality of biotechnology R\&D projects. New biotechnology companies have a tendency to offer inferior R\&D projects for collaboration, while maintaining the more promising projects in-house for solo development. Such opportunistic behavior of alliance partners may pose severe problems to incumbent pharmaceutical firms' competitive advantage in the 
market. Research evidence indicates that the distribution of financial returns for new drugs in the pharmaceutical industry is highly skewed (Grabowski and Vernon, 1990, 1994; Grabowski et al., 2002) such that a relatively small number of 'blockbuster' products have yielded a disproportionate share of industry returns (Grabowski, 2011). ${ }^{63}$ In other words, a few top-selling drug products are essential for the long-run economic success of established pharmaceutical firms. Hence, their R\&D investments are mainly driven by a search for products that can achieve blockbuster-level sales (Grabowski, 2011). Under such conditions, some inferior or even less promising R\&D projects offered by new biotechnology companies can be severely detrimental, as they foreclose potential opportunities for incumbent pharmaceutical firms to introduce blockbuster products in the market.

Given the risk of partner opportunism in interfirm R\&D collaborations in the context of exploitative innovation, network closure can serve as a governance mechanism for a focal firm to inhibit such risk (Ahuja, 2000a; Coleman, 1988; Rowley et al., 2000). In a dense, interconnected network where a focal firm's partners are linked to each other, the focal firm can learn more about its current and prospective partners through common third parties, thereby reducing information asymmetries among network members (Granovetter, 1985; Gulati et al., 2000; Larson, 1992). More importantly, as argued by Coleman (1988), network closure facilitates the production of a set of effective norms and sanctions that can monitor and guide behavior. This makes it less risky for network members to engage in collaborations with each other, since in such a dense structure, information on one firm's opportunistic behavior is readily disseminated to other related parties and the behavior more easily sanctioned (Walker et al., 1997). Finally, opportunistic behavior is less likely to arise in interconnected, closed networks because it would cause reputation loss of firms, jeopardize their existing alliances, and reduce their collaborative opportunities at a future date (Ahuja, 2000a; Gulati, 1998; Kreps, 1990).

Taken together, in the context of a focal firm's innovative output in terms of new products, which are characterized by exploitation or knowledge application, compared with a dense or closed alliance network, a network rich in structural

${ }^{63}$ The current industry metric for blockbuster status is $\$ 1$ billion or more in global sales (Grabowski, 2011). Through an examination of comprehensive samples comprising new drug introductions in the pharmaceutical industry for successive periods in the 1970s, 1980s, and 1990s, Grabowski and Vernon $(1990 ; 1994)$ and Grabowski et al. (2002) find that the distribution of 'quasi rents'-the surplus revenues over costs of production and marketing - for new drugs is highly skewed. In particular, the top $10 \%$ of new drug introductions has accounted for $48 \%$ to $55 \%$ of the overall quasi rents in these three sample periods. In light of this highly skewed distribution, even the maintenance of a large, diversified portfolio of $\mathrm{R} \& \mathrm{D}$ projects does not guarantee a relatively stable pattern of new drug approvals for pharmaceutical firms (Grabowski, 2011). 
holes is expected to be less valuable for accessing relatively specific information and curbing opportunistic behavior of alliance partners. We therefore hypothesize:

Hypothesis 1b: The more the structural holes spanned by a firm, the less the firm's subsequent innovative output in terms of new products.

\subsubsection{Indirect Ties and Innovative Output}

Apart from network closure vs. structural holes as demonstrated in the above, the role of indirect ties is another important aspect of alliance network structure relating to a firm's innovative output (Ahuja, 2000a; Vanhaverbeke et al., 2012). In addition to reaching within a focal firm's ego network and increasing connectivity between each other, alliance partners can reach beyond the ego network and serve as an information channel between the focal firm and its indirect contacts, i.e., the partners of its partners (Ahuja, 2000a; Gulati, 1995; Haunschild, 1993). Alliance partners bring the knowledge and resources from their interactions with their other partners to their interaction with the focal firm and vice versa (Gulati and Garguilo, 1999). Thus, a focal actor's collaborative linkages provide it with access not just to the information held by its partners but also to the information held by its partners' partners (Gulati and Garguilo, 1999). Ahuja (2000a) suggests that indirect ties can increase a focal firm's informational reach in interfirm alliance networks by acting as an information gathering and screening device. Indirect ties may fulfill a radar function by bringing information on relevant developments in different technologies to the early notice of a focal firm (Ahuja, 2000a; Vanhaverbeke et al., 2012). Alternately, faced with a particular problem, the focal firm can activate its indirect ties to identify the sources that are likely to be well informed about the issue at hand (Ahuja, 2000a; Freeman, 1991).

The benefits provided by indirect ties are especially important for firm exploration. Indirect ties allow a focal firm to monitor a wide and flexible range of information which may also include what is not expected nor searched for by the firm (Granovetter, 1982). Such information tends to provide it with a relatively comprehensive overview on many unfamiliar domains (Vanhaverbeke et al., 2012). Since exploration often entails gathering new and diverse information for emerging opportunities (Levinthal and March, 1993; March, 1991; Rowley et al., 2000), firms can leverage their indirect ties to obtain a broad range of novel information and perspectives that are important prerequisites for the creation of exploratory innovations. Hence, a focal firm with more indirect ties in an $R \& D$ alliance network is privy to greater information diversity, which is expected to reinforce its innovative output with respect to the creation of new technology. 
Hypothesis 2a: The more the number of indirect ties that a firm maintains, the greater the firm's subsequent innovative output in terms of new technology.

To the extent that each firm connected to an alliance network is both a recipient and a transmitter of information, a focal actor's indirect contacts can simultaneously play two different roles (Ahuja, 2000a). On the one hand, they are resources that can extend a focal firm's informational reach in the alliance network (Ahuja, 2000a). Yet, information from indirect ties tends to be noisy or even distorted as it has to pass through a common partner which may interpret and attach meaning to this information in a different way than the focal firm (Vanhaverbeke $e t$ al., 2012). As a consequence, indirect ties are relatively less valuable for firm exploitation, which is less tolerant of information noise and often requires more specific, fine-grained information (Gilsing and Nooteboom, 2006; Rowley et al., 2000) so as to fully understand how to transform existing technologies into marketable products.

On the other hand, in many networks, indirect ties are also competitors of a focal firm in terms of using similar information (Ahuja, 2000a). Ahuja (2000a) argues that if the same information can be used profitably by indirect contacts and one firm's use of it precludes its most fruitful use by another, then the information benefits from indirect ties will be substantially decreased for the focal firm. Within the empirical setting of this study, incumbent pharmaceutical firms are more experienced at FDA regulatory management, marketing, and distribution-all downstream value chain activities, while new biotechnology companies possess strong technological competences in drug discovery - an upstream value chain activity (Roijakkers et al., 2005; Rothaermel, 2001; Rothaermel and Boeker, 2008). As a consequence, incumbent pharmaceutical firms are more liable to engage in $R \& D$ alliances with small biotechnology ventures, rather than with other large, established pharmaceuticals, for accessing the most novel technologies to complement their in-house R\&D. Likewise, relative to partnering with their counterparts, small biotechnology companies are in a greater likelihood of collaborating with incumbent pharmaceutical firms to replenish the necessary development and regulatory experience required to transform the technological competences into final drug products. In view of such asset complementarity, the vast majority of interfirm $\mathrm{R} \& \mathrm{D}$ alliances in the pharmaceutical industry are formed between large, incumbent pharmaceutical firms and small, R\&D-intensive biotechnology companies (See e.g., Adegbesan and Higgins, 2011; Diestre and Rajagopalan, 2012; Hagedoorn et al., 
2008). ${ }^{64}$ Hence, from the perspective of a focal actor in our network analysis, an incumbent pharmaceutical firm's R\&D alliance network is essentially characterized by a large-small-large structure, with small biotechnology companies mainly as its partners and other large pharmaceutical firms mainly as its partners' partners. In other words, the indirect contacts are, more often than not, other incumbent pharmaceuticals as potential providers of information to the focal pharmaceutical firm. To the extent that incumbent pharmaceutical firms are often pursuing similar leads based on new technological opportunities, only firms whose products are "first-in-class" or "best-in-class" can earn disproportionate returns in this innovation race (Grabowski, 2011). Losers in the race may even face difficulties in covering their R\&D investments. Under such circumstances, the indirect contacts (i.e., other incumbent pharmaceuticals) represent intense competition for the focal pharmaceutical firm in terms of using the same information. As a result, the information benefits from these indirect ties will be substantially reduced.

Moreover, knowledge that a focal firm develops in collaboration with a partner may reach this partner's partners, i.e., the indirect ties (Gulati and Garguilo, 1999; Vanhaverbeke et al., 2012). This is especially risky in the case of exploitative innovation, as the leakage of proprietary knowledge associated with a focal firm's new product development may put the firm at a great disadvantage or even jeopardize its core competences and competitiveness in the market. However, given the fact that indirect ties are usually outside a focal firm's sphere of direct control, such spillovers or leakages of knowledge are very hard to monitor and prevent, let alone to enforce sanctions (Vanhaverbeke et al., 2012). Taken together, in the context of the pharmaceutical industry, a focal firm with more indirect ties in an R\&D alliance network is more liable to potential competitors using similar information in the network, which will substantially reduce the information benefits from indirect ties that accrue to the focal firm. This is often accompanied by risks of spillovers or leakages of proprietary knowledge held by the focal firm, thereby leading to a lower level of its innovative output in terms of new products. Accordingly, we propose:

Hypothesis 2b: The more the number of indirect ties that a firm maintains, the less the firm's subsequent innovative output in terms of new products.

\footnotetext{
${ }^{64} \mathrm{It}$ is also important to note that new biotechnology ventures are highly specialized in a specific technological field. Meanwhile, incumbent pharmaceutical firms that engage in R\&D alliances with new biotechnology ventures tend to explore various opportunities simultaneously, without making substantial specific investments up front. These factors provide further explanations for interfirm $\mathrm{R} \& \mathrm{D}$ alliances in the industry formed mainly between large pharmaceutical firms and small biotechnology companies (Gilsing and Nooteboom, 2006; Rothaermel and Deeds, 2006; Vassolo et al., 2004).
} 


\subsection{METHODOLODY}

\subsubsection{Data and Sample}

The research setting for testing the postulated hypotheses is the global pharmaceutical industry. During the last one and a half decades of the twentieth century, the pharmaceutical industry can be characterized as a high-tech sector with a strong dual market structure, which is largely determined by a small group of incumbent pharmaceutical firms and a large group of entrepreneurial biotechnology companies (Hagedoorn et al., 2008). In particular, the focal actors in our study are incumbent pharmaceutical firms that are defined as pharmaceutical firms that were in existence prior to the emergence of biotechnology. These incumbents, such as Bayer, Hoffmann-La Roche, Merck, and Pfizer, are generally mature and very large firms which have dominated the industry since the 1940s. In the mid-1970s, the advent of biotechnology led to significant scientific and technological breakthroughs in genetic engineering (recombinant DNA, 1973) and hybridization (monoclonal antibodies, 1975). Such technological advances have been altering the drug discovery process profoundly in the following decades, accompanied by the upsurge of numerous new dedicated biotechnology companies which possess strong competences in drug discovery in the field of biotechnological research. These new biotechnology companies have been virtually at the leading edge in transforming the highly scientific knowledge created at universities and research institutes into commercially useful technologies and products. In doing so, (most of) the new biotechnology ventures do not aim to become drug producers themselves, but rather act as providers of new technologies that form the research tools in the drug discovery and development process of incumbent pharmaceutical firms (Gilsing and Nooteboom, 2006). By and large, in the context of the pharmaceutical industry within the new biotechnology regime, incumbent pharmaceutical firms are more experienced at FDA regulatory management, marketing, and distribution_all downstream value chain activities, while new biotechnology companies possess strong technological competences in drug discovery-an upstream value chain activity (Roijakkers et al., 2005; Rothaermel, 2001; Rothaermel and Boeker, 2008). In view of such asset complementarity, the vast majority of interfirm R\&D alliances in the industry network are formed between large, established pharmaceutical firms and small, R\&D-intensive biotechnology companies, as accessing to each other's capabilities is a key to success (Adegbesan and Higgins, 2011; Diestre and Rajagopalan, 2012; Hagedoorn et al., 2008).

We used data from several major sources as follows. (1) The source for the patent data is the Technology Profile Report maintained by the U.S. Patent and Trademark Office (USPTO). We obtained detailed data comprising the population of all biotechnology patents granted to incumbent pharmaceutical firms annually 
since the emergence of biotechnology. (2) A second source of data to construct a non-patent based innovative output is the Gale Group's New Product Announcements/Plus (NPA/PLUS) database from which we obtained the annual number of new product announcements in the area of biotechnology by incumbent pharmaceutical firms. The NPA/PLUS database includes the press releases from all industries covering announcements related to products, with a focus on new products and services. (3) Data on interfirm R\&D alliances in the technological field of biotechnology within the global pharmaceutical industry were retrieved from the MERIT-CATI database, which is developed and maintained by researchers at the Maastricht Economic Research Institute on Innovation and Technology (MERIT). The CATI (Cooperative Agreements and Technology Indicators) database provides information on each cooperative technology agreement and some information on companies participating in these agreements. ${ }^{65}$ (4) Data on R\&D acquisitions of new biotechnology companies by incumbent pharmaceutical firms were obtained from the SDC (Securities Database Corporation) Platinum database of Thomson Financial. This database contains information on the year of acquisition, with details on the (parent) acquirer, the (parent) target, and a brief description of the acquisition transaction. (5) Financial data were cross-tracked through Compustat and Datastream (Thomson Financial). All financial data were first converted to U.S. dollars by year-end exchange rates provided by Compustat, and then inflation-adjusted to year 2000 U.S. dollars using U.S. CPI.

Our analytic focus in this study is on interfirm $\mathrm{R} \& \mathrm{D}$ alliances in the technological field of biotechnology within the global pharmaceutical industry. Interfirm R\&D alliances are defined as interfirm agreements in which a combined innovative activity or an exchange of technology is engaged between independent, industrial firms. Since interfirm R\&D alliances are established at both the subsidiary and parent level, all R\&D alliance data were aggregated up to the ultimate parent level (Rosenkopf and Padula, 2008; Schilling and Phelps, 2007; Vanhaverbeke et al., 2012). Likewise, patents and new product announcements can be assigned to both the sample firm and its various levels of subsidiaries, we thus identified all subsidiaries of firms in the sample, using D\&Bs Who Owns Whom, and then aggregated the number of granted patents and new product announcements to the sample firms (Ahuja, 2000a; Schilling and Phelps, 2007). Overall, 1,780 interfirm R\&D alliances were included in our network analysis, of which about $63 \%$ (i.e., 1,116 R\&D alliances) accounts for the alliances formed between incumbent pharmaceutical firms and new biotechnology companies, about $28 \%$ (i.e., 501 R\&D alliances) in between

\footnotetext{
${ }^{65}$ The CATI database only collects cooperative agreements in which a combined innovative activity or an exchange of technology is undertaken by at least two industrial partners. Agreements involving only universities or government labs, or just one firm with a university are disregarded. See more details of the CATI data collection in Hagedoorn (1993) and Duysters and Hagedoorn (1993).
} 
new biotechnology companies, and the remaining 9\% (i.e., 163 R\&D alliances) in between incumbent pharmaceutical firms. As such, an incumbent pharmaceutical firm is in an approximately 7 times higher likelihood of partnering with new biotechnology companies than with other large, established pharmaceuticals. In a similar vein, a new biotechnology venture is as much as 2.25 times more likely to engage in alliances with incumbent pharmaceutical firms than with its counterparts. Such pattern of alliance behavior demonstrates the large-small-large structure of R\&D alliance network in the global pharmaceutical industry.

The alliance network variables including structural holes, indirect ties, and direct ties were calculated by using Ucinet 6 (Borgatti et al., 2002) on the basis of the alliance adjacency matrices that were constructed from the CATI data on interfirm R\&D alliances. An alliance with more than two firms entered the adjacency matrix as separate dyadic combinations of all firms in the alliance. ${ }^{66}$ Since the database usually does not provide information on the date of dissolution for each alliance, in line with prior research (Kogut, 1988, 1989), we followed the assumption of an average life span of five years for interfirm alliances. More precisely, we utilized a five-year moving window approach (Gulati, 1995; Vanhaverbeke et al., 2009, 2012) in which an alliance matrix was constructed per firm-year through aggregating the R\&D alliances established by an incumbent pharmaceutical firm during the five years prior to the year of observation. To mitigate a potential survivor bias, we started with a comprehensive set of global pharmaceutical firms that were in existence as of 1986 according to various industry sources. In this manner 89 incumbent pharmaceutical firms were identified, which are defined as pharmaceutical firms that were founded prior to the emergence of biotechnology in the mid-1970s. In the aggregation of interfirm $R \& D$ alliance data up to the ultimate parent level, most incumbent pharmaceutical firms in the sample are the ultimate parent companies themselves, with four pharmaceutical firms being subsidiaries of outsiders and thus left out of the sample. ${ }^{67}$ As a result, 85 incumbent pharmaceutical firms, as focal actors in the industry network, were included in the sample covering the 15-year period from 1986 to 2000. Hypotheses 1a and 2a were tested on this panel dataset comprising the $\mathrm{R} \& \mathrm{D}$ alliance activities of the incumbent pharmaceutical firms and their resultant patenting rates. Furthermore, hypotheses $1 \mathrm{~b}$ and $2 \mathrm{~b}$ postulate the effects of R\&D alliance network on another, non-patent based innovative outcome, i.e., biotechnology product announcements, the data of which were only available from 1994 to 2000 for 80 incumbent pharmaceutical firms. Thus,

\footnotetext{
${ }^{66} \mathrm{Of}$ the 1,780 interfirm R\&D alliances included in the network analysis, $55 \mathrm{R} \& \mathrm{D}$ alliances involved with more than two firms.

${ }^{67}$ In a few cases in which the sample firms were acquired by outsiders toward the end of the study period, we kept such firms in the sample and treated them as unbalanced data by considering their data of post-acquisition year(s) 'missing'.
} 
hypotheses $1 \mathrm{~b}$ and $2 \mathrm{~b}$ were tested on a reduced panel dataset of 80 incumbent pharmaceutical firms over the 1994-2000 period. The above two samples are unbalanced due to horizontal M\&As between incumbent pharmaceutical firms during the periods of observation. As a horizontal M\&A took place, both the acquired and the acquiring firms were kept in the sample and treated as unbalanced data up to the merger or acquisition year.

\subsubsection{Dependent Variables}

Biotechnology Patents. A firm's new technology or technological novelty is usually measured by patents (Ahuja, 2000a; Baum et al., 2000; Hagedoorn and Duysters, 2002b; Phelps, 2010; Vanhaverbeke et al., 2009, 2012). Patents are directly related to inventiveness (Hagedoorn and Cloodt, 2003; Walker, 1995) and represent an externally validated measure of technological novelty (Griliches, 1990). In this study, we focus specifically on the number of annual biotechnology patents (Biotechnology Patents) granted to an incumbent pharmaceutical firm so as to proxy for its innovative output within the new biotechnology regime (also see Nicholls-Nixon and Woo, 2003; Rothaermel and Hess, 2007). Our measure of Biotechnology Patents is based on successful patent applications, i.e., granted patents. The application date of a patent is only reported when the patent is successfully granted. On average it may take three years for the USPTO to grant a patent after it was originally applied for by an inventing firm. In contrast, there is essentially no lag time between the completed invention and the patent application date, which is on average no more than three months (Darby and Zucker, 2010). Thus, the patent application date is closely tied to the timing of the new knowledge creation and it should be used as the relevant time placer for patents (Hall et al., 2001; Trajtenberg, 1990). Accordingly, we assigned a granted biotechnology patent to the particular year in which the patent was originally applied for. For instance, a biotechnology patent applied for in 2000 but granted in 2003 is considered a 2000 patent.

Biotechnology Product Announcements. Another, non-patent based measure of an incumbent pharmaceutical firm's innovative output within the new biotechnology regime is Biotechnology Product Announcements, proxied by the annual count of new product announcements in the area of biotechnology introduced by the firm to the market. In contrast with the creation of new technology as an indicator of intermediate output (Ahuja and Katila, 2001; Faems et al., 2005), a firm's successful introduction of new products in the market serves as a relatively direct measure of the commercial value generated by new technological innovations and thus an indicator of the firm's final innovative output (Ahuja and Katila, 2001; Nerkar, 2003; Rosenkopf and Nerkar, 2001). The data for biotechnology product announcements in our study were available for the 1994-2000 time frame. 


\subsubsection{Independent Variables}

Structural Holes. The structural holes in a firm's ego network is measured by efficiency (Burt, 1992: 51-53), i.e., the ratio of nonredundant contacts (the number of which gives the effective size of the network) to all primary contacts the firm is connected to in the network. This measure is computed as,

$$
\left[\sum_{\mathrm{j}}\left[1-\sum_{\mathrm{q}} \mathrm{P}_{\mathrm{iq}} \mathrm{M}_{\mathrm{iq}}\right]\right] / \mathrm{C}_{\mathrm{i}}, \quad \mathrm{q} \neq \mathrm{i}, \mathrm{j}
$$

where $P_{\text {iq }}$ is the proportion of i's relations invested in the connection with contact $\mathrm{q}, \mathrm{M}_{\mathrm{iq}}$ is the marginal strength of the relationship between contact $\mathrm{j}$ and contact $\mathrm{q}$, and $\mathrm{C}_{\mathrm{i}}$ is the total number of contacts for firm $\mathrm{i}$ (as we used binary data for contact relations, values of $\mathrm{M}_{\mathrm{iq}}$ are set to one if the relationship is present and zero otherwise). Higher values for this ratio suggest that firm i's ego network is rich in structural holes and that its partners are disconnected to each other. The above efficiency ratio varies from a maximum of 1 , indicating that every contact in the network is nonredundant, to a minimum of 0 , reflective of high contact redundancy and therefore low efficiency. For firms without any $R \& D$ alliance partners, the ratio is set to 0 (Ahuja, 2000a).

Indirect Ties. We measure a focal firm's indirect ties as the number of other firms in the network that the focal firm was connected to at path distances of two. We choose this measurement instrument for two main reasons. First, in line with the idea of local ties as argued by Baum et al. (2005) and Sorenson and Stuart (2008), indirect ties that are connected to the focal firm through a common partner (i.e., a path length of two) are considered to be a particular type of local ties. Conversely, indirect ties at path distances of greater than two are defined as distant ties. In their study on the information value of interfirm R\&D alliances, Hagedoorn et al. (2011) suggest that a focal firm is not likely to receive useful information from distant ties indirectly, passed on through intermediaries, as the information needs to travel a long way through the network from the distant ties to the focal firm. Thus, we focus on indirect ties at path distances of two that bring much more significant information value to the focal firm than those ties with a path length longer than two.

Second, following Ahuja (2000a), indirect ties are characterized by a dual role, not only as resources that extend the focal firm's informational reach in an alliance network, but also as competitors in terms of using similar information. If the same information can also be used profitably by indirect ties and one firm's use of it precludes its most fruitful use by another, then the information benefits from indirect ties that accrue to the focal firm will be substantially reduced. In our study, the large-small-large structure of interfirm R\&D alliance network in the pharmaceutical industry, as illustrated in Figure 4.1, constitutes an especially appropriate 
context to examine the dual role played by indirect ties. In Figure 4.1, a focal pharmaceutical firm builds three direct ties to biotechnology companies A, B, and C. The focal firm also has three indirect ties-incumbent pharmaceutical firms $X$, $\mathrm{Y}$, and $\mathrm{Z}$ that it can reach in the network through its two partners, biotechnology companies B and C. Further, there is some connectivity between the focal firm's partners (biotechnology companies A and B; biotechnology companies A and C), thereby reducing structural holes (from the focal firm's perspective). As seen in Figure 4.1, both the focal firm and its indirect contacts are incumbent pharmaceutical firms. To the extent that incumbent pharmaceuticals are often pursuing similar leads based on new technological opportunities, the indirect contacts represent intense competition for the focal firm in using the same information. Hence, in the pharmaceutical industry network, an investigation of indirect ties that are connected to the focal firm through a common partner can provide an elucidation of the dual role as embodied in indirect ties.

\section{Figure 4.1 Illustration of interfirm R\&D alliance network in the industry}

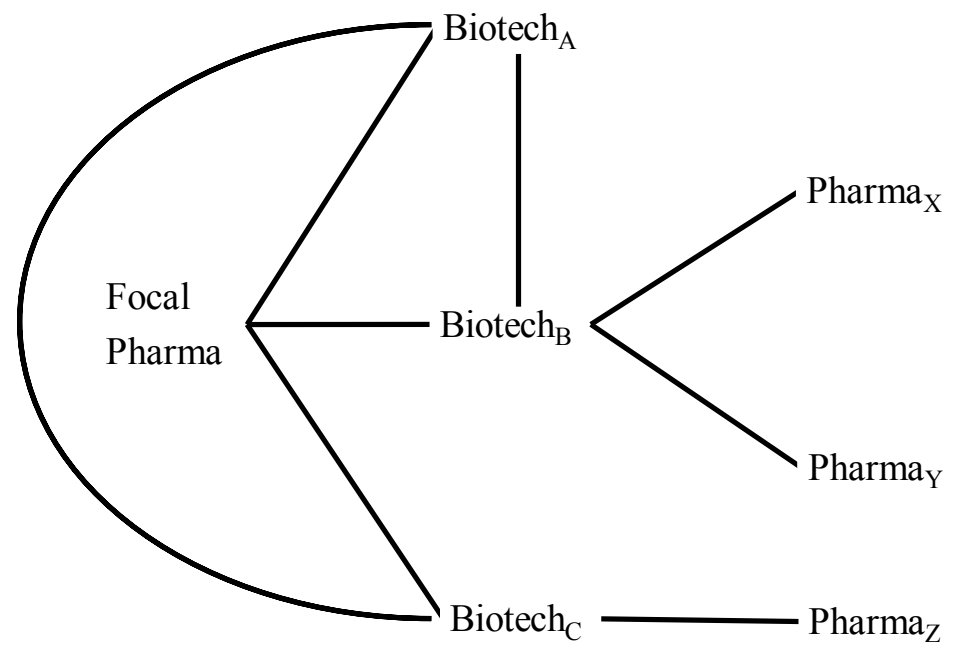

\subsubsection{Control Variables}

Direct Ties. The variable of direct ties is included as one dimension of interfirm network structure that can influence a focal firm's innovative output (Ahuja, 2000a). Direct ties are measured as the number of direct partners of a focal firm, i.e., the number of contacts to which a focal firm is directly connected to in the alliance network. 
Prior research suggests that firms' direct ties can reinforce their innovative performance by providing complementary knowledge from alliance partners and by producing scale economies in research through interfirm collaborations (Ahuja, 2000a).

R\&D Intensity. Both a firm's internal and external R\&D investments contribute significantly to its innovative output. We controlled for the impact of a pharmaceutical firm's internal $R \& D$ investments by including its $R \& D$ intensity, measured as annual R\&D expenditures divided by firm revenues. Previous studies suggest that $R \& D$ expenditures are primarily taken as an input indicator of a firm's efforts in internal R\&D that might eventually lead to innovative output (Ahuja, 2000a; Griliches, 1990, 1998; Hitt et al., 1997). Moreover, internal R\&D investments are conducive to a firm's absorptive capacity (Cohen and Levinthal, 1989, 1990), which influences its ability to exploit the externally acquired knowledge or resources from alliance partners (Zaheer and Bell, 2005).

R $\approx D$ Acquisitions. $\mathrm{R} \& \mathrm{D}$ acquisitions serve as an alternative to $\mathrm{R} \& \mathrm{D}$ alliances for firms to access external knowledge or technology sources that can impact on their innovative performance (Hagedoorn and Duysters, 2002b; Vanhaverbeke et al., 2002). We controlled for such effects by including the annual number of R\&D acquisitions of new biotechnology companies undertaken by an incumbent pharmaceutical firm. Following Higgins and Rodriguez (2006), we identified R\&D acquisitions through checking the business description of acquisition transactions as registered in SDC Platinum, which suggested that the acquired biotechnology companies were targeted for their R\&D capabilities.

Firm Nationality. To control for institutional and country-specific differences with respect to propensities for innovation and $\mathrm{R} \& \mathrm{D}$ alliance strategies, we included two indicator variables based on the location of firm headquarters. One indicator variable is coded as 1 if a pharmaceutical firm is headquartered in the United States $(1=$ U.S. Firm $)$, and the other indicator variable is coded as 1 if a pharmaceutical firm is headquartered in Europe $(1=$ European Firm), with a Japanese location as the reference category. The global representation of the two samples is reflected in the fact that about $1 / 3$ of the firms are U.S. based, slightly less than $1 / 3$ are European based, with the remaining headquartered in Japan.

Pharmacentical Firm. The global pharmaceutical industry is made up of both specialized pharmaceutical firms and more diversified, mainly chemical, conglomerates. A firm's level of diversification indicates its previous experience in entering new businesses (Chang and Singh, 1999; Yip, 1982), and therefore may influence the degree to which it attempts to innovate within the new biotechnology regime. Thus, we controlled for a pharmaceutical firm's level of diversification by coding the firm as 1 if it is a specialized pharmaceutical company ( 1 = Pharma Firm), and 0 otherwise. Specialized pharmaceutical companies are firms that are active in SIC 2834 (Pharmaceutical Preparations Manufacturing), whereas a conglomerate might 
engage, for instance, in both SIC 2834 and SIC 2890 (Chemical Products Manufacturing). About one half of the firms in both samples are fully specialized.

Firm Size. Firm size has been shown to exert a direct effect on innovative output (Acs and Audretsch, 1988; Freeman and Soete, 1997). Previous studies have also examined how factors associated with firm size influence a firm's incentive to invest in R\&D (Cohen and Klepper, 1996; Cohen and Levinthal, 1989; Schumpeter, 1942; Teece, 1982, 1992). To control for these effects, we included firm size, proxied by the total number of employees (Employees), in the regression equations.

Firm Performance. We also allowed for the profitability of incumbent pharmaceutical firms, measured by their Return on Equity.

Year Fixed Effects. Innovative output may increase or decrease with timevarying factors which may influence all sample firms. To control for such period effects, we included Year Fixed Effects for each year.

The above-mentioned control variables were included in the regression equations of incumbent pharmaceutical firms' innovative output in terms of biotechnology patents as well as biotechnology product announcements. Two additional control variables, pre-sample innovation and technological capital, as argued below, were treated separately. The former was included in the regression for biotechnology patents and the latter included for biotechnology product announcements.

Pre-sample Innovation. Blundell et al. (1995) argue that the 'permanent' capabilities of firm innovation should be reflected in the pre-sample history of innovative output. Hence, we included both the pre-sample average patent count, i.e., Presample Mean (the average number of biotechnology patents by a pharmaceutical firm in the period from 1974 to 1985) and a Pre-sample Dummy (1 = if the firm had ever patented prior to 1980) to proxy for the unobserved heterogeneity in incumbent pharmaceutical firms' patenting rate (Blundell et al., 1995, 2002).

Technological Capital. Patents are often considered as an indicator of important technology inputs in the new product development process (Coombs et al., 2009; Griliches, 1990; Rothaermel and Deeds, 2004), we thus included technological capital in the regression for incumbent pharmaceutical firms' biotechnology product announcements. In line with previous studies (Rothaermel and Deeds, 2004; Vanhaverbeke et al., 2009), technological capital is operationalized by using a moving window approach of five years, i.e., biotechnology patents received in the five years prior to the year of observation. Moreover, since technological capital can serve as a proxy for firm innovativeness (Baum et al., 2000; Rothaermel and Deeds, 2004), including this variable provides the additional benefit of allowing for the unobserved heterogeneity in the pharmaceutical firms' innovative performance with respect to the development of new products. 


\subsubsection{Estimation Technique}

The dependent variable in this study, a focal firm's innovative output, as measured by the number of biotechnology patents as well as biotechnology product announcements, is a count variable taking only non-negative integer values. To model count data, the linear exponential or log-link family is a good alternative (Cameron and Trivedi, 1986). On account of the overdispersion phenomenon usually displayed by a firm's patent counts and new product announcements, the negative binomial estimation provides a better fit for the data than the more restrictive Poisson model (Hausman et al., 1984).

In estimating count panel data model in this study, either fixed- or randomeffects specification can, in theory, be used to control for firm-specific unobserved heterogeneity (Greene, 2003; Gujarati, 2003). One difficulty with the randomeffects specification is its underlying assumption that firm-specific unobserved heterogeneity is uncorrelated with regressors of interest. However, some unobserved characteristics of a focal firm may be correlated with both alliance network variables and the firm's innovative output, thereby leading to a potential endogeneity bias (Ahuja, 2000a; Hamilton and Nickerson, 2003; Schilling and Phelps, 2007). To alleviate such endogeneity bias, we used the fixed-effects specification so as to estimate the model parameters consistently (Hamilton and Nickerson, 2003; Winkelmann, 2008). Further, we included the pre-sample history of firm patenting (Blundell et al., 1995, 2002) to allow for the unobserved heterogeneity of a pharmaceutical firm's biotechnology patents. Likewise, technological capital was included, as a proxy for firm innovativeness (Rothaermel and Deeds, 2004), to control for the unobserved heterogeneity in a pharmaceutical firm's innovative output in terms of biotechnology product announcements. In addition, to alleviate a potential simultaneity bias, a one-period lag is employed on all explanatory variables in estimating an incumbent pharmaceutical firm's innovative output in terms of biotechnology patents as well as biotechnology product announcements.

\subsection{RESULTS}

Tables 4.1-a and 4.1-b depict the descriptive statistics and the bivariate correlation matrixes, respectively, for incumbent pharmaceutical firms' two types of innovative output within the new biotechnology regime, i.e., new technology, as measured by biotechnology patents, and new products, measured by biotechnology product announcements. The bivariate correlations among the explanatory variables are, with the exception of direct ties and indirect ties ${ }^{68}$ quite low, well below the cut-off

\footnotetext{
${ }^{68} \mathrm{It}$ is not uncommon that alliance network variables such as direct ties, indirect ties, and structural holes (or density) are highly correlated (see e.g., Ahuja, 2000a; Koka and Prescott, 2002, 2008). 
R\&D Alliance Network Structure and Innovative Output

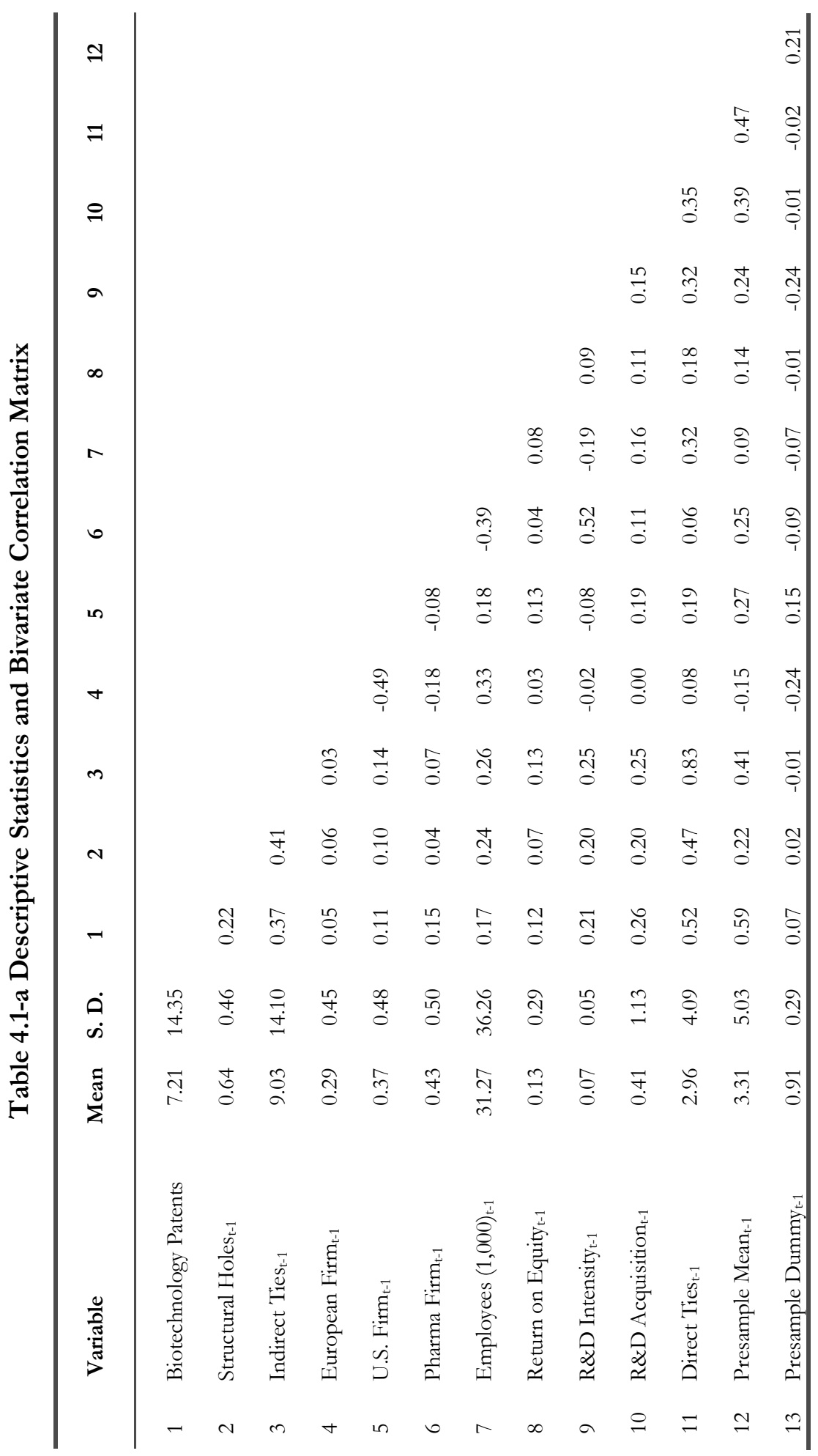




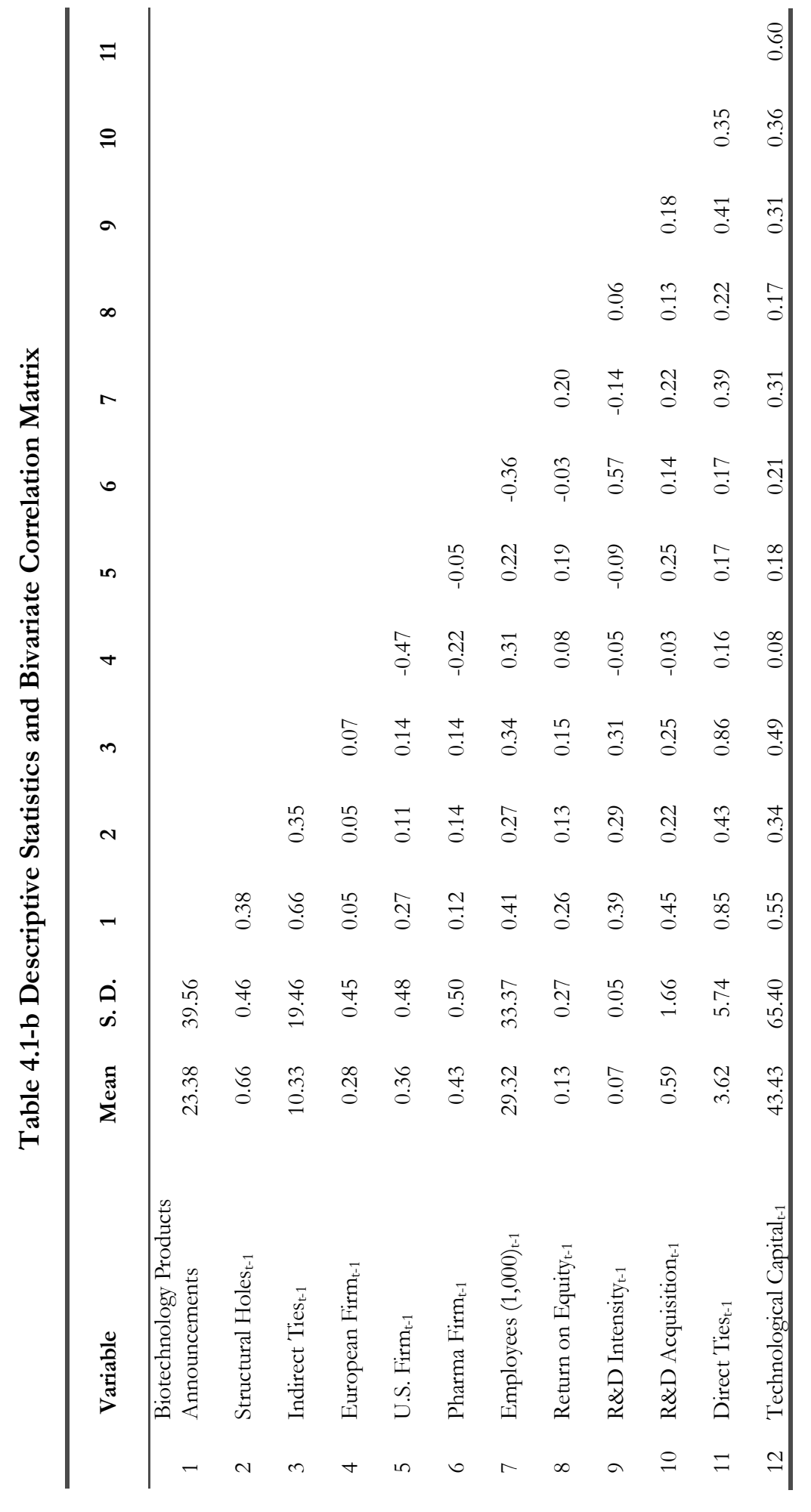


point of $\mathrm{r}<0.70$ (Cohen et al., 2003). Moreover, to assess the severity of multicollinearity, we computed variance inflation factors (VIFs), with an average VIF value of 1.91 and a maximum VIF value of 4.49 in the regression analysis of biotechnology patents, and an average VIF value of 2.12 and a maximum VIF value of 5.87 in the case of biotechnology product announcements. All VIF values are well below the cut-off point of 10 (Cohen et al., 2003), indicating that multicollinearity does not pose a problem for our estimation.

Table 4.2 presents the results of the regression analyses using fixed-effects negative binomial estimation for incumbent pharmaceutical firms' innovative output in terms of biotechnology patents (Models 1a through 3a) and biotechnology product announcements (Models $1 \mathrm{~b}$ through $3 \mathrm{~b}$ ). Models $1 \mathrm{a}$ and $1 \mathrm{~b}$ provide the basic specification including only the control variables. Models $2 \mathrm{a}$ and $2 \mathrm{~b}$ introduce the impact of structural holes spanned by firms on their innovative output in terms of biotechnology patents and biotechnology product announcements, respectively. Models $3 \mathrm{a}$ and $3 \mathrm{~b}$ add the indirect tie variables and represent the full estimation models. Each subsequent model demonstrates a significant improvement over the basic specification. In the remainder of this study, we use the full models, i.e., Models $3 \mathrm{a}$ and $3 \mathrm{~b}$, to discuss the regression results.

In Hypothesis 1a, we postulate that the greater the structural holes spanned by a focal firm in an alliance network, the greater the firm's subsequent innovative output in terms of new technology. As shown by Model 3a in Table 4.2, the estimated coefficient on structural holes is positive and marginally significant $(p<0.10)$ with respect to incumbent pharmaceutical firms' biotechnology patents, supporting Hypothesis 1a. By contrast, Model 3b in Table 4.2 suggests that structural holes are negatively and significantly $(p<0.05)$ associated with incumbent pharmaceutical firms' biotechnology product announcements, confirming Hypothesis 1b's prediction of a negative relationship between structural holes and innovative output in terms of new products. The above findings indicate that an $R \& D$ alliance network rich in structural holes is more advantageous for incumbent pharmaceutical firms' creation of new technology, whereas a dense, interconnected network of R\&D alliances turns out to be more beneficial for their development of new products in the market.

Hypothesis $2 \mathrm{a}$ proposes that the more the number of indirect ties maintained by a focal firm, the greater the firm's subsequent innovative output in term of new technology. Model 3a shows a predicted positive effect of indirect ties on incumbent pharmaceutical firms' biotechnology patents. Yet the coefficient for indirect ties is statistically insignificant. Hypothesis $2 \mathrm{~b}$, predicting a negative impact of a focal firm's indirect ties on its innovative output in term of new products, is confirmed. As seen in Model 3b, the estimated coefficient on indirect ties is negative and significant $(p<0.05)$, indicating that increasing the number of indirect ties in 


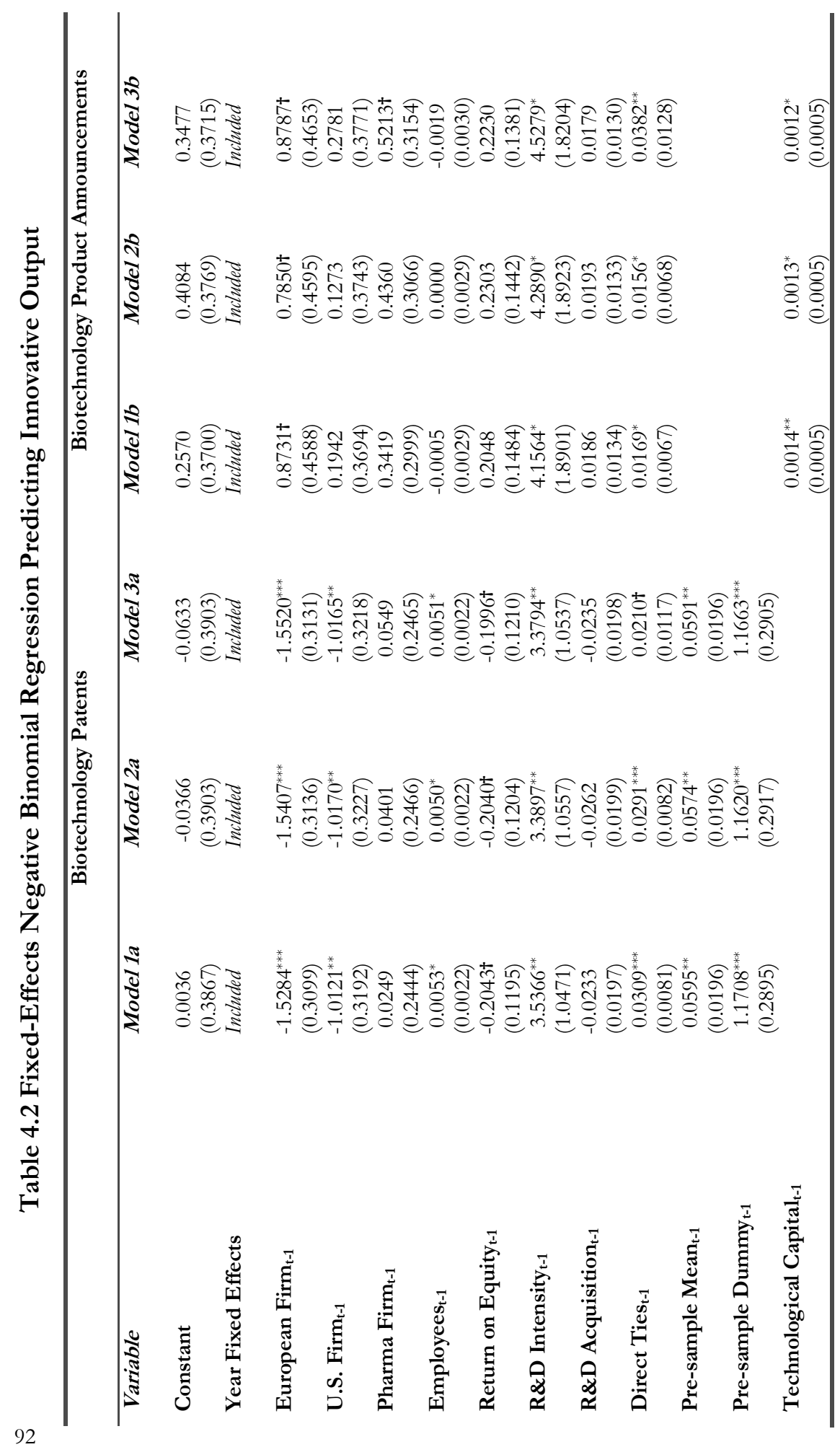


R\&D Alliance Network Structure and Innovative Output

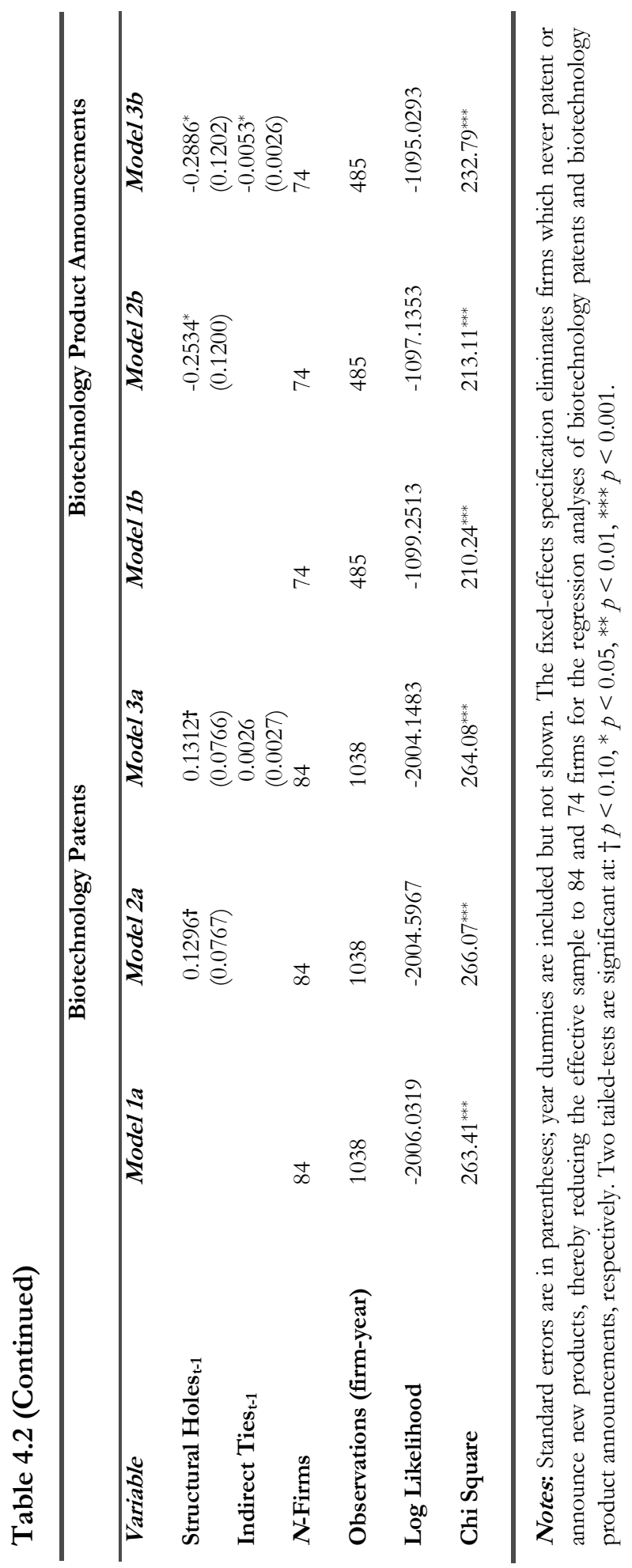


an R\&D alliance network actually reduces incumbent pharmaceutical firms' biotechnology product announcements.

With regard to the effects of control variables, we found largely consistent results across various models in Table 4.2. Direct ties have a significant positive effect on incumbent pharmaceutical firms' innovative output with respect to biotechnology patents $(p<0.10)$ and biotechnology product announcements $(p<$ 0.01). These findings are consistent with prior research which suggests that direct ties maintained by firms can enhance their innovative performance (Ahuja, 2000a; Vanhaverbeke et al., 2012). A significant, positive relationship is also found between R\&D intensity and firm innovative output in terms of biotechnology patents $(\phi<0.01)$ as well as biotechnology product announcements $(p<0.05)$, suggesting that internal R\&D investments contribute significantly to firm innovation. The effects of firm size and firm profitability, as measured by employees and return on equity, are both significant $(p<0.05$ and $p<0.10$, respectively) with respect to incumbent pharmaceutical firms' biotechnology patents, albeit in different directions. The estimated coefficients on the pre-sample patent variables, i.e., the presample mean and the dummy, are positive and significant $(p<0.01$ and $p<0.001$, respectively, Model 3a), thus it is important to control for the unobserved heterogeneity in the innovative capabilities with which firms entered the sample. Finally, technological capital has a positive and significant $(p<0.05$, Model $3 \mathrm{~b})$ effect on biotechnology product announcements, indicating that firm patenting serves as an important technology input in the new product development process.

\subsection{DISCUSSION AND CONCLUSIONS}

The goal of our study is to examine the impact of two aspects of interfirm alliance network structure - structural holes and indirect ties-on a focal firm's innovative output. We utilize a contingency approach by considering the various dimensions of a focal firm's innovative output — new technology and new products-and identify their divergent requirements on the focal firm's network structure of interfirm R\&D alliances in the global pharmaceutical industry. Specifically, we focus on incumbent pharmaceutical firms as the focal actors in the industry network. In distinguishing the two types of firm innovative output, with new technology being comparatively exploratory and new products more exploitative in nature, we make two contingency arguments accordingly. First, based on the distinct benefits provided by network closure vs. structural holes, firms can enhance the creation of new technology by configuring them into an R\&D alliance network rich in structural holes, whereas a dense, interconnected network of interfirm R\&D alliances is expected to be more valuable for their development of new products in the market. Second, in light of the dual role of indirect ties, the number of indirect ties main- 
tained by firms in an R\&D alliance network is positively related to their creation of new technology, while firms with more indirect ties may experience adverse effects on their innovative output in terms of new products. The results from our empirical analysis confirm, to a great extent, the above contingency framework. More specifically, our findings on the relative efficacy of network closure vs. structural holes suggest that an R\&D alliance network rich in structural holes is more advantageous for incumbent pharmaceutical firms' creation of new technology, whereas a dense network of interfirm R\&D alliances turns out to be more beneficial for their development of new products. Concerning the dual role of indirect ties, our estimation results indicate that incumbent pharmaceutical firms with more indirect ties in an R\&D alliance network are actually associated with reduced innovative output in terms of new products, while no significant effect is found in the case of new technology.

Our empirical findings provide important implications for the literature on interfirm network structure and firm innovation. On the one hand, the results for the relative efficacy of network closure vs. structural holes for firm innovation reinforce the idea that neither a dense nor a sparse network of interfirm alliances is universally beneficial and the effectiveness of different forms of network structure can only be understood relative to a particular context (Adler and Kwon, 2002; Ahuja, 2000a; Burt, 2000; Rowley et al., 2000). For firms striving to enhance the creation of new technology, which is an upstream R\&D activity along the value chain and thus characterized as a form of knowledge generation or exploration, speedy access to diverse information, relative to the development of trust and collaborative norms, is more essential to success. Therefore, a structural-hole-rich network of R\&D alliances is more valuable for a firm's creation of new technology. By contrast, in the development of new products in the market, which is the downstream R\&D activity along the value chain and more related to knowledge application or exploitation, it appears that the benefits of developing trust and overcoming partner opportunism outweigh the disadvantages of less information diversity. Hence, a dense alliance network, compared with a network rich in structural holes, turns out to be more advantageous for new product development by firms. In a nutshell, the above results of our study contribute to a better understanding of under what conditions firms mandate the distinct benefits provided by the different forms of network structure.

On the other hand, in contrast with prior research that has predominately demonstrated the benefits from indirect ties as sources of information (Karamanos, 2012; Salman and Saives, 2005; Vanhaverbeke et al., 2012), our findings shed insights into the dual role of indirect ties (Ahuja, 2000a) as potential competitors as well as information sources for a focal firm. First, depending on the content of information provided by indirect ties, they may contribute differently to the vari- 
ous types of a focal firm's innovative output. In our study, given the large-smalllarge structure of $\mathrm{R} \& \mathrm{D}$ alliance network for incumbent pharmaceutical firms, their indirect contacts are, more often than not, other large, established pharmaceuticals which are also more experienced at downstream R\&D activities, such as FDA regulatory management, marketing and distribution of new drugs (Roijakkers et al., 2005; Rothaermel and Boeker, 2008; Rothaermel, 2001), than upstream R\&D. As such, information from these indirect contacts is more valuable for the development of new products in the market, but of relatively less value for the creation of new technology. Second, in many networks, indirect ties act not only as information sources but also as competitors for a focal firm in terms of using similar information (Ahuja, 2000a). In our network analysis, indirect ties of a focal pharmaceutical firm tend to be other large incumbent pharmaceuticals, which represent intense competition for the focal firm in terms of using the same information in the alliance network. As a consequence, the information benefits from these indirect ties are substantially reduced, given that one firm's use of the information precludes its most fruitful use by another. A final aspect, closely related to the previous one, is that indirect ties to competitors often entail risks of spillovers or leakages of proprietary knowledge held by a focal firm (Gulati and Garguilo, 1999; Vanhaverbeke et al., 2012). As shown by our results, indirect ties to competitors actually inhibit an incumbent pharmaceutical firm's innovative output in terms of new products, as the indirect ties cause leakages of proprietary knowledge associated with the firm's new product development and jeopardize its core competences and competitiveness in the market. Taken together, our study contributes to illuminating the dual role of indirect ties and suggests that the impact of a firm's indirect ties on its innovative output is dependent on the nature of the ties as well as the content of the information provided (Ahuja, 2000a).

From a managerial perspective, our findings offer important implications for the network configuration of interfirm $R \& D$ alliances towards the improvement of firm innovativeness. Our study suggests that whether a dense or a sparse network constitutes an optimal network structure for firms to embed themselves in is contingent on the various types of innovative output, i.e., new technology and new products. Managers need to assess the conditions under which firms require the distinct benefits provided by the different forms of network structure. When developing collaborative norms and reducing partner opportunism are important, a dense network is more valuable; when information diversity is crucial, a sparse network is more beneficial (Ahuja, 2000a). Moreover, managers should attend to the dual role of indirect ties as both information sources and potential competitors in interfirm alliance networks. Our study reveals that indirect ties maintained by firms, especially with their competitors, could cause risks and liabilities that may counteract or even outweigh the benefits from these indirect ties as sources of 
information. In this respect, a network of partners exclusively tied to a focal firm, relative to one in which the focal firm's partners have other partners (i.e., indirect ties), provides more control advantage over alliance partners (Ahuja, 2000a; Brass and Burkhardt, 1992) so as to mitigate competition and information leakage and is thus considered to be more beneficial. Therefore, managers have to be fully aware of the dual role reflected by indirect ties and determine under what circumstances control advantage over alliance partners is more essential to success than the information benefits provided by indirect ties, and vice versa.

Our study is subject to several limitations which suggest possible avenues for future research. The restriction of the sample to a single industrial context raises the question of the generalizability of our findings, thus further efforts could be made to conduct research in other high-technology industries. In this paper, we introduce the distinction between a focal firm's two types of innovative output, i.e., new technology and new products, with the former being conceptualized as comparatively exploratory and the latter as more exploitative in nature, as a contingency factor in determining the focal firm's appropriate network structure of interfirm R\&D alliances. However, we acknowledge that each new technology or new product may not be equally exploratory or exploitative and can thus be operationalized as a multidimensional construct. For instance, previous studies have categorized new technology into core and noncore technologies (Vanhaverbeke et al., 2009, 2012), and new products into incremental and radical innovations (QuintanaGarcía and Benavides-Velasco, 2011; Sternitzke, 2010). Future research could probe deeply into the constituent structure of innovative outcomes so as to yield additional insights into the facilitative network structure of interfirm alliances. Further, in regard to the pharmaceutical industry network, small biotechnology companies, mostly as direct partners of a focal pharmaceutical firm, may also engage in R\&D alliances with upstream academia (Baum et al., 2000; Gilsing and Nooteboom, 2006). Put differently, in addition to large, established pharmaceuticals, indirect ties may as well be universities and research institutes which usually act as valuable information sources of science or fundamental research rather than as potential competitors for the focal pharmaceutical firm. Incorporating these interorganizational alliances could be a fruitful line of future inquiry into the dual role of indirect ties in firm innovation. Finally, the analytic focus in our study is on alliance network at the interfirm level. It would be also intriguing to investigate collaborative networks at alternative levels of analysis, such as interpersonal and intraorganizational networks, and their interactions with interfirm alliance network. Such multi-level network analysis is of increasing popularity and constitutes an interesting avenue for future research (Phelps et al., 2012). 



\section{CHAPTER 5}

\section{CONCLUSIONS}

\subsection{OVERVIEW OF MAIN FINDINGS AND IMPLICATIONS}

This dissertation aims to contribute to a better understanding of the role of internal $R \& D$, external $R \& D$ (and its interactions with internal $R \& D$ ), and interfirm R\&D alliance network in firm innovation. To this end, three research questions have been developed and empirically examined in Chapters 2, 3, and 4, respectively. Below is an overview of the main findings and implications presented in the three studies.

\subsubsection{The Role of Internal R\&D in Firm Innovation}

The goal of Study 1 (Chapter 2) is to revisit the classic research question regarding the lag structure of the patents-R\&D relationship through an examination of the impact of internal R\&D on firm patenting in the context of the global pharmaceutical industry. Based upon the far-reaching influence of older knowledge in new knowledge creation and a real options logic for managing $R \& D$ investment strategies of firms, we propose the following main hypothesis in Study 1:

Hypothesis: Taking patents as an output indicator of firms' innovativeness, lag effects of firms' internal R\&D investments are expected to impact their long run knowledge production process.

Our empirical analysis, using both a multiplicative distributed lag model and a dynamic linear feedback model, differs from previous work that examines the patents-R\&D relationship in three aspects. First, our estimation results exhibit direct evidence on lagged $R \& D$ effects, with the first lag $(t-1)$ of $R \& D$ being significant in all distributed lag specifications. Evidence for the contribution of the first lag of R\&D to the current year's patent counts is of more than $25 \%$ of the total R\&D elasticity. Second, a U-shaped lag structure of the patents-R\&D relationship is identified across the various estimations of the multiplicative distributed lag model (except for PSM I). This finding suggests a potential long-run effect of 
internal R\&D investments on firm patenting. Finally, the estimation results for the dynamic linear feedback model, especially from the PSM estimator, coincide with those from the multiplicative distributed lag model, with a fairly low depreciation rate of approximately $10 \%$ of internal $\mathrm{R} \& \mathrm{D}$ investments over time and accordingly an overall long-run effect of internal R\&D on firm patenting. In short, our empirical findings, from both the multiplicative distributed lag model and the dynamic linear feedback model, provide evidence for not only lag effects from more recent R\&D but, in support of our main hypothesis, also a potential long-run effect of internal $R \& D$ investments in the distant past on the knowledge production or innovation process of incumbent pharmaceutical firms.

The above results illustrate a cumulative knowledge production or innovation process of incumbent pharmaceutical firms, with current patent production being historically dependent on past investments in internal R\&D. Our results are consistent with prior research which suggests that not only recent knowledge is important for new knowledge creation, but that older knowledge in knowledge stock accruing from long past R\&D investments may also be valuable for firm innovativeness (Katila, 2002; Nerkar, 2003). This finding echoes the real options logic for managing R\&D investment strategies of firms (McGrath, 1997; McGrath and Nerkar, 2004), according to which early R\&D investments by firms in a new area with technical uncertainty may be influential in their knowledge production or innovation process over a long-term horizon. Subsequent R\&D investments in the same area can further reduce technical uncertainty and reinforce the value of options opened earlier. Alternatively, firms may choose to wait or even exit the area they invested before. In this way, the earlier investments in R\&D can still serve as part of the firms' stock of knowledge, which may contribute substantially to their later innovations when conditions favor its use.

From a managerial perspective, our study offers important insights into the cumulative knowledge production or innovation process of firms. In addition to emphasizing recent investments in internal R\&D to stay abreast of the latest, cutting edge technologies, decision-makers in firms should also adopt a long-term perspective for organizing $R \& D$ investment strategies. Through periodically reviewing and recombining older, useful but under-utilized knowledge, firms can increase their creation of new knowledge (Garud and Nayyar, 1994; Nerkar, 2003). However, it is noteworthy that older knowledge tends to be lost over time due to lack of adequate organizational memory, inaccurate recording, and turnover in R\&D personnel (Argote, 1999). As a consequence, for firms to effectively transfer knowledge across time, they need to build up the 'transformative capacity' which pertains to the choice of knowledge for future use, its maintenance over time, and the reactivation and synthesis of such knowledge when required (Garud and Nayyar, 1994; Nerkar, 2003). In this way, by making better use of older knowledge 
and actively maintaining stock of knowledge for future use, firms can enhance their returns from internal R\&D investments.

\subsubsection{The Role of Internal and External R\&D in Firm Innovation}

Study 2 (Chapter 3) seeks to provide empirical evidence on the conditions under which there is complementarity or substitutability between internal and external R\&D strategies within the context of the global pharmaceutical industry. In particular, we focus on incumbent pharmaceutical firms, examining the contingency role of their in-house R\&D efforts, as a critical source of absorptive capacity, in determining the condition under which there is complementarity or substitutability between the various innovation strategies. Hence, the main hypothesis (i.e., Hypothesis 3) proposed in Study 2 is as follows:

Hypothesis: There is a contingent relationship between internal and external ReD strategies in shaping a firm's innovative output: internal and external R\&D strategies are complementary innovation activities at higher levels of in-house R\&D investments, whereas at lower levels of in-house R\&D investments, they are substitutive innovation activities.

Our empirical analysis suggests that, instead of a clear-cut answer to the question whether internal and external $\mathrm{R} \& \mathrm{D}$ are complementary or substitutive innovation activities, there appears to be a contingent relationship between internal and external R\&D strategies in shaping a firm's innovative output. The results from our study indicate that the level of in-house $R \& D$ investments is a contingency variable that critically influences the association between internal and external $R \& D$ strategies. More specifically, internal $R \& D$ and external $R \& D$, through either $R \& D$ alliances or $R \& D$ acquisitions, are complementary innovation activities at higher levels of in-house R\&D investments, whereas at lower levels of in-house $R \& D$ efforts, internal and external $R \& D$ activities turn out to be substitutive strategic options. These findings highlight the complexity of understanding the relationship between internal and external $\mathrm{R} \& \mathrm{D}$ strategies, where the existence of a potential complementarity is contingent.

Our findings provide important implications for the literature on complementarity or substitutability between various innovation strategies. A large body of research literature has examined the relationship between internal R\&D and external technology sourcing strategies, so far focusing mainly on either complementarity or substitutability. However, as suggested by Cassiman and Veugelers (2006), understanding under what conditions different $R \& D$ strategies may in fact be complementary is more important than merely determining what activities are 
complementary per se. Given the scarcity of prior work on this line of research (exceptions are Cassiman and Veugelers, 2006; Hess and Rothaermel, 2011), we contribute to the existing literature by advancing and testing the contingency role of a firm's in-house R\&D efforts in determining the condition under which there may actually be complementarity or substitutability between its various R\&D strategies.

From a managerial perspective, our empirical findings provide implications for firms in organizing their internal and external R\&D strategies to match the rapidly changing technological environment. In order to continually update a firm's technological know-how and capabilities, managers often choose to pursue internal and external R\&D strategies in parallel, in hope of a potential complementarity between various innovation activities. Such complementarity, unfortunately, does not always exist. Our results show that it is contingent on the development of a firm's absorptive capacity, which is mainly determined by how much the firm would invest in its in-house R\&D. In other words, in-house R\&D efforts play a key role in the interrelationship between internal and external R\&D strategies to influence firms' innovative output. Managers who can leverage external sources of innovation to adapt to the relentlessly changing technological environment and, at the same time, lay emphasis on in-house $R \& D$ endeavors will be most successful in building up sustainable innovative capabilities of firms.

\subsubsection{The Role of R\&D Alliance Network in Firm Innovation}

The goal of Study 3 (Chapter 4) is to examine the impact of two aspects of interfirm alliance network structure-structural holes and indirect ties-on a focal firm's innovative output. We utilize a contingency approach by considering the various dimensions of a focal firm's innovative output-new technology and new products-and identify their divergent requirements on the focal firm's network structure of interfirm R\&D alliances. Specifically, we focus on incumbent pharmaceutical firms as the focal actors in the pharmaceutical industry network of interfirm R\&D alliances. In distinguishing the two types of firm innovative output, with new technology being comparatively exploratory and new products more exploitative in nature, we make two contingency arguments accordingly. First, based on the distinct benefits provided by network closure vs. structural holes, firms can enhance their creation of new technology by configuring them into an $\mathrm{R} \& \mathrm{D}$ alliance network rich in structural holes (Hypothesis 1a), whereas a dense, interconnected network of interfirm R\&D alliances is expected to be more valuable for their development of new products in the market (Hypothesis 1b). Second, in light of the dual role of indirect ties, the number of indirect ties maintained by firms in an $\mathrm{R} \& \mathrm{D}$ alliance network is positively related to their creation of new technology 
(Hypothesis 2a), while firms with more indirect ties may experience adverse effects on their innovative output in terms of new products (Hypothesis $2 \mathrm{~b}$ ).

The results from our empirical analyses confirm, to a great extent, the above contingency framework. More specifically, our findings on the relative efficacy of network closure vs. structural holes suggest that an R\&D alliance network rich in structural holes is more advantageous for incumbent pharmaceutical firms' creation of new technology, whereas a dense, interconnected network of interfirm $R \& D$ alliances turns out to be more beneficial for their development of new products in the market. Concerning the dual role of indirect ties, our estimation results indicate that incumbent pharmaceutical firms with more indirect ties in an R\&D alliance network are actually associated with reduced innovative output in terms of new products, while no significant effect is found in the case of new technology.

Our empirical findings provide important implications for the literature on interfirm network structure and firm innovation. On the one hand, the results for the relative efficacy of network closure vs. structural holes for firm innovation reinforce the idea that neither a sparse nor a dense network of interfirm alliances is universally beneficial and the effectiveness of different forms of network structure can only be understood relative to a particular context (Adler and Kwon, 2002; Ahuja, 2000a; Burt, 2000; Rowley et al., 2000). By showing that the optimal network structure for firms to embed themselves in is contingent on the various types of innovative output, our study contributes to a better understanding of under what conditions firms mandate the distinct benefits provided by the different forms of network structure. On the other hand, in contrast with prior research that has predominately demonstrated the benefits from indirect ties as sources of information (Karamanos, 2012; Salman and Saives, 2005; Vanhaverbeke et al., 2012), our findings shed insights into the dual role of indirect ties (Ahuja, 2000a) as potential competitors as well as information sources for a focal firm. First, depending on the content of information provided by indirect ties, they may contribute differently to the various types of a focal firm's innovative output. Second, in many networks, indirect ties act not only as information sources but also as competitors for a focal firm in terms of using similar information. A final aspect, closely related to the previous one, is that indirect ties to competitors often entail risks of spillovers or leakages of proprietary knowledge held by a focal firm. Taken together, our study contributes to illuminating the dual role of indirect ties and suggests that the impact of a firm's indirect ties on its innovative output is dependent on the nature of the ties and the content of the information provided (Ahuja, 2000a).

From a managerial perspective, our findings offer implications for the network configuration of interfirm R\&D alliances towards the improvement of firm innovativeness. Our study suggests that whether a dense or a sparse network con- 
stitutes an optimal network structure for firms to embed themselves in is contingent on the various types of innovative output, i.e., new technology and new products. Managers need to assess the conditions under which firms require the distinct benefits provided by the different forms of network structure. When developing collaborative norms and reducing partner opportunism are important, a dense network is more valuable; conversely, when information diversity is crucial, a sparse network is more advantageous (Ahuja, 2000a). Moreover, managers should attend to the dual role of indirect ties as both information sources and potential competitors in interfirm alliance networks. Our study reveals that indirect ties maintained by firms, especially with their competitors, would cause risks and liabilities that may counteract or even outweigh the benefits from these indirect ties as sources of information. In this respect, a network of partners exclusively tied to a focal firm, relative to one in which the focal firm's partners have other partners (i.e., indirect ties), provides more control advantage over alliance partners (Ahuja, 2000a; Brass and Burkhardt, 1992) so as to mitigate competition and information leakages and is thus considered to be more beneficial. Therefore, managers have to be fully aware of the dual role reflected by indirect ties and determine under what circumstances control advantage over alliance partners is more essential to success than the information benefits provided by indirect ties, and vice versa.

\subsection{LIMITATIONS AND SUGGESTIONS FOR FUTURE RESEARCH}

The three studies in this dissertation are subject to several limitations in common which suggest possible avenues for future research. First, the restriction of the sample to the pharmaceutical industrial context raises the question of the generalizability of our findings, thus further efforts could be made to conduct research in other high-technology industries such as information technologies and aerospace and defense (Hagedoorn, 2002).

Second, it is important to note that, despite their desirable properties, patent counts are an imperfect measure of a firm's innovative output. Since some inventions are not patentable and others are not patented for strategic reasons (Griliches, 1990), patents account for only a fraction of a firm's innovative output and the fraction may vary considerably across industries (Hall et al., 1986). Limiting our study to a single industrial sector-the pharmaceutical industry which is characterized by high R\&D intensity and high propensity to patent-minimizes problems related to inter-sectoral differences in patenting propensity. In addition, we used USPTO patent data for both U.S. and non-U.S. firms. Although U.S. patent data could imply a bias against non-U.S. firms, it is mentioned in the literature that, given the importance of the U.S. market, the patent protection offered by U.S. authorities, and the level of technological sophistication of the U.S. market, it is 
inevitable that non-U.S. firms, in particular leading large firms, file their patents in the USA (Hagedoorn and Cloodt, 2003; Patel and Pavitt, 1991). Moreover, as suggested by Ahuja and Katila (2001), to maintain a certain level of consistency, reliability and comparability, choosing one patenting system is preferred to using several patenting systems across nations.

Third, innovative outcome as measured by patents is often considered to be a merely intermediate output (Ahuja and Katila, 2001; Faems et al., 2005) from firms' upstream R\&D activity. In contrast, the final innovative outcome from the downstream R\&D activity is the successful introduction of new products in the market, which can serve as a relatively direct measure of the commercial value generated by new technological innovations. Although we have conceptualized patents as comparatively exploratory and new products as more exploitative in nature, we also acknowledge that each patent or new product may not be equally exploratory or exploitative and can thus be operationalized as a multidimensional construct. For instance, previous studies have categorized patents into exploratory and exploitative ones (Vanhaverbeke et al., 2009), and new products into incremental and radical innovations (Quintana-García and Benavides-Velasco, 2011; Sternitzke, 2010). Future research could probe deeply into the constituent structure of innovative outcomes to yield additional insights into the relationship between R\&D strategies and firm innovation.

Finally, it is noteworthy that not only the level of R\&D investments by firms influences their innovative output, but that the various components of R\&D may also have differential effects on firm innovativeness. For instance, the proportion of research ('R') in R\&D investments is more related to upstream R\&D activities and thus serves as the main contributor to patents (Czarnitzki et al., 2009; Griliches, 1990). By contrast, the proportion of development ('D') costs is mainly associated with downstream $\mathrm{R} \& \mathrm{D}$ activities, thereby leading more to products and processes (Czarnitzki et al., 2009). Alternatively, within the industrial context of our studies, R\&D investments by incumbent pharmaceutical firms can be disaggregated into biotechnology-orientated and non-biotechnology related. As such, pharmaceutical firms with higher proportions of biotechnology $R \& D$, holding the level of $R \& D$ investments constant, are expected to exhibit greater levels of innovative output within the new biotechnology regime. Future work directed towards a fine-grained analysis of R\&D investments may contribute to a richer understanding of the role of internal and external R\&D strategies in firm innovation. 



\section{BIBLIOGRAPHY}

A

Abrahamson, E. 1996. Management fashion. Academy of Management Review 21: 254-286.

Acs, Z. J., Audretsch, D. B. 1988. Innovation in large and small firms: An empirical analysis. American Economic Review 78: 678-690.

Acs, Z. J., Audretsch, D. B. 1989. Patents as a measure of innovative activity. Kyklos 42: 171-180.

Adegbesan, J. A., Higgins, M. J. 2011. The intra-alliance division of value created through collaboration. Strategic Management Journal 32: 187-211.

Adler, P. S., Kwon, S. K. 2002. Social capital: Prospects for a new concept. Academy of Management Review 27: 17-40.

Ahuja, G. 2000a. Collaboration networks, structural holes, and innovation: A longitudinal study. Administrative Science Quarterly 45: 425-455.

Ahuja, G. 2000b. The duality of collaboration: Inducements and opportunities in the formation of interfirm linkages. Strategic Management Journal, Special Issue 21: 317-343.

Ahuja, G., Katila, R. 2001. Technological acquisitions and the innovation performance of acquiring firms: A longitudinal study. Strategic Management Journal 22: 197-220.

Ai, C., Norton, E. C. 2003. Interaction terms in logit and probit models. Economics Letters 80: 123-129.

Allen, T. 1986. Organizational structure, information technology, and R\&D productivity. IEEE Transactions on Engineering Management 4: 212-217.

Argote, L. 1999. Organizational Learning: Creating, Retaining, and Transferring Knowledge. Boston: Kluwer Academic.

Arora, A., Gambardella, A. 1990. Complementarity and external linkages: The strategies of the large firms in biotechnology. Journal of Industrial Economics 38: 361-379.

Arora, A., Gambardella, A. 1994. Evaluating technological information and utilizing it: Scientific knowledge, technological capability, and external linkages in biotechnology. Journal of Economic Behavior and Organization 24: 91-114.

Audretsch, D. B., Menkveld, A. J., Thurik, A. R. 1996. The decision between internal and external R\&D. Journal of Institutional and Theoretical Economics 152: 519-530.

B

Baum, J. A. C., Calabrese, T., Silverman, B. S. 2000. Don't go it alone: Alliance network composition and startups' performance in Canadian biotechnology. Strategic Man- 
Bibliography

agement Journal 21: 267-294.

Baum, J. A. C., Rowley, T. J., Shipilov, A. V., Chuang, Y. T. 2005. Dancing with strangers: Aspiration performance and the search for underwriting syndicate partners. Administrative Science Quarterly 50: 536-575.

Beneito, P. 2006. The innovative performance of in-house and contracted R\&D in terms of patents and utility models. Research Policy 35: 502-517.

Benner, M. J., Tushman, M. 2003. Exploitation, exploration, and process management: The productivity dilemma revisited. Academy of Management Review 28: 238-256.

Bettis, R. A., Hitt, M. A. 1995. The new competitive landscape. Strategic Management Journal 16: $7-19$.

Blonigen, B. A., Taylor, C. T. 2000. R\&D intensity and acquisitions in high-technology industries: Evidence from the US electronic and electrical equipment industries. Journal of Industrial Economics 48: 47-70.

Blundell, R., Griffith, R., Reenen, J. V. 1995. Dynamic count data models of technological innovation. Economic Journal 105: 333-344.

Blundell, R., Griffith, R., Windmeijer, F. 2002. Individual effects and dynamics in count data models. Journal of Econometrics 108: 113-131.

Bond, S., Windmeijer, F., 2005. Reliable inference for GMM estimators? Finite sample properties of alternative test procedures in linear panel data models. Econometric Reviews 24: 1-37.

Borgatti, S. P., Everett, M. G., Freeman, L. C. 2002. Ucinet for Windows: Software for Social Network Analysis. Harvard, MA: Analytic Technologies.

Bound, J., Cummins, C., Griliches, Z., Hall, B. H., Jaffe, A. 1984. Who does R\&D and who patents? In: Griliches, Z. (ed.). R\&D, Patents, and Productivity. Chicago: University of Chicago Press.

Brambor, T., Clark, W. R., Golder, M. 2006. Understanding interaction models: Improving empirical analyses. Political Analysis 14: 63-82.

Brass, D. J., Burkhardt, M. E. 1992. Centrality and power in organizations. In: Nohria, N., Eccles, R. (ed.). Networks and Organizations. Boston: Harvard Business School Press.

Burt, R. S. 1992. Structural Holes: The Social Structure of Competition. Cambridge, MA: Harvard University Press.

Burt, R. S. 1997. The contingent value of social capital. Administrative Science Quarterly 42: 339-365.

Burt, R. S. 2000. The network structure of social capital. Research in Organization Behavior 22: 345-423.

C

Caloghirou, Y., Kastelli, I., Tsakanikas, A. 2004. Internal capabilities and external 
knowledge sources: Complements or substitutes for innovative performance? Technovation 24: 29-39.

Cameron, A. C., Trivedi, P. K. 1986. Econometric models based on count data: Comparisons and applications of some estimators and tests. Journal of Applied Econometrics 1: 29-54.

Cameron, A. C., Trivedi, P. K. 1998. Regression Analysis of Count Data. Econometric Society Monograph No.30. Cambridge University Press.

Cassiman, B., Veugelers, R. 1999. Make and buy in innovation strategies: Evidence from Belgian manufacturing firms. Research Policy 28: 63-80.

Cassiman, B., Veugelers, R. 2006. In search of complementarity in innovation strategy: Internal R\&D and external technology acquisition. Management Science 52: 68-82.

Catozzella, A., Vivarelli, M. 2007. The catalysing role of in-house R\&D in fostering the complementarity of innovative inputs. IZA Discussion Paper No. 3126.

CBO Study: Research and Development in the Pharmaceutical Industry, Publication No. 2589, Congressional Budget Office, October 2006, available at http://www.cbo.gov/ftpdocs/76xx/doc7615/10-02-DrugR-D.pdf.

Chamberlain, G. 1992. Comment: Sequential moment restrictions in panel data. Journal of Business \& Economic Statistics 10: 20-26.

Chang, S. J., Singh, H. 1999. The impact of modes of entry and resource fit on modes of exit by multibusiness firms. Strategic Management Journal 20: 1019-1035.

Chesbrough, H. W. 2003. Open Innovation: The New Imperative for Creating and Profiting from Technology. Boston: Harvard Business School Press.

Cincera, M. 1997. Patents, R\&D, and technological spillovers at the firm level: Some evidence from econometric count models for panel data. Journal of Applied Econometrics 12: 265-280.

Cohen, P., Cohen, J., West, S. G., Aiken, L. S. 2003. Applied Multiple Regression/Correlation Analysis for the Behavioral Science. $3^{\text {rd }}$ ed. Hillsdale, NJ: Erlbaum.

Cohen, W. M., Klepper, S. 1996. A reprise of size and R\&D. Economic Journal 106: 925-951.

Cohen, W. M., Levinthal, D. A. 1989. Innovation and learning: The two faces of R\&D. Economic Journal 99: 569-596.

Cohen, W. M., Levinthal, D. A. 1990. Absorptive capacity: A new perspective on learning and innovation. Administrative Science Quarterly 35: 128-152.

Cohen, W. M., Nelson, R. R., Walsh, J. P. 2000. Protecting their intellectual assets: Appropriability conditions and why U.S. manufacturing firms patent (or not). NBER Working papers 7552. National Bureau of Economic Research, Inc.

Coleman, J. S. 1988. Social capital in the creation of human capital. American Journal of Sociology 94 (Supplement): S95-S120.

Colombo, M. G., Garrone, P. 1996. Technological cooperative agreements and firm's R\&D 
Bibliography

intensity: A note on causality relations. Research Policy 25: 923-932.

Colombo, M. G., Grilli, L., Piva, E. 2006. In search of complementary assets: The determinants of alliance formation of high-tech start-ups. Research Policy 35: 1166-1199.

Cook, J. P., Golec, J. H., Vernon, J. A., Pink, G. H. 2011. Real option value and path dependence in oncology innovation. International Journal of the Economics of Business 18 : $225-238$.

Coombs, G. E., Deeds, D. L., Ireland, R. D. 2009. Placing the choice between exploration and exploitation in context: A study of geography and new product development. Strategic Entrepreneurship Journal 3: 261-279.

Crépon, B., Duguet, E. 1997. Estimating the innovation function from the patent numbers: GMM on count panel data. Journal of Applied Econometrics 12: 243-264.

Czarnitzki, D., Kraft, K., Thorwarth, S. 2009. The knowledge production of 'R' and 'D'. Economics Letters 105: 141-143.

D

Darby, M. R., Zucker, L. G. 2010. Grilichesian breakthroughs: Inventions of methods of inventing and firm entry in nanotechnology. NBER Chapters, in: Contributions in Memory of Zvi Griliches: 143-164. National Bureau of Economic Research, Inc.

Demirkan, I., Demirkan, S. 2012. Network characteristics and patenting in biotechnology, 1990-2006. Journal of Management 38: 1892-1927.

Diestre, L., Rajagopalan, N. 2012. Are all 'sharks' dangerous? New biotechnology ventures and partner selection in R\&D alliances. Strategic Management Journal 33: 1115-1134.

Dixit, A., Pindyck, R. 1994. Investment under Uncertainty. Princeton, NJ: Princeton University Press.

Dushnitsky, G., Lenox, M. J. 2005a. When do firms undertake R\&D by investing in new ventures? Strategic Management Journal 26: 947-965.

Dushnitsky, G., Lenox, M. J. 2005b. When do incumbents learn from entrepreneurial ventures? Corporate venture capital and investing firm innovation rates. Research Policy 34: 615-639.

Duysters, G., Hagedoorn, J. 1993. The Cooperative Agreements and Technology Indicators (CATI) Information System. Maastricht: MERIT.

Duysters, G., Lemmens, C. E. A. V. 2003. Cohesive subgroup formation: Enabling and enforcing factors in strategic technology alliance networks. International Studies on Management and Organization 33: 49-68.

$\mathbf{E}$

Eisenhardt, K. 1989. Making fast strategic decisions in high-velocity environments. Academy of Management Journal 32: 543-576.

Eisenhardt, K. M., Martin, J. A. 2000. Dynamic capabilities: What are they? Strategic Man- 
agement Journal 21: 1105-1121.

\section{$\mathbf{F}$}

Faems, D., Looy, B. V., Debackere, K. 2005. Interorganizational collaboration and innovation: Toward a portfolio approach. Journal of Product Innovation Management 22: $238-250$.

Fleming, L. 2001. Recombinant uncertainty in technological search. Management Science 47: $117-132$.

Freeman, C. 1991. Networks of innovators: A synthesis of research issues. Research Policy 20: 499-514.

Freeman, C., Soete, L. 1997. The Economics of Industrial Innovation. London: Printer.

G

Gargiulo, M., Ertug, G., Galunic, C. 2009. The two faces of control: Network closure and individual performance among knowledge workers. Administrative Science Quarterly 54: 299-333.

Garud, R., Nayyar, P. R. 1994. Transformative capacity: Continual structuring by intertemporal technology transfer. Strategic Management Journal 15: 365-385.

Gilsing, V., Duysters, G. 2008. Understanding novelty creation in exploration networks Structural and relational embeddedness jointly considered. Technovation 28: 693-708.

Gilsing, V., Nooteboom, B. 2006. Exploration and exploitation in innovation systems: The case of pharmaceutical biotechnology. Research Policy 35: 1-23.

Grabowski, H. 2006. Patents and new product development in the pharmaceutical and biotechnology industries. In: Smith, C.G., O’Donnell, J.T. (ed.). The Process of New Drug Discovery and Development. $2^{\text {nd }}$ ed. New York: Informa Healthcare USA Inc.

Grabowski, H. 2011. The evolution of the pharmaceutical industry over the past 50 years: A personal reflection. International Journal of the Economics of Business 18: 161-176.

Grabowski, H., Vernon, J. 1990. A new look at the returns and risks to pharmaceutical R\&D. Management Science 36: 804-821.

Grabowski, H., Vernon, J. 1994. Returns to R\&D on New Drug Introductions in the 1980s. Journal of Health Economics 13: 383-406.

Grabowski, H., Vernon, J., DiMasi, J. 2002. Returns on research and development for 1990s new drug introductions. Pharmacoeconomics 20: 11-29.

Granovetter, M. 1982. The strength of weak ties: A network theory revisited. In: Marsden, P., Lin, N. (ed.). Social Structure and Network Analysis. Beverly Hills, CA: Sage.

Granovetter, M. 1985. Economic action and social structure: The problem of embeddedness. American Journal of Sociology 91: 481-510. 
Bibliography

Graves, S. B., Langowitz, N. S. 1993. Innovative productivity and returns to scale in the pharmaceutical industry. Strategic Management Journal 14: 593-605.

Greene, W. H. 2003. Econometric Analysis. 4th ed. New York: Prentice Hall.

Griliches, Z. 1979. Issues in assessing the contribution of research and development to productivity growth. Bell Journal of Economics 10: 92-116.

Griliches, Z. 1990. Patent statistics as economic indicators: A survey. Journal of Economic Literature 28: 1661-1707.

Griliches, Z. 1998. R\&DD and Productivity - The Econometric Evidence. Chicago: University of Chicago Press.

Gujarati, D. N. 2003. Basic Econometrics. $4^{\text {th }}$ ed. Boston: McGraw-Hill.

Gulati, R. 1995. Social structure and alliance formation patterns: A longitudinal analysis. Administrative Science Quarterly 40: 619-652.

Gulati, R. 1998. Alliances and networks. Strategic Management Journal 19: 293-317.

Gulati, R., Garguilo, M. 1999. Where do interorganizational networks come from? American Journal of Sociology 104: 1439-1493.

Gulati, R., Nohria, N., Zaheer, A. 2000. Strategic networks. Strategic Management Journal 21: 203-215.

Guo, J. Q., Trivedi, P. K. 2002. Flexible parametric models for long-tailed patent count distributions. Oxford Bulletin of Economics and Statistics 63: 63-82.

Gurmu, S., Pérez-Sebastián, F. 2008. Patents, R\&D, and lag effects: Evidence from flexible methods for count panel data on manufacturing firms. Empirical Economics 35: 507-526.

\section{$\mathbf{H}$}

Hagedoorn, J. 1993. Understanding the rationale of strategic technological partnering: Inter-organizational modes of cooperation and sectoral differences. Strategic Management Journal 14: 371-385.

Hagedoorn, J. 2002. Inter-firm R\&D partnerships: An overview of major trends and patterns since 1960. Research Policy 31: 477-482.

Hagedoorn, J., Cloodt, M. 2003. Measuring innovative performance: Is there an advantage in using multiple indicators? Research Policy 32: 1365-1379.

Hagedoorn, J., Duysters, G. 2002a. The effect of mergers and acquisitions on the technological performance of companies in a high-tech environment. Technology Analysis and Strategic Management 14: 68-85.

Hagedoorn, J., Duysters, G. 2002b. Learning in dynamic interfirm networks: The efficacy of multiple contacts. Organization Studies 23: 525-548.

Hagedoorn, J., Letterie, W., Palm, F. 2011. The information value of R\&D alliances: The preference for local or distant ties. Strategic Organization 9: 283-309. 
Hagedoorn, J., Roijakkers, N., Kranenburg, H. 2008. The formation of subsequent interfirm R\&D partnerships between large pharmaceutical companies and small, entrepreneurial biotechnology firms - How important is inter-organizational trust? International Journal of Technology Management 44: 81-92.

Hall, A. J., Sivamohan, M. V. K., Clark, N., Taylor, S., Bockett, G. 2001. Why research partnerships really matter: Innovation theory, institutional arrangements and implications for developing new technology for the poor. World Development 29: 783-797.

Hall, B. H., Hausman, J., Griliches, Z. 1986. Patents and R\&D: Is there a lag? International Economic Review 27: 265-283.

Hamel, G. 1991. Competition for competence and inter-partner learning within international strategic alliances. Strategic Management Journal 12: 83-103.

Hamilton, B. H., Nickerson, J. A. 2003. Correcting for endogeneity in strategic management research. Strategic Organization 1: 51-78.

Hargadon, A., Sutton, R. I. 1997. Technology brokering and innovation in a product development firm. Administrative Science Quarterly 42: 716-749.

Haunschild, P. R. 1993. Interorganizational imitation: The impact of interlocks on corporate acquisition activity. Administrative Science Quarterly 38: 564-592.

Hausman, J., Hall, B. H., Griliches, Z. 1984. Econometric models for count data with an application to the patents-R\&D relationship. Econometrica 52: 909-938.

He, Z. L., Wong, P. K. 2004. Exploration vs. exploitation: An empirical test of the ambidexterity hypothesis. Organization Science 15: 481-494.

Helfat, C. E. 1994. Evolutionary trajectories in petroleum firm R\&D. Management Science 40: 1720-1747.

Helfat, C. E., Raubitschek, R. S. 2000. Product sequencing: Co-evolution of knowledge, capabilities and products. Strategic Management Journal 21: 961-979.

Henderson, R. M., Clark, K. B. 1990. Architectural innovation: The reconfiguration of existing product technologies and the failure of established firms. Administrative Science Quarterly 35: 9-30.

Henderson, R., Cockburn, I. 1994. Measuring competence? Exploring firm effects in pharmaceutical research. Strategic Management Journal 15: 63-84.

Hess, A. M., Rothaermel, F. T. 2011. When are assets complementary? Star scientists, strategic alliances, and innovation in the pharmaceutical industry. Strategic Management Journal 32: 895-909.

Higgins, M., Rodriguez, D. 2006. The outsourcing of R\&D through acquisition in the pharmaceutical industry. Journal of Financial Economics 80: 351-383.

Hilbe, J. M. 2007. Negative Binomial Regression. Cambridge: Cambridge University Press.

Hill, C. W. L., Rothaermel, F. T. 2003. The performance of incumbent firms in the face of radical technological change. Academy of Management Review 28: 257-274. 
Bibliography

Hitt, M. A., Hoskisson, R. E., Ireland, R. D. 1990. Mergers and acquisitions and managerial commitment to innovation in M-form firms. Strategic Management Journal 11: 29-47.

Hitt, M. A., Hoskisson, R. E., Kim, H. 1997. International diversification: Effects of innovation and firm performance in product-diversified firms. Academy of Management Journal 40: 767-798.

Hitt, M. A., Johnson, R. A., Moesel, D. D. 1996. The market for corporate control and firm innovation. Academy of Management Journal 39: 1084-1119.

Hoetker, G. 2007. The use of probit and logit models in strategic management research: Critical issues. Strategic Management Journal 28: 331-343.

\section{$\mathbf{J}$}

Jaffe, A. B., Trajtenberg, M. 1999. International knowledge flows: Evidence from patent citations. Economics of Innovation and New Technology 8: 105-136.

K

Kale, P., Singh, H., Perlmutter, H., 2000. Learning and protection of proprietary assets in strategic alliances: Building relational capital. Strategic Management Journal 21: $217-238$.

Karamanos, A. G., 2012. Leveraging micro- and macro-structures of embeddedness in alliance networks for exploratory innovation in biotechnology. R\&D Management 42: 71-89.

Katila, R. 2002. New product search over time: Past ideas in their prime? Academy of Management Journal 45: 995-1010.

Keil, T., Maula, M., Schildt, H., Zahra, S. A. 2008. The effect of governance modes and relatedness of external business development activities on innovative performance. Strategic Management Journal 29: 895-907.

Khanna, T., Gulati, R., Nohria, N. 1998. The dynamics of learning races: Competition, cooperation and relative scope. Strategic Management Journal 19: 193-210.

Kogut, B. 1988. A study of the life cycle of joint ventures. Management International Review 28: 39-52.

Kogut, B. 1989. The stability of joint ventures: Reciprocity and competitive rivalry. Journal of Industrial Economics 38: 183-198.

Kogut, B., Zander, U. 1992. Knowledge of the firm, combinative capabilities, and the replication of technology. Organization Science 3: 383-397.

Koka, B., Prescott, J. 2002. Strategic alliances as social capital: A multidimensional view. Strategic Management Journal 23: 795-816.

Koka, B., Prescott, J. 2008. Designing alliance networks: The influence of network position, environmental change, and strategy on firm performance. Strategic Management Journal 29: 639-661. 
Kranenburg, H. L., Hagedoorn, J. 2008. Strategic focus of incumbents in the European telecommunications industry: The cases of BT, Deutsche Telekom and KPN. Telecommunications Policy 32: 116-130.

Kreps, D. M. 1990. Corporate culture and economic theory. In: Alt, J. E., Shepsle, K. A. (ed.). Perspectives on Positive Political Economy. New York: Cambridge University Press.

$\mathbf{L}$

Larson, A. 1992. Network dyads in entrepreneurial settings: A study of the governance of exchange relationships. Administrative Science Quarterly 37: 76-104.

Laursen, K., Salter, A. 2006. Open for innovation: The role of openness in explaining innovation performance among U.K. manufacturing firms. Strategic Management Journal 27: 131-150.

Lavie, D., Rosenkopf, L. 2006. Balancing exploration and exploitation alliance formation. Academy of Management Journal 49: 797-818.

Lavie, D., Stettner, U., Tushman, M. L. 2010. Exploration and exploitation within and across organizations. The Academy of Management Annals 4: 109-155.

Leiblein, M. J., Reuer, J. J., Daisace, F. 2002. Do make or buy decisions matter? The influence of organizational governance on technological performance. Strategic Management Journal 23: 817-833.

Leonard-Barton, D. 1984. Inter-personal communication patterns among Swedish and Boston-area entrepreneurs. Research Policy 13: 101-114.

Levin, R. C., Klevorick, A. K., Nelson, R. R., Winter, S. G. 1987. Appropriating the returns from industrial research and development. Brookings Papers on Economic Activity 3: 783-831.

Levinthal, D. A., March, J. G. 1993. The myopia of learning. Strategic Management Journal 14: 95-112.

Li, Y., Vanhaverbeke, W., Schoenmakers, W. 2008. Exploration and exploitation in innovation: Reframing the interpretation. Creativity and Innovation Management 17: 107-126.

Lokshin, B, Belderbos, R., Carree, M. 2008. The productivity effects of internal and external R\&D: Evidence from a dynamic panel data model. Oxford Bulletin of Economics and Statistics 70: 399-413.

\section{$\mathbf{M}$}

March, J. G. 1991. Exploration and exploitation in organizational learning. Organization Science 2: 71-87.

Martin, X., Mitchell, W. 1998. The influence of local search and performance heuristics on new design introduction in a new product market. Research Policy 26: 753-771.

Martins, L. L., Kambil, A. 1999. Looking back and thinking ahead: Effects of prior success on managers' interpretations of new information technologies. Academy of Man- 
Bibliography

agement Journal 42: 652-661.

McEvily, B., Zaheer, A. 1999. Bridging ties: A source of firm heterogeneity in competitive capabilities. Strategic Management Journal 20: 1133-1156.

McGrath, R. G. 1997. A real options logic for initiating technology positioning investments. Academy of Management Review 22: 974-996.

McGrath, R. G. 1999. Falling forward: Real options reasoning and entrepreneurial failure. Academy of Management Review 24: 13-30.

McGrath, R. G., Nerkar, A. 2004. Real options reasoning and a new look at the R\&D investment strategies of pharmaceutical firms. Strategic Management Journal 25: 1-21.

Milgrom, P., Roberts, J. 1990. The economics of modern manufacturing: Technology, strategy, and organization. American Economic Review 80: 511-528.

Milgrom, P., Roberts, J. 1995. Complementarities and fit: Strategy, structure, and organizational change in manufacturing. Journal of Accounting and Economics 19: 179-208.

Montalvo, J. G. 1997. GMM estimation of count-panel-data models with fixed effects and predetermined instruments. Journal of Business \& Economic Statistics 15: 82-89.

Mullahy, J. 1999. Interaction effects and difference-in-difference estimation in loglinear models. NBER Technical Working Paper No. 245.

Myers, S. C. 1984. Financial theory and financial strategy. Interfaces 14: 126-137.

$\mathbf{N}$

Nahapiet, J., Ghoshal, S. 1998. Social capital, intellectual capital, and the organizational advantage. Academy of Management Review 23: 242-266.

Nerkar, A. 2003. Old is gold? The value of temporal exploration in the creation of new knowledge. Management Science 49: 211-229.

Nicholls-Nixon, C. L. 1995. Responding to technological change: Why some firms do and others die. The Journal of High Technology Management Research 6: 1-16.

Nicholls-Nixon, C. L., Woo, C. Y. 2003. Technology sourcing and output of established firms in a regime of encompassing technological change. Strategic Management Journal 24: 651-666.

Nooteboom, B. 2004. Governance and competence: How can they be combined? Cambridge Journal of Economics 28: 505-526.

\section{$\mathbf{P}$}

Pakes, A., Griliches, Z. 1984a. Patents and R\&D at the firm level: A first look. In: Griliches, Z. (ed.). R\&D, Patents, and Productivity. Chicago: University of Chicago Press.

Pakes, A., Griliches, Z. 1984b. Estimating distributed lags in short panels with an application to the specification of depreciation patterns and capital stock constructs. Review of Economic Studies 51: 243-262. 
Park, S. H., Chen, R., Gallagher, S. 2002. Firm resources as moderators of the relationship between market growth and strategic alliances in semiconductor start-ups. Academy of Management Journal 45: 527-545.

Patel, P., Pavitt, K., 1991. Large firms in the production of the world's technology: An important case of non-globalization. Journal of International Business Studies 22: 1-21.

Pennings, J. M., Harianto, F. 1992. Technological networking and innovation implementation. Organization Science 3: 356-382.

Phelps, C. C. 2010. A longitudinal study of the influence of alliance network structure and composition on firm exploratory innovation. Academy of Management Journal 53: 890-913.

Phelps, C. C., Heidl, R., Wadhwa, A. 2012. Knowledge, networks, and knowledge networks: A review and research agenda. Journal of Management 38: 1115-1166.

Pisano, P. G. 1997a. The Development Factory: Unlocking the Potential of Process Innovation. Boston, MA: Harvard Business School Press.

Pisano, P. G. 1997b. R\&D performance, collaborative arrangements, and the market-forknow-how: A test of the 'lemons' hypothesis in biotechnology. Harvard Business School Working paper No. 97-105.

Powell, W. W. 1998. Learning from collaboration: Knowledge and networks in the biotechnology and pharmaceutical industries. California Management Review 40: $228-240$.

Powell, W. W., Koput, K. W., Smith-Doerr, L. 1996. Interorganizational collaboration and the locus of innovation: Networks of learning in biotechnology. Administrative Science Quarterly 41: 116-145.

\section{Q}

Quintana-García C., Benavides-Velasco C. A. 2004. Cooperation, competition, and innovative capability: A panel data of European dedicated biotechnology firms, Technovation 24: 927-938.

Quintana-García, C., Benavides-Velasco, C. A. 2011. Knowledge organization in R\&D alliances: Its impact on product innovation, Technology Analysis and Strategic Management 23: 1047-1061.

\section{R}

Ranft, A. L., Lord, M. D. 2002. Acquiring new technologies and capabilities: A grounded model of acquisition implementation. Organization Science 13: 420-441.

Roijakkers, N., Hagedoorn, J., Kranenburg, H. V. 2005. Dual market structures and the likelihood of repeated ties - evidence from pharmaceutical biotechnology. Research Policy 34: 235-245.

Rosenkopf, L., Nerkar, A. 2001. Beyond local search: Boundary-spanning, exploration, and impact in the optical disk industry. Strategic Management Journal 22: 287-306. 
Bibliography

Rosenkopf, L. Padula, G. 2008. Investigating the microstructure of network evolution: Alliance formation in the mobile communications industry. Organization Science 19: 669-687.

Rothaermel, F. T. 2001. Incumbent's advantage through exploiting complementary assets via interfirm cooperation. Strategic Management Journal 22: 687-699.

Rothaermel, F. T., Boeker, W. 2008. Old technology meets new technology: Complementarities, similarities, and alliance formation. Strategic Management Journal 29: 47-77.

Rothaermel, F. T., Deeds, D. L. 2004. Exploration and exploitation alliances in biotechnology: A system of new product development. Strategic Management Journal 25: 201-221.

Rothaermel, F. T., Deeds, D. L. 2006. Alliance type, alliance experience, and alliance management capability in high-technology ventures. Journal of Business Venturing 21: $429-460$.

Rothaermel, F. T., Hess, A. M. 2007. Building dynamic capabilities: Innovation driven by individual-, firm-, and network-level effects. Organization Science 18: 898-921.

Rowley, T., Behrens, D., Krackhardt, D. 2000. Redundant governance structures: An analysis of structural and relational embeddedness in the steel and semiconductor industries. Strategic Management Journal 21: 369-386.

S

Salman, N., Saives, A. 2005. Indirect networks: An intangible resource for biotechnology innovation. RひD Management 35: 203-215.

Sampson, R. C. 2004. Organizational choice in R\&D alliances: Knowledge-based and transaction cost perspectives. Managerial and Decision Economics 25: 421-436.

Sampson, R. C. 2007. R\&D alliances and firm performance: The impact of technological diversity and alliance organization on innovation. Academy of Management Journal 50: 364-386.

Scherer, F. M. 1982. Inter-technology flows and productivity growth. Review of Economics and Statistics 64: 627-634.

Scherer, F. M. 1983. The propensity to patent. International Journal of Industrial Organization 1: $107-128$.

Schilling, M. A. 2009. Understanding the alliance data. Strategic Management Journal 30: $233-260$.

Schilling, M. A., Phelps, C. C. 2007. Interfirm collaboration networks: The impact of largescale network structure on firm innovation. Management Science 53: 1113-1126.

Schmiedeberg, C. 2008. Complementarities of innovation activities: An empirical analysis of the German manufacturing sector. Research Policy 37: 1492-1503.

Schumpeter, J. A. 1942. Capitalism, Socialism and Democracy. New York: Harper. 
Scotchmer, S. 1991. Standing on the shoulders of giants: Cumulative research and the patent law. Journal of Economic Perspectives 5: 29-41.

Simons, J. 2006. Big Pharma's new R\&D center: The trash bin. Fortune 154 (12): 38.

Sorenson, O., Stuart, T. E. 2008. Bringing the context back in: Settings and the search for syndicate partners in venture capital investment networks. Administrative Science Quarterly 53: 266-294.

Sørensen, J., Stuart, T. 2000. Aging, obsolescence, and organizational innovation. Administrative Science Quarterly 45: 81-112.

Spender, J-C. 1992. Limits to learning from the West: How western management advice may prove limited in Eastern Europe. The International Executive 34: 389-410.

Sternitzke, C. 2010. Knowledge sources, patent protection, and commercialization of pharmaceutical innovations. Research Policy 39: 810-821.

Stock, J. H., Wright, J. H., Yogo, M. 2002. A survey of weak instruments and weak identification in generalized method of moments. Journal of Business \& Economic Statistics 20: $518-529$.

Stuart, T. E. 2000. Interorganizational alliances and the performance of firms: A study of growth and innovation rates in a high-technology industry. Strategic Management Journal 21: 791-811.

Stuart, T. E., Hoang, H., Hybels, R. C. 1999. Interorganizational endorsements and the performance of entrepreneurial ventures. Administrative Science Quarterly 44: 315-349.

\section{$\mathbf{T}$}

Teece, D. J. 1982. Towards an economic theory of the multiproduct firm. Journal of Economic Behavior and Organization 3: 39-63.

Teece, D. J. 1986. Profiting from technological innovation: Implications for integration, collaboration, licensing and public policy. Research Policy 15: 285-305.

Teece, D. J. 1988. Technological change and the nature of the firm. In: Dosi, G., Freeman, C., Nelson, R., Silverberg, G., Soete, L. (ed.). Technical Change and Economic Theory. London: Pinter Publisher.

Teece, D. J. 1992. Competition, cooperation, and innovation: Organizational arrangements for regimes of rapid technological progress. Journal of Economic Behavior and Organization 18: 1-25.

Topkis, D. M. 1998. Supermodularity and Complementarity. Princeton, New Jersey: Princeton University Press.

Trajtenberg, M. 1990. A penny for your quotes: Patent citations and the value of innovations. RAND Journal of Economics 20: 172-187. 
Bibliography

Tripsas, M. 1997. Unraveling the process of creative destruction: Complementary assets and incumbent survival in the typesetter industry. Strategic Management Journal 18: $119-142$.

$\mathbf{U}$

Uzzi, B. 1996. The sources and consequences of embeddedness for economic performance of organizations: The network effect. American Sociological Review 61: 674-698.

Uzzi, B. 1997. Social structure and competition in interfirm networks: The paradox of embeddedness. Administrative Science Quarterly 42: 35-67.

V

Vanhaverbeke, W., Duysters, G., Noorderhaven, N. 2002. External technology sourcing through alliances or acquisitions: An analysis of the application-specific integrated circuits industry. Organization Science 13: 714-733.

Vanhaverbeke, W., Gilsing, V., Beerkens, B., Duysters, G. 2009. The role of alliance network redundancy in the creation of core and non-core technologies. Journal of Management Studies 46: 215-244.

Vanhaverbeke, W., Gilsing, V., Duysters, G. 2012. Competence and governance in strategic collaboration: The differential effect of network structure on the creation of core and noncore technology. Journal of Production Innovation Management 29: 784-802.

Vassolo, R. S., Anand, J., Folta, T. B. 2004. Non-additivity in portfolios of exploration activities: A real options-based analysis of equity alliances in biotechnology. Strategic Management Journal 25: 1045-1061.

Vega-Jurado, J., Gutiérrez-Gracia, A., Fernández-de-Lucio, I. 2009. Does external knowledge sourcing matter for innovation? Evidence from the Spanish manufacturing industry. Industrial and Corporate Change 18: 637-670.

Veugelers, R. 1997. Internal R\&D expenditures and external technology sourcing. Research Policy 26: 303-315.

W

Walker, G., Kogut, B., Shan, W. 1997. Social capital, structural holes, and the formation of an industry network. Organization Science 8: 109-125.

Walker, R. D. 1995. Patents as Scientific and Technical Literature. Metuchen, NJ, and London: The Scarecrow Press.

Whittington, K. B., Owen-Smith, J., Powell, W. W. 2009. Networks, propinquity and innovation in knowledge-intensive industries. Administrative Science Quarterly 54: 90-122.

Wiersema, M. F., Bowen, H. P. 2009. The use of limited dependent variable techniques in strategy research: Issues and methods. Strategic Management Journal 30: 679-692.

Windmeijer, F. 2002. ExpEnd, a Gauss programme for non-linear GMM estimation of exponential models with endogenous regressors for cross section and panel data. 
Manuscript. Institute for Fiscal Studies.

Winkelmann, R. 2008. Econometric Analysis of Count Data. $5^{\text {th }}$ ed. Berlin: Springer-Verlag.

Wooldridge, J. M. 1997. Multiplicative panel data models without the strict exogeneity assumption. Econometric Theory 13: 667-679.

$\mathbf{Y}$

Yip, G. 1982. Diversification entry: Internal development versus acquisition. Strategic Management Journal 3: 331-345.

\section{Z}

Zaheer, A., Bell, G. G. 2005. Benefiting from network position: Firm capabilities, structural holes, and performance. Strategic Management Journal 26: 809-825.

Zahra, S. A., George, G. 2002. Absorptive capacity: A review, reconceptualization, and extension. Academy of Management Review 27: 185-203. 



\section{VALORIZATION}

"We increasingly recognize that valorization is an excellent tool for promoting economic growth. This is especially important at a time of economic decline. We are thinking, working and collaborating on all fronts to raise the utilization of our scientific knowledge to the same high level as the knowledge itself." (Aad Veenman, 2013)

The addendum as follows mainly addresses the valorization opportunities for the three empirical studies presented in this dissertation, including the social and economic relevance of the research topics covered by the dissertation, the innovativeness of the respective research findings, and their value for firm innovation and practices in management.

As stated in the introduction chapter, the principal purpose of this dissertation is to develop a better understanding of the impact of internal and external R\&D strategies of firms on their innovative output. On the one hand, internal R\&D is an important, and perhaps even the most important, contributor to firm innovativeness (Griliches, 1979; Scherer, 1982). On the other hand, the openness of firms to external R\&D sources is another key element for firm innovation. In view of the increasing complexity and multidisciplinarity of research, even the largest and most self-contained organizations cannot keep abreast of all the relevant technological advances solely through their internal R\&D (Teece, 1988; Veugelers, 1997). In recent years, more and more firms have actually been pursuing an 'open innovation' (Chesbrough, 2003) approach by leveraging internal and external knowledge development in parallel so as to build and hone their innovative capabilities.

Specifically, three research questions have been empirically examined in the dissertation. Firstly, in the attempt to learn about gestation lags in knowledge production of internal R\&D by firms, researchers have repeatedly examined the relationship between $\mathrm{R} \& \mathrm{D}$ expenditures and patents. In line with a cumulative knowledge production or innovation process of firms, the current patenting output is expected to be dependent not only on recent R\&D (i.e., a short-run effect of $\mathrm{R} \& \mathrm{D}$ ) but also on R\&D investments in the distant past (i.e., a long-run effect of $\mathrm{R} \& \mathrm{D})$. However, the previous studies suggest that there was very little direct evidence of anything but simultaneity in the year-to-year movement of patents and $R \& D$ expenditures, or that the lag effects on patents were identified only for more recent R\&D (Blundell et al., 2002; Gurmu and Pérez-Sebastián, 2008; Hall et al., 1986; Hausman et al., 1984; Montalvo, 1997; Pakes and Griliches, 1984a). To ex- 
plore the potential long-run impact of internal $R \& D$ on firm patenting, the first empirical study in this dissertation revisits the classic research question regarding the lag structure of the patents-R\&D relationship in the context of the global pharmaceutical industry.

The results from the first empirical study illustrate a cumulative knowledge production or innovation process of incumbent pharmaceutical firms, with current patent production being historically dependent on past investments in internal R\&D. Our results are consistent with prior research which suggests that not only recent knowledge is important for new knowledge creation, but that older knowledge in knowledge stock accruing from long past $\mathrm{R} \& \mathrm{D}$ investments may also be valuable for firm innovativeness (Katila, 2002; Nerkar, 2003). This finding echoes the real options logic for managing $R \& D$ investment strategies of firms (McGrath, 1997; McGrath and Nerkar, 2004), according to which early R\&D investments by firms in a new area with technical uncertainty may be influential in their knowledge production or innovation process over a long-term horizon. Subsequent R\&D investments in the same area can further reduce technical uncertainty and reinforce the value of options opened earlier. Alternatively, firms may choose to wait or even exit the area they invested before. In this way, the earlier investments in R\&D can still serve as part of the firms' stock of knowledge, which may contribute substantially to their later innovations when conditions favor its use. From a managerial perspective, our study offers important insights into the cumulative knowledge production or innovation process of firms. In addition to emphasizing recent investments in internal R\&D to stay abreast of the latest, cutting edge technologies, decision-makers in firms should also adopt a long-term perspective for organizing R\&D investment strategies. Through periodically reviewing and recombining older, useful but under-utilized knowledge, firms can increase their creation of new knowledge (Garud and Nayyar, 1994; Nerkar, 2003). However, it is noteworthy that older knowledge tends to be lost over time due to lack of adequate organizational memory, inaccurate recording, and turnover in R\&D personnel (Argote, 1999). As a consequence, for firms to effectively transfer knowledge across time, they need to build up the 'transformative capacity' which pertains to the choice of knowledge for future use, its maintenance over time, and the reactivation and synthesis of such knowledge when required (Garud and Nayyar, 1994; Nerkar, 2003). In this way, by making better use of older knowledge and actively maintaining stock of knowledge for future use, firms can enhance their returns from internal $\mathrm{R} \& \mathrm{D}$ investments.

Secondly, a substantial body of research literature has examined the interrelationship between internal and external R\&D strategies in relation with firms' innovative output, which has been accompanied by mixed empirical evidence. One set of studies demonstrate that internal and external $\mathrm{R} \& \mathrm{D}$ are complementary innova- 
tion activities, suggesting their interrelatedness in improving a firm's innovative performance (Cassiman and Veugelers, 2006; Lokshin et al., 2008; Rothaermel and Hess, 2007; Schmiedeberg, 2008). By contrast, a second set of studies indicates that there is substitutability (or, no complementarity) between internal and external R\&D strategies (Hess and Rothaermel, 2011; Laursen and Salter, 2006; VegaJurado et al., 2009). The above studies are thus inconclusive about the relationship between different innovation mechanisms and focus merely on either complementarity or substitutability. However, as suggested by Cassiman and Veugelers (2006), understanding under what conditions different R\&D strategies may in fact be complementary is more important than merely determining what activities are complementary per se. Given the scarcity of prior work on this line of research (exceptions are Cassiman and Veugelers, 2006; Hess and Rothaermel, 2011), our second study seeks to provide empirical evidence on the conditions under which there is complementarity or substitutability between internal and external R\&D strategies within the context of the global pharmaceutical industry.

The results from the second study suggests that, instead of a clear-cut answer to the question whether internal and external R\&D are complementary or substitutive innovation activities, there appears to be a contingent relationship between internal and external R\&D strategies in shaping a firm's innovative output. More specifically, internal $R \& D$ and external $R \& D$, through either $R \& D$ alliances or R\&D acquisitions, are complementary innovation activities at higher levels of inhouse R\&D investments, whereas at lower levels of in-house R\&D efforts, internal and external R\&D activities turn out to be substitutive strategic options. These findings highlight the complexity of understanding the relationship between internal and external R\&D strategies and contribute to the extent literature by advancing and testing the contingency role of a firm's in-house R\&D efforts in determining the condition under which there is complementarity or substitutability between its various R\&D strategies. From a managerial perspective, our empirical findings provide implications for firms in organizing their internal and external R\&D strategies to match the rapidly changing technological environment. In order to continually update a firm's technological know-how and capabilities, managers often choose to pursue internal and external R\&D strategies in parallel, in hope of a potential complementarity between various innovation activities. Such complementarity, unfortunately, does not always exist. Our results show that it is contingent on the development of a firm's absorptive capacity, which is mainly determined by how much the firm would invest in its in-house R\&D. In other words, in-house R\&D efforts play a key role in the interrelationship between internal and external R\&D strategies to influence firms' innovative output. Managers who can leverage external sources of innovation to adapt to the relentlessly changing technological 
environment and, at the same time, lay emphasis on in-house R\&D endeavors will be most successful in building up sustainable innovative capabilities of firms.

Finally, the third empirical study moves from a dyad level to a network level to investigate the impact of alliance network structure on a firm's innovative output. In spite of the growing consensus on the facilitative role of alliance networks, there has been an ongoing debate over the relative efficacy of different forms of network structure-network closure (Coleman, 1988) vs. structural holes (Burt, 1992) — as critical determinants of firm innovation. The empirical evidence has produced a rather mixed picture of how firms should be structurally embedded in interfirm alliance networks (e.g., Ahuja, 2000a; Baum et al., 2000; McEvily and Zaheer, 1999; Schilling and Phelps, 2007). To reconcile these conflicting arguments and results, researchers have proposed a contingency approach (Ahuja, 2000a; Burt, 2000). However, until recently there are relatively few studies (exceptions are Koka and Prescott, 2008; Vanhaverbeke et al., 2012) that have employed such an approach to examine the effects of interfirm network structure on a focal firm's innovative output. Relatedly, apart from network closure vs. structural holes as aforementioned, the role of indirect ties is another important aspect of alliance network structure relating to a focal firm's innovative output. As argued by Ahuja (2000a), indirect ties are essentially characterized by a dual role vis-a-vis the focal actor-both as sources of information and as competitors in terms of using similar information. Although scholars have long studied the relationship between indirect ties and innovation, most research in this tradition has largely focused on the benefits from indirect ties as information sources but paid little attention to the role of indirect ties as potential competitors. To fill such research gaps, the goal of the third empirical study is to examine the impact of two aspects of interfirm network structure, i.e., structural holes and indirect ties, on a focal firm's innovative output. A contingency approach is utilized in the study by considering the various dimensions of a focal firm's innovative output-new technology and new products-and identifying their divergent requirements on the focal firm's network structure of interfirm R\&D alliances. In particular, the analytic focus is on incumbent pharmaceutical firms as the focal actors in the pharmaceutical industry network of interfirm R\&D alliances.

The results from the third study confirm, to a great extent, the above contingency framework. Research findings on the relative efficacy of network closure vs. structural holes suggest that an R\&D alliance network rich in structural holes is more advantageous for incumbent pharmaceutical firms' creation of new technology, whereas a dense, interconnected network of interfirm R\&D alliances turns out to be more beneficial for their development of new products in the market. Concerning the dual role of indirect ties, our estimation results indicate that incumbent pharmaceutical firms with more indirect ties in an R\&D alliance network are actu- 
ally associated with reduced innovative output in terms of new products, while no significant effect is found in the case of new technology. These findings provide important implications for the literature on interfirm network structure and firm innovation. On the one hand, by showing that the optimal network structure for firms to embed themselves in is contingent on the various types of innovative output, our study contributes to a better understanding of under what conditions firms mandate the distinct benefits provided by the different forms of network structure. On the other hand, in contrast with prior research that has predominately demonstrated the benefits from indirect ties as sources of information (Karamanos, 2012; Salman and Saives, 2005; Vanhaverbeke et al., 2012), our results shed insights into the dual role of indirect ties (Ahuja, 2000a) as potential competitors as well as information sources for a focal firm. From a managerial perspective, our findings offer implications for the network configuration of interfirm R\&D alliances towards the improvement of firm innovativeness. Our study suggests that whether a dense or a sparse network constitutes an optimal network structure for firms to embed themselves in is contingent on the various types of innovative output, i.e., new technology and new products. Managers need to assess the conditions under which firms require the distinct benefits provided by the different forms of network structure. When developing collaborative norms and reducing partner opportunism are important, a dense network is more valuable; conversely, when information diversity is crucial, a sparse network is more advantageous (Ahuja, 2000a). Moreover, managers should attend to the dual role of indirect ties as both information sources and potential competitors in interfirm alliance networks. Our study reveals that indirect ties maintained by firms, especially with their competitors, would cause risks and liabilities that may counteract or even outweigh the benefits from these indirect ties as sources of information. In this respect, a network of partners exclusively tied to a focal firm, relative to one in which the focal firm's partners have other partners (i.e., indirect ties), provides more control advantage over alliance partners (Ahuja, 2000a; Brass and Burkhardt, 1992) so as to mitigate competition and information leakages and is thus considered to be more beneficial. Therefore, managers have to be fully aware of the dual role reflected by indirect ties and determine under what circumstances control advantage over alliance partners is more essential to success than the information benefits provided by indirect ties, and vice versa.

By and large, the studies presented in this dissertation can be found useful to anyone, especially researchers and decision-makers in firms, who are interested in improving the innovative output of firms by efficiently and effectively organizing the various $R \& D$ strategies. As aforementioned, in-house R\&D investments are a crucial contributor to firm innovativeness, which not only give rise to a potential long-run impact in the innovation process, but also serve as a contingency variable 
that critically influences the association between internal and external R\&D strategies in shaping firms' innovative output. Moreover, a network analysis of interfirm R\&D alliances - an important manifestation of external R\&D strategy pursued by firms - suggests that the various dimensions of firms' innovative output, i.e., new technology and new products, put divergent requirements on the network structure of interfirm R\&D alliances. Yet, for any research or theory to be of any use and to create (societal and economic) value, it has to apply in practice and needs to be thoroughly tested. The knowledge valorization opportunities outlined in this addendum serve as an illustration of how to utilize the research of this dissertation not only for academic purposes but also for managerial practices in the business world. In so doing, I sincerely hope that the studies presented here can be applied to, and what's more, enriched by real world practice, thereby opening up new avenues of research - a reciprocal process from theory to practice and from practice to theory. 


\section{Curriculum Vitae}

Ning Wang was born on July 15th, 1979 in China. She obtained her Master's degree in Accounting at Xiamen University (China) in 2004. In 2005, she joined a two-year Research Master program in Business with specializations in Organization and Strategy at the CentER graduate school, Tilburg University (the Netherlands). After completing her Research Master in August 2007, she joined the Department of Organization and Strategy at Maastricht University (the Netherlands) in January 2008 as a Ph.D. candidate under the supervision of Prof. Dr. John Hagedoorn. The results of her Ph.D. research are presented in this dissertation and two chapters of the dissertation have been published in the academic journal of Research Policy $(2012$, 2014). 
